UNIVERSIDAdE DE SÃo PAULO

Faculdade de EConomia, Administração e Contabilidade de Ribeirão Preto DePartamento de ECONOMia

Programa de Pós-GraduaÇão em Economia - Área: Economia APlicada

LAURA DUARTE OGANDO

Creche e o desenvolvimento de habilidades socioemocionais: uma análise do Ceará e Sertãozinho-SP

Orientador: Prof. Dr. Daniel Domingues dos Santos

Ribeirão Preto

2019 
Prof. Dr. Vahan Agopyan

Reitor da Universidade de São Paulo

Prof. Dr. André Lucirton Costa

Diretor da Faculdade de Economia, Administração e Contabilidade de Ribeirão Preto

Prof. Dr. Sérgio Kannebley Júnior

Chefe do Departamento de Economia

Prof. Dr. Sérgio Naruhiko Sakurai

Coordenador do Programa de Pós-Graduação em Economia 


\section{Creche e o desenvolvimento de habilidades socioemocionais: uma análise do Ceará e Sertãozinho-SP}

Dissertação de mestrado apresentada ao Programa de Pós-Graduação em Economia - Área: Economia Aplicada da Faculdade de Economia, Administração e Contabilidade de Ribeirão Preto da Universidade de São Paulo para obtenção do título de Mestre em Ciências. Versão Corrigida. A original encontra-se disponível na FEA-RP/USP.

Orientador: Prof. Dr. Daniel Domingues dos Santos

Ribeirão Preto 
Autorizo a reprodução e divulgação total ou parcial deste trabalho, por qualquer meio convencional ou eletrônico, para fins de estudo e pesquisa, desde que citada a fonte.

Ogando, Laura Duarte.

Creche e o desenvolvimento de habilidades socioemocionais: uma análise do Ceará e Sertãozinho-SP / Laura Duarte Ogando - Ribeirão Preto, SP, 2019.

82 p.: il.; $30 \mathrm{~cm}$

Dissertação de mestrado apresentada ao Programa de PósGraduação em Economia - Área: Economia Aplicada da Faculdade de Economia, Administração e Contabilidade de Ribeirão Preto da Universidade de São Paulo, para obtenção do título de Mestre em Ciências. - Universidade de São Paulo

Orientador: Santos, Daniel Domingues dos

1. Habilidades socioemocionais. 2. Primeira infância. 3. Creche. 


\section{Agradecimentos}

Gostaria de agradecer ao meu orientador Daniel Domingues dos Santos, pela autonomonia dada e pelos comentários e ideias, sempre muito precisos e preciosos, e por ser um profissional inspirador. Gostaria de agradecer também por ter me dado a oportunidade de trabalhar no LEPES!! Agradeço também aos professores Luiz Guilherme Scorzafave e Elaine Pazello pelos comentários na qualificação e pré-defesa e por serem professores maravilhosos!

Agradeço também à banca de defesa, Cristine Campos, Beatriz Abuchaim e Luiz Guilherme, por terem lido o trabalho e pelos comentários muito enriquecedores.

Gostaria de agradecer imensamente a Bernardo Ostrovski e Marcos Paulo Cambrainha, sem os quais jamais teria conseguido fazer esse trabalho. Obrigada por toda a ajuda, opiniões, ensinamentos, ideias e palavras de conforto nos momentos em que tudo dava errado. Vocês são incríveis e se um dia eu for um décimo dos pesquisadores que vocês são, ficarei extremamente realizada. Tenho muito orgulho de ver o quanto vocês evoluíram e cresceram durante a graduação e o mestrado. Vocês são verdadeiras inspirações pra mim. Sempre estarei na torcida por vocês.

Agradeço aos meus pais, Victor e Cláudia, e a minha avó Marlene, por terem me apoiado, ainda que as vezes não entendessem muito bem o porquê das minhas decisões, e por entenderem a minha ausência nos dois anos de mestrado. Obrigada por não desistirem de mim e por todas as chamadas em vídeo e de voz que me fizeram menos só.

Obrigada a todos os amigos que fiz no PPGE. Vocês foram a minha família ribeirão pretana nesses dois anos de mestrado. Em especial, gostaria de agradecer ao Felipe Costa, minha duplinha de todas as horas, que foi um irmão pra mim durante esses dois anos (e espero que continue sendo por muitos outros) e um grande exemplo também. Torço muito por você e espero que nossas vidas tenham muitos encontros ainda. Agradeço também a Diego Menezes por todas as risadas e bobeiras que fizeram o mestrado mais leve.

Obrigada aos membros do LEPES. Em primeiro lugar por terem realizado a coleta da base de dados de Sertãozinho, sem a qual esse trabalho ficaria pela metade. Em segundo lugar, por terem me acolhido tão bem no meu segundo ano de mestrado. Poder trabalhar no LEPES foi uma oportunidade incrível, principalmente porque eu pude conhecer vocês. Obrigada Nó, Miró (melhor equipe!), Cali, Erica, Sunga, Chapéu, Poke, Lobão, Lívia, Ricardo, Diego, Livinho e Denis, por me ensinarem tanto e serem pessoas maravilhosas!

Agradeço também ao professor Martin Carnoy, Leonardo Rosa e aos demais amigos do Lemann Center da Universidade de Stanford na Califórnia pelos comentários a este trabalho. 
O presente trabalho foi realizado com apoio da Coordenação de Aperfeiçoamento de Pessoal de Nível Superior - Brasil (CAPES) - Código de Financiamento 001. 


\section{Resumo}

OGANDO, L. D. Creche e o desenvolvimento de habilidades socioemocionais: uma análise do Ceará e Sertãozinho-SP. Dissertação (Mestrado) - Faculdade de Economia, Administração e Contabilidade de Ribeirão Preto, Universidade de São Paulo, Ribeirão Preto, 2019.

Diversos estudos apontam que o estímulo de crianças na primeira infância é fundamental para o desenvolvimento de habilidades socioemocionais, que, por sua vez, contribuem para melhores resultados no futuro. O presente projeto estuda como se dá a relação de se frequentar creche no desenvolvimento dessas habilidades, analisando dados do município de Sertãozinho (SP) e do Ceará. Utiliza-se a taxonomia dos cinco grandes domínios de personalidade. O primeiro conjunto de dados é composto por uma coleta longitudinal realizada nos anos de 2012 e 2017, em que os alunos realizaram testes cognitivos e não-cognitivos, além de responderem questionários que reconstruíam sua trajetória escolar. Já o segundo é uma coleta cross-section em larga escala da aplicação do instrumento socioemocional SENNA, conjuntamente com informações de contexto e notas do SPAECE. Em ambas as análises, os resultados coletados remetem a estágios posteriores da vida (ensino fundamental ou ensino médio). Foram utilizados três métodos: Mínimos Quadrados Ordinários, modelo de fading out e painel de efeitos aleatórios. Verifica-se resultado positivo de se frequentar a creche pública sobre quase todas as habilidades socioemocionais, exceto sobre estabilidade emocional, para os dados do Ceará, ao controlar por características contextuais e da escola. Já para os dados de Sertãozinho, frequentar creche afeta positivamente a habilidade de extroversão.

Palavras-chave: educação, primeira infância, habilidades socioemocionais, creche, habilidades não-cognitivas.

Códigos JEL: I26, I28, C25 



\section{Abstract}

OGANDO, L. D. Daycares and the development of socioemotional skills: an analysis of Ceará and Sertãozinho-SP. Dissertation (Master Degree) - School of Economics, Business and Accounting at Ribeirão Preto, University of São Paulo, Ribeirão Preto, 2019.

A variety of studies show that incentives in early childhood are fundamental to the development of non-cognitive skills, which are related with improved future outcomes. The present project analyzes how participating in daycares programs influences the development of non-cognitive skills, using data from Sertãozinho, a municipality of São Paulo state, and from Ceará state. Big Five taxonomy is used to conceptualize socioemotional skills. The former is a longitudinal data set collected in 2012 and 2017, which students have cognitive and non-cognitive outcomes, and also answered surveys that rebuilt their scholar path (if they were retained, e.g.). The latter is a cross-section data of an application of SENNA, a social and emotional instrument, jointly with background and school achievement data of SPAECE. In both data sets outcomes are measured later in life (middle or high school). Three methods were used: Ordinary Least Squares, fading out model and random effects panel data. Positive results of public daycares programs were found under non-cognitive skills to Ceará data after controlling for background and school features. For Sertãozinho data, attending daycares had a positive correlation with extraversion.

Keywords: education, economics, early childhood, socioemotional skills, non-cognitive skills, kindergarten.

JEL code: $\mathrm{I} 26, \mathrm{I} 28, \mathrm{C} 25$ 



\section{Lista de ilustrações}

Figura 1 - Abertura para novas experiências por idade para crianças que frequentaram e não frequentaram creche . . . . . . . . . . . . . . . . . . 29

Figura 2 - Conscienciosidade por idade para crianças que frequentaram e não frequenta-

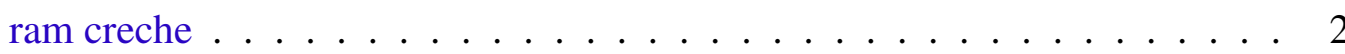

Figura 3 - Extroversão por idade para crianças que frequentaram e não frequentaram

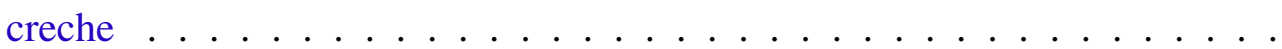

Figura 4 - Amabilidade por idade para crianças que frequentaram e não frequentaram

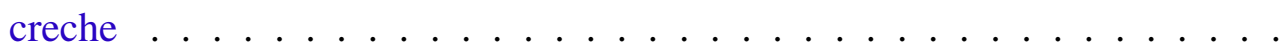

Figura 5 - Estabilidade emocional por idade para crianças que frequentaram e não frequentaram creche . . . . . . . . . . . . . . 30

Figura 6 - Abertura para novas experiências por idade para crianças que frequentaram e não frequentaram creche . . . . . . . . . . . . . . .

Figura 7 - Conscienciosidade por idade para crianças que frequentaram e não frequentaram creche . . . . . . . . . . . . . . . . . .

Figura 8 - Extroversão por idade para crianças que frequentaram e não frequentaram

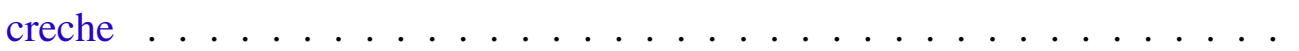

Figura 9 - Amabilidade por idade para crianças que frequentaram e não frequentaram

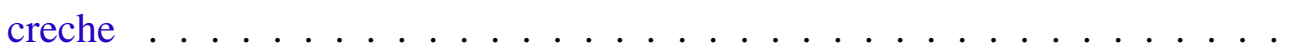

Figura 10 - Estabilidade emocional por idade para crianças que frequentaram e não frequentaram creche . . . . . . . . . . . . . . 38

Figura 11 - Abertura para novas experiências por idade de acordo com as categorias de creche- Ceará . . . . . . . . . . . . . . . . . . . . 69

Figura 12 - Conscienciosidade por idade de acordo com as categorias de creche - Ceará 69

Figura 13 - Extroversão por idade de acordo com as categorias de creche - Ceará . . . . 69

Figura 14 - Amabilidade por idade de acordo com as categorias de creche - Ceará _ . . 69

Figura 15 - Estabilidade emocional por idade de acordo com as categorias de creche - Ceará 70 


\section{Lista de tabelas}

Tabela 1 - Características dos alunos - Ceará . . . . . . . . . . . . . 27

Tabela 2 - Características socioeconômicas dos alunos - Ceará . . . . . . . . . 28

Tabela 3 - Distribuição da variável idade - Ceará . . . . . . . . . . . . . . 31

Tabela 4 - Comparação do SPAECE com o Censo Escolar de 2002 por tipo de creche -

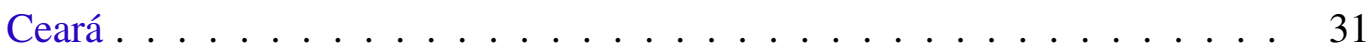

Tabela 5 - Atrito amostral dos alunos presentes em 2012 e 2017 - Sertãozinho . . . . . 34

Tabela 6 - Diferença de resposta da variável de creche - Sertãozinho . . . . . . . . . . 34

Tabela 7 - Diferença de resposta da variável de pré-escola - Sertãozinho . . . . . . . 35

Tabela 8 - Idade dos indivíduos da amostra para os anos de 2012 e 2017 - Sertãozinho 35

Tabela 9 - Idade em 2012 e 2017 - Sertãozinho . . . . . . . . . . . . . . . . 36

Tabela 10 - Estatísticas dos socioemocionais com ano base em 2012 - Sertãozinho . . . 36

Tabela 11 - Teste de diferença de média por socioemocional para frequentadores e não frequentadores de creche . . . . . . . . . . . . . 38

Tabela 12 - Estatísticas de características sociais e educacionais para os sobreviventes de

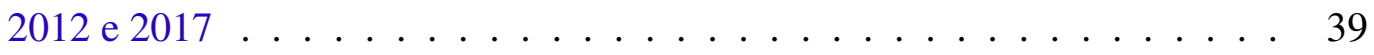

Tabela 13 - Estimação de MQO - Abertura para novas experiências - Ceará . . . . . . . 46

Tabela 14 - Estimação de MQO - Conscienciosidade - Ceará . . . . . . . . . . . . . . . 47

Tabela 15 - Estimação de MQO - Extroversão - Ceará . . . . . . . . . . . . . . . . . 47

Tabela 16 - Estimação de MQO - Amabilidade - Ceará . . . . . . . . . . . . . . . . . . 48

Tabela 17 - Estimação de MQO - Estabilidade Emocional - Ceará . . . . . . . . . . . . 48

Tabela 18 - Estimação de MQO - Extensões - Ceará . . . . . . . . . . . . . . . . . . 49

Tabela 19 - Estimação de MQO por ano - Abertura para novas experiências - Sertãozinho 51

Tabela 20 - Estimação de MQO por ano - Conscienciosidade - Sertãozinho . . . . . . . 52

Tabela 21 - Estimação de MQO por ano - Extroversão - Sertãozinho . . . . . . . . . . . 53

Tabela 22 - Estimação de MQO por ano - Amabilidade - Sertãozinho . . . . . . . . . . 54

Tabela 23 - Estimação de MQO por ano - Estabilidade Emocional - Sertãozinho . . . . 55

Tabela 24 - Estimações de fading out - Sertãozinho . . . . . . . . . . . . . . . . 56 
Tabela 25 - Estimações de fading out - Sertãozinho . . . . . . . . . . . . . . . . . 56

Tabela 26 - Modelo de efeitos aleatórios para Abertura para novas experiências - Sertão-

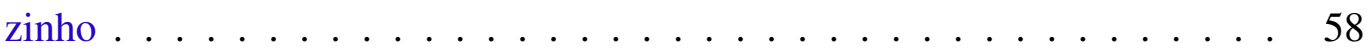

Tabela 27 - Modelo de efeitos aleatórios para Conscienciosidade - Sertãozinho . . . . 59

Tabela 28 - Modelo de efeitos aleatórios para Extroversão - Sertãozinho . . . . . . . . . 60

Tabela 29 - Modelo de efeitos aleatórios para Amabilidade - Sertãozinho . . . . . . . . 61

Tabela 30 - Modelo de efeitos aleatórios para Estabilidade Emocional - Sertãozinho . 62

Tabela 31 - Estatísticas descritivas para os indivíduos condicionada ao tipo de creche Ceará .............................. 71

Tabela 32 - Estimação de MQO - Extensões - Ceará ． . . . . . . . . . . . . . . . . 72

Tabela 33 - Estimação de MQO para o ano de 2012 - Abertura para novas experiências Sertãozinho . . . . . . . . . . . . . . . . 73

Tabela 34 - Estimação de MQO para o ano de 2017 - Abertura para novas experiências Sertãozinho . . . . . . . . . . . . . . . . . . 74

Tabela 35 - Estimação de MQO para o ano de 2012 - Conscienciosidade - Sertãozinho 75

Tabela 36 - Estimação de MQO para o ano de 2017 - Conscienciosidade - Sertãozinho 76

Tabela 37 - Estimação de MQO para o ano de 2012 - Extroversão - Sertãozinho . . . . 77

Tabela 38 - Estimação de MQO para o ano de 2017 - Extroversão - Sertãozinho . . . . 78

Tabela 39 - Estimação de MQO para o ano de 2012 - Amabilidade - Sertãozinho . . . 79

Tabela 40 - Estimação de MQO para o ano de 2017 - Amabilidade - Sertãozinho . . . . 80

Tabela 41 - Estimação de MQO para o ano de 2012 - Estabilidade Emocional - Sertãozinho 81

Tabela 42 - Estimação de MQO para o ano de 2017 - Estabilidade Emocional - Sertãozinho 82 


\section{Sumário}

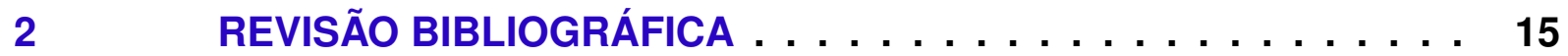

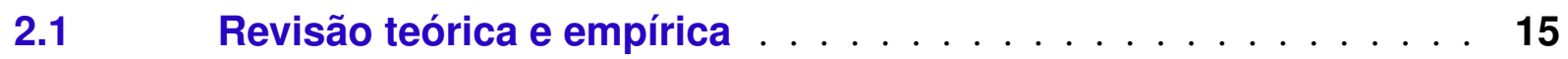

2.2 Documentos Nacionais . . . . . . . . . . . . . . . . . . . 20

3 INSTRUMENTOS SOCIOEMOCIONAIS $\ldots \ldots \ldots \ldots \ldots$

$3.1 \quad$ Big Five Inventory $(\mathrm{BFI}) \ldots \ldots \ldots \ldots$

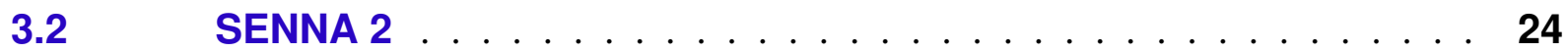

$4 \quad$ BASE DE DADOS $\ldots \ldots \ldots \ldots \ldots \ldots \ldots \ldots$

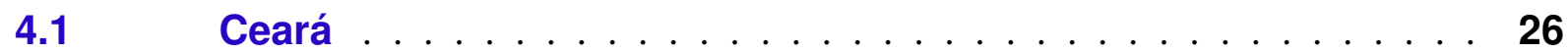

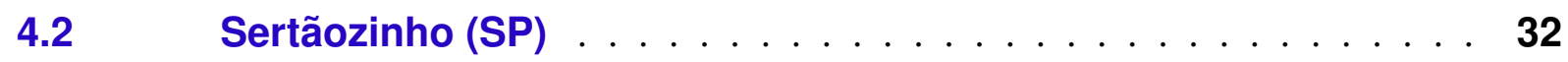

$5 \quad$ METODOLOGIA $\ldots \ldots \ldots \ldots \ldots \ldots \ldots \ldots \ldots$

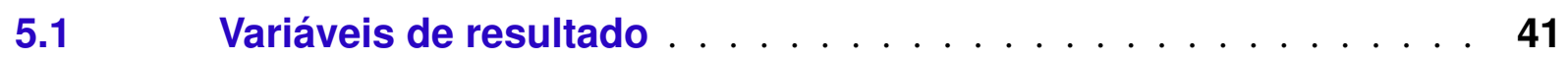

$5.2 \quad$ Modelos econométricos . . . . . . . . . . . . . . . . . 42

$6 \quad$ RESULTADOS $\ldots \ldots \ldots \ldots \ldots \ldots \ldots \ldots$

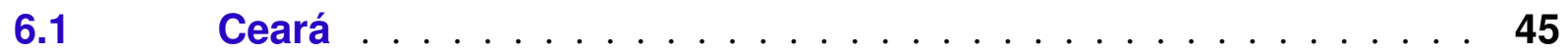

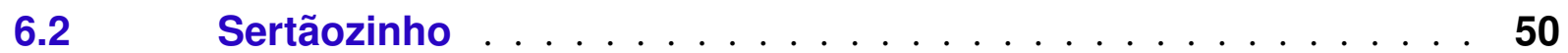

$7 \quad$ CONCLUSÃo $\ldots \ldots \ldots \ldots \ldots \ldots \ldots \ldots \ldots \ldots$

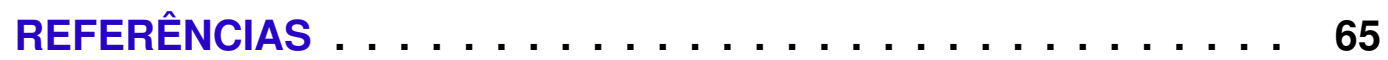

APÊNDICE A - TABELAS E GRÁFICOS . . . . . . . . . 69 


\section{Introdução}

A literatura internacional aponta que intervenções na primeira infância ${ }^{1}$, em diferentes contextos sociais e diferentes países, geram benefícios cognitivos, comportamentais, além de outros benefícios associados à saúde e a escolaridade, os quais persistem ao longo do tempo ${ }^{2}$ (NORES; BARNETT, 2010). Também existem evidências de que investimentos nessa fase da vida, principalmente no que tange a políticas de educação, têm maior custo-benefício quando comparado aos demais estágios de aprendizado (HECKMAN; MASTEROV, 2007).

Além disso, existem evidências de que o próprio aprendizado, bem como os resultados futuros, não são explicados somente por habilidades cognitivas. Uma literatura extensa vem dando importância para o desenvolvimento de habilidades socioemocionais, ou não cognitivas ${ }^{3}$, que geram benefícios persistentes ao longo da vida, sejam eles melhores salários, baixa incidência em atividades criminais, menores taxas de gravidez na adolescência, etc (HECKMAN; PINTO; SAVELYEV, 2013). Heckman, Stixrud e Urzua (2006) apontam ainda que habilidades socioemocionais são aguçadas majoritariamente no início da vida, principalmente entre zero e cinco anos de idade.

Nesse sentido, a Lei n ${ }^{0} 8.069$ do Estatuto da Criança e do Adolescente (BRASIL, 1990) prevê a obrigatoriedade do Estado de assegurar o atendimento em creche e pré-escola à crianças desta faixa etária. A legislação brasileira ainda prevê que crianças de zero a três anos podem estar matriculadas em creches ou instituições equivalentes e de quatro a cinco anos devem estar matriculadas em pré-escolas (BRASIL, 2016). Entretanto, não existem evidências de que estas etapas de ensino produzam benefícios para as crianças no Brasil, isto é, não se sabe ao certo se a educação infantil brasileira atende a requisitos mínimos de qualidade. Ademais, considerando o fato de que esse estágio da vida ${ }^{4}$ é crítico na cristalização de características individuais, deve-se destacar que toda desigualdade gerada ou mantida neste período pode resultar em um ciclo perverso de desigualdades futuras. Em trabalho realizado no Brasil, verifica-se que intervenções neste período têm grande poder compensador no que tange as desvantagens iniciais de crianças nascidas em ambientes familiares adversos (SANTOS, 2015), de modo que crianças corretamente estimuladas durante este estágio apresentam um melhor desempenho ao longo de todo o ciclo escolar.

Por conta dos estímulos na faixa etária de zero a três anos, especialmente, serem tão

1 Define-se primeira infância como o período de 0 a 6 anos de idade.

2 Os autores revisam a literatura internacional (exceto evidências para os Estados Unidos) de intervenções quasi-experimentais ou advindas de aleatorização.

3 Para os fins deste trabalho, ainda que o termo "não cognitivo" seja de natureza mais ampla que as habilidades socioemocionais aqui discutidas, utilizaremos ambos os termos como sinônimos, sem perda de significado e/ou conteúdo.

4 Sabe-se que traços de personalidade são desenvolvidos em algum período entre a infância e a adolescência, resultando em padrões estáveis na vida adulta (ROBERTS, 2009; SOTO et al., 2011). 
importantes no desenvolvimento futuro das crianças, o presente trabalho tenta analisar o impacto de creche no desenvolvimento de habilidades socioemocionais. O objetivo central deste trabalho é entender como intervenções na primeira infância podem afetar o desenvolvimento socioemocional em períodos posteriores. Portanto, busca-se encontrar padrões sistemáticos nas habilidades socioemocionais de indivíduos que frequentaram creche.

A análise será realizada a partir de duas bases de dados. A primeira foi coletada no município de Sertãozinho (SP), nos anos de 2008, 2012 e 2017, pelo Laboratório de Estudos e Pesquisas em Economia Social (LEPES). Já a segunda é uma coleta conjunta da prova de proficiência em português e matemática do estado do Ceará, o SPAECE, com a aplicação de um instrumento socioemocional, o SENNA. A metodologia será conduzida em três etapas: a primeira consiste no uso de mínimos quadrados ordinários com seus devidos controles, a fim de verificar a correlação entre as variáveis; a segunda consiste na realização da análise de um modelo de fading out restrita a base de dados de Sertãozinho, que visa observar o efeito decaimento temporal de se ter frequentado creche; e a terceira será a de uso do painel de efeitos aleatórios. Encontram-se resultados positivos e significantes de se frequentar creche sobre a habilidade de extroversão em ambas as bases de dados. Para o caso do Ceará, também são encontrados resultados positivos e significantes sobre as habilidades de abertura para novas experiências, conscienciosidade e amabilidade. Já para os dados de Sertãozinho, encontra-se efeito negativo de se frequentar creche sobre as habilidades de conscienciosidade e amabilidade.

O restante do projeto segue como descrito. Na Seção 2 será realizada uma revisão bibliográfica, a qual tem como finalidade situar o tema e coletar as principais evidências apontadas pela literatura, bem como abordar os principais documentos nacionais que providenciaram mudanças no âmbito da primeira infância no Brasil. A Seção 3 descreve os instrumentos socioemocionais utilizados em cada uma das coletas. A Seção 4 conta com uma descrição das bases de dados utilizadas e suas principais estatísticas descritivas. A metodologia utilizada será descrita na Seção 5. A Seção 6 apresenta os principais resultados encontrados. Por fim, a Seção 7 conclui o trabalho. 


\section{Revisão Bibliográfica}

Existem duas discussões distintas, porém centrais para a justificação deste trabalho. Em primeiro lugar, há de se considerar a vasta literatura que aborda a importância da primeira infância como a principal fase do desenvolvimento humano, bem como outra literatura importante que discute o papel das habilidades socioemocionais e não cognitivas neste processo. Depois, mas não menos importante, ressalta-se o contexto brasileiro de políticas de ampliação ao acesso e da qualidade da educação infantil, sobretudo ao longo dos últimos 20 anos.

Desse modo, a revisão bibliográfica aqui discutida divide-se em duas subseções igualmente importantes: Revisão teórica e empírica; e Documentos nacionais. Na primeira, discute-se o conhecimento acadêmico acerca deste tema. Na segunda, discute-se a relevância de documentos publicados no Brasil, desde a Constituição Federal à Base Nacional Curricular Comum, no que se refere ao foco educacional na primeira infância.

\subsection{Revisão teórica e empírica}

O conceito de capital humano pode ser considerado o fundador da área de economia da educação. A necessidade de diferenciação com relação ao conceito de capital usual se deu por conta da impossibilidade de separação de um indivíduo da sua habilidade e de seus conhecimentos (BECKER, 1994), surgindo assim tal conceito. O autor aponta que treinamento e educação são os principais estimulantes do capital humano. A partir de então, começam a surgir diversos estudos e modelos que incorporam esse conceito. Em outro artigo, Becker e Tomes (1976) descrevem o capital humano como sendo algo que afeta direta e positivamente a produtividade do trabalhador. Entretanto, ao longo dos anos, essa teoria se mostrou ineficiente para explicar resultados individuais, como salário e diferenciais no mercado de trabalho. Nesse sentido, Heckman e Rubinstein (2001) ressaltam a deficiência da literatura de capital humano ao medir formação de habilidades unidimensionalmente, propondo a separação entre habilidades cognitivas e não cognitivas, estas também conhecidas como habilidades socioemocionais.

Habilidades não cognitivas são aquelas associadas a traços de personalidade de um indivíduo (HECKMAN; STIXRUD; URZUA, 2006). Em um famoso teste conhecido como "teste do marshmallow", realizado por Walter Mischel na universidade de Stanford no final dos anos 1960, mostrou-se que crianças capazes de esperar mais tempo por recompensas tinham associados melhores resultados futuros, tais como melhores notas no Scholastic Assessment Test (SAT), exame americano utilizado para ingresso em universidades (MISCHEL; EBBESEN; ZEISS, 1972). Em síntese, este teste consistia em colocar a criança em uma sala de espera, oferecendo-a duas opções ao início do teste: a criança ganha um único marshmallow participando do teste e o pegando antes do retorno do pesquisador ou; a criança ganha dois marshmallows 
se esperar até o retorno do pesquisador, que ficava fora da sala em torno de 15 minutos. Este experimento foi realizado com cerca de 50 crianças. Este teste pode ser associado ao autocontrole do indivíduo, isto é, a capacidade que o indivíduo tem de controlar as suas próprias emoções ou desejos, bem como sua capacidade de postergar recompensas. É possível destacar esse trabalho como o pioneiro na área de estudo das habilidades não-cognitivas, enquanto testes de QI existem desde 1905.

É possível agrupar características e traços de personalidade de diversas maneiras e, tendo em vista o grande número de possibilidades, a partir de meados dos anos 1920 iniciaramse esforços para elaborar uma taxonomia ou modelo descritivo desses traços, de modo que seria possível estudar domínios específicos (JOHN; SRIVASTAVA, 1999). Iniciando com a documentação de características por meio de palavras do dicionário, totalizando cerca de 18 mil termos possíveis, o número de traços de personalidade foi sendo reduzido ao longo dos anos, através de empenho de diversos psicólogos, passando para 16 domínios com Cattell, Eber e Tatsuoka (1970), até chegar a 5 domínios de personalidade com Goldberg (1981), conhecidos como Big Five ou os cinco grandes domínios de personalidade.

Hoje em dia, pode-se dizer existir um consenso na literatura em agrupar os traços de personalidade com estes cinco domínios, representados por: abertura para novas experiências, conscienciosidade, extroversão, amabilidade e neuroticismo (JOHN; SRIVASTAVA, 1999). São tipicamente descritos como:

- Abertura para novas experiências: Define-se como a capacidade do indivíduo a aceitar e participar de novas experiências sejam elas intelectuais ou sociais. Também é conhecido como intelecto ou imaginação;

- Conscienciosidade: Define-se como a a tendência a controlar impulsos e agir de maneiras socialmente aceitas;

- Extroversão: Define-se como a capacidade do indivíduo de se envolver com outras pessoas, estabelecendo relações sociais;

- Amabilidade: Define-se como a capacidade do indivíduo se colocar no lugar do outro e de cooperar;

- Neuroticismo: Define-se como a previsibilidade e consistência de reações emocionais. É o oposto do que é conhecido na literatura por estabilidade emocional.

Cada uma dessas habilidades possui resultados tipicamente associados a elas. Abertura para novas experiências costuma estar relacionado com indicadores educacionais, como escolha de cursos mais difíceis em universidades e escolaridade final atingida, sendo este o motivo pelo qual tal habilidade também é conhecida como intelecto. Conscienciosidade está tipicamente associado a disciplina e perseverança, também estando associada à escolaridade final atingida. Já 
a habilidade de extroversão não possui um efeito muito claro na literatura, tendo em vista que não se observam efeitos estáveis e bem comportados de tal habilidade em resultados educacionais, isto é, ter mais dessa habilidade não indicam, necessariamente, melhores resultados educacionais. Amabilidade está tipicamente associada a atividades realizadas em grupo, pois observa-se características de agressividade e irritabilidade em indivíduos com tal habilidade associada. Ademais, aponta-se que há uma correlação com o desempenho escolar restrita ao estágio inicial da educação, isto é, o efeito desaparece a medida em que o indivíduo avança nos anos escolares. Por fim, associa-se ao neuroticismo à chance de permanência na escola e conclusão do ensino médio, ainda que não hajam evidências apontando para melhores notas (SANTOS; PRIMI, 2014).

Uma diversidade de estudos evidenciam um papel ao menos tão importante de habilidades não cognitivas quanto o já notável das cognitivas em resultados de aprendizado (DUCKWORTH; SELIGMAN, 2005; BLAIR; RAZZA, 2007; ALMLUND et al., 2011), bem como em resultados econômicos e comportamentais (CUNHA; HECKMAN, 2008) ${ }^{1}$. O desenvolvimento de habilidades socioemocionais se dá majoritariamente na primeira infância, ou seja, nos primeiros cinco anos de vida (HECKMAN; STIXRUD; URZUA, 2006). Sabe-se ainda que os indivíduos são sensíveis a estímulos no ambiente em que estão inseridos, de modo que tentar incentivar ambos os tipos de habilidades (cognitivas e não cognitivas) nesse período crítico da vida pode produzir efeitos que perduram ao longo do tempo (DUNCAN; MAGNUSON, 2013), importante fator ao se considerar a implementação de políticas públicas nesse contexto.

As evidências apontam para o impacto de habilidades socioemocionais em diversas esferas. Cunha e Heckman (2008) apontam que habilidades cognitivas e não cognitivas têm impacto sobre os salários, nível educacional e participação em comportamentos de risco. Heckman, Stixrud e Urzua (2006) evidenciam que ambas as habilidades são responsáveis por explicar a variedade no mercado de trabalho e resultados comportamentais, além de serem cruciais para o sucesso econômico e social. Os autores encontram ainda que alguns fatores podem influenciar o desenvolvimento de tais habilidades. Apontam que pais têm papel importante no desenvolvimento de habilidades socioemocionais de seus filhos, isto é, pais mais engajados e capacitados têm maior sucesso em influenciar o desenvolvimento dessas habilidades, levantando evidências de que a escolaridade e o background familiar afetam o desempenho nas provas que medem habilidades socioemocionais (HECKMAN; STIXRUD; URZUA, 2006). Carneiro, Crawford e Goodman (2007) revelam a importância do background familiar no desenvolvimento da criança, assim como a do ambiente de aprendizado em casa na formação de habilidades socioemocionais, corroborando com os resultados anteriores.

Mostra-se que a primeira infância possui importância singular no desenvolvimento

1 Duckworth e Seligman (2005) mostram que alunos com auto-disciplina tendem a ter maior desempenho escolar, controlando pelo Q.I. Enquanto em Almlund et al. (2011), verifica-se que para diversos resultados, habilidades não cognitivas são tão preditivas quando as cognitivas, mesmo ao se controlar por escolaridade da mãe e características do ambiente familiar. 
de algumas habilidades. Experiências na primeira infância, principalmente para crianças de contexto social mais desvantajoso, têm uma influência única e poderosa no desenvolvimento de habilidades cognitivas, sociais e na maneira como o cérebro funciona (KNUDSEN et al., 2006) $)^{2}$. A base para o desenvolvimento de habilidades socioemocionais e circuitos neurais é maior quanto mais nova for a criança. Apontam ainda que tal desenvolvimento vai decaindo a medida em que o indivíduo avança de idade, isto é, a taxa de retorno do investimento do capital humano é maior quanto mais novo é o indivíduo.

A partir da literatura levantada, poderia-se pensar que o investimento nessa faixa etária para crianças de famílias provenientes de uma condição social pior estaria restrito a uma questão associada a justiça social. Entretanto, tal investimento engloba também a questão da produtividade, considerando-se que crianças de ambientes desvantajosos tendem a ter maior envolvimento com crimes e abandono escolar. Nesse sentido, o benefício de intervenções precoces não se limita somente ao bem-estar individual da criança, como também gera um ganho para a sociedade, isto é, investir em crianças de famílias desfavorecidas reduz a desigualdade e aumenta a produtividade da sociedade (HECKMAN; MASTEROV, 2007). Intervenções posteriores a esse período da vida são menos eficazes.

Haja vista a importância da primeira infância no desenvolvimento de tais habilidades que, comprovadamente, estão associadas a diversos resultados, uma variedade de estudos têm como objetivo verificar o impacto de se frequentar creche e pré-escola no desenvolvimento de habilidades cognitivas e não cognitivas. Alguns resultados apontam que crianças que frequentam creches de boa qualidade tendem a ter habilidades socioemocionais melhores (HAGEKULL; BOHLIN, 1995). Ainda, ao acompanhar as crianças ao longo do tempo, a evidência encontrada é de que a qualidade da creche estava relacionada de maneira negativa com problemas sociais e que crianças com ambiente domiciliar de baixa qualidade são as mais beneficiadas por creches de boa qualidade, quando se trata do desenvolvimento de habilidades socioemocionais.

Um famoso experimento randomizado que visa verificar os efeitos da educação infantil em resultados futuros é o Perry Preschool, realizado com crianças de 3 a 4 anos provenientes de famílias de baixa renda, as quais pertenciam a um grupo caracterizado como de alto risco no que tange a reprovação e o abandono escolar. As 123 crianças do estudo foram separadas em um grupo de tratamento, em que elas recebiam educação de alta qualidade em pré-escola, e um grupo de controle, em que elas não recebiam nenhuma educação nessa idade. As crianças participantes do estudo foram seguidas até 40 anos após o experimento, o que permitiu verificar uma diversidade de resultados (SCHWEINHART et al., 2005).

Tal experimento foi examinado por Heckman, Pinto e Savelyev (2013), onde os autores verificam que o comportamento social perdura, ao contrário do observado para o QI das crianças. O estudo evidencia que, ainda que inicialmente o efeito da pré-escola sobre o QI das crianças tenha sido positivo, esse efeito rapidamente desaparece, não apresentando significância estatística 
poucos anos após o programa. Entretanto, encontra-se uma melhora em comportamentos externalizantes, a exemplo de agressividade e anti sociabilidade, que, por sua vez, melhoraram diversos resultados no mercado de trabalho, saúde e atividades criminais. Também encontraram efeito sobre motivação acadêmica, efeito restrito às mulheres.

Sendo assim, o estudo de Heckman, Pinto e Savelyev (2013) corrobora com as evidências de que 30 a $40 \%$ da variância nos resultados dos testes realizados por estudantes tem origem em traços da sua personalidade ao invés de estar relacionado com o QI. Esse resultado também foi visto em Barnett (1995) que evidencia impacto de curto prazo para intervenções na primeira infância sobre o QI e impacto de longo prazo dessas intervenções sobre sucesso escolar, notas, posição social e posição em educação especial, destacando que a qualidade dessas intervenções é um fator crucial.

Um famoso projeto conhecido como Abecedarian Project acompanhou crianças provenientes de famílias de baixa renda ${ }^{3}$ durante anos após terem participado de educação infantil, visando analisar os impactos do mesmo sobre os resultados futuros dessas crianças. Verificou-se que, aos 21 anos de idade, ter frequentado creches e pré-escolas de alta qualidade traziam benefícios a essas crianças, observando um impacto positivo em anos de estudo e negativo em gravidez na adolescência (CAMPBELL et al., 2002).

Ainda, parte da literatura foca em analisar, especificamente, o impacto de intervenções, desenvolvidas no ambiente escolar, direcionadas para a promoção de habilidades socioemocionais. Evidências apontam que estas promovem mudanças positivas no desenvolvimento futuro dos indivíduos, tais como melhor desempenho acadêmico, menor incidência de uso de drogas, menor incidência de problemas de conduta e comportamento social positivo (TAYLOR et al., 2017). Com relação ao desempenho acadêmico, evidências apontam ainda que tais programas podem refletir um aumento médio de 11 pontos percentuais no desempenho acadêmico (DURLAK et al., 2011). Também existem evidências de que há benefícios para a sociedade como um todo de investimentos em programas desse gênero, que oferecem retornos econômicos tão altos quanto o do sistema educacional convencional (BELFIELD et al., 2015).

Um experimento conhecido na temática é o associado à implementação do currículo socioemocional conhecido como Promoting Alternative Thinking Strategies curriculum (PATHS), currículo desenvolvido para professores com o objetivo de reduzir problemas de comportamento dos alunos de pré-escola e melhorar competências sociais. Os resultados do programa sugerem que, de acordo com os pais e professores, crianças expostas a essa intervenção se mostraram mais sociáveis quando comparadas com seus pares (DOMITROVICH; CORTES; GREENBERG, 2007). Reforça-se que o desenho da política é importante para a sua eficácia, destacando que características da implementação influenciam o resultado final da política (KAM; GREENBERG;

3 Campbell et al. (2002) motivam a escolha da análise de crianças provenientes de famílias de baixa renda, apontando que a literatura associa pobreza ao desenvolvimento infantil, destacando fatores como nutrição menos adequada, menores notas em testes psicológicos, maiores taxas de reprovação acadêmica e maior incidência de abandono escolar. 


\section{WALLS, 2003).}

No Brasil, poucos estudos tratam do tema. Há evidências de que crianças advindas de famílias com menor renda se beneficiam menos da creche em termos de habilidades socioemocionais (SANTOS, 2015) ${ }^{4}$, resultado oposto do que o encontrado em Hagekull e Bohlin (1995). No estudo de Santos (2015) foi aplicado um questionário de autoeficácia, uma medida de habilidades não cognitivas que visa captar aquilo que o aluno é capaz de fazer. Nesse sentido, a creche, para as crianças brasileiras, teria um efeito indesejado para a promoção das habilidades socioemocionais. No mesmo trabalho, mas analisando dados do município de Sertãozinho (SP), ao realizar estudo de efeitos heterogêneos para o tipo de creche, isto é, se a criança frequentou creche pública ou privada, Santos (2015) verificou que creches privadas tendem a compensar desvantagens, enquanto creches públicas prejudicariam o desenvolvimento de habilidades socioemocionais.

Os estudos mencionados acima evidenciam que habilidades socioemocionais são importantes para os resultados futuros dos indivíduos e que estas se desenvolvem majoritariamente na faixa etária de 0 a 5 anos, com maior custo-benefício de 0 a 3 anos, de modo que, se a criança frequenta creche nessa idade, é importante entender como essa creche afeta o desenvolvimento destas habilidades.

\subsection{Documentos Nacionais}

É na primeira infância em que se desenvolvem em maior intensidade os circuitos neurais, formam-se traços de personalidade e ocorrem ganhos de aprendizado, também mais intensificados neste período. Entretanto, o Brasil, por muito tempo, não reconheceu a importância desta etapa, cada vez mais evidenciada como essencial na literatura (HECKMAN; MASTEROV, 2007). No Brasil, historicamente, a primeira infância ganhou espaço dentro da educação como um meio de gerar oportunidade para mulheres ingressarem no mercado de trabalho e as creches se tornaram um local onde a principal preocupação não era a qualidade das interações as quais as crianças estavam expostas, mas sim de que fosse um local seguro para que, durante a jornada de trabalho, as mulheres pudessem deixar seus filhos neste local (CAMPOS; ESPOSITO; GIMENES, 2014).

Ao longo dos últimos 10 anos, o governo brasileiro foi adotando medidas que manifestavam que esta era não só uma importante etapa para o desenvolvimento infantil, bem como um direito que todas as crianças da faixa etária deveriam ter acesso. A partir de 2009, a obrigatoriedade do ensino passou não mais a se iniciar no ciclo do fundamental, mas na pré-escola (BRASIL, 2009). Ademais, o Brasil vem passando por uma rápida expansão da pré-escola, devido a meta de universalização desta até 2016, saindo de $67,6 \%$ de crianças matriculadas em 2006 para 93\% das crianças matriculadas em 2017 (TODOS, 2019), um aumento considerável para um período de 11 anos, sobretudo levando-se em conta que alguns municípios tiveram uma

4 Estudo realizado nas cidades de Campinas, Salvador, Rio de Janeiro, Belo Horizonte e Campo Grande. 
evolução muito mais acelerada. A creche, objeto principal desse estudo, teve uma evolução de 14,9\% no total de matrículas em 2002 para 34,1\% em 2017, restando ainda um avanço de 15\% para o alcance da meta de 2024.

A Constituição Brasileira de 1988, documento jurídico de maior hierarquia dentro do país e responsável por garantir direitos fundamentais, considera como um dever do Estado a garantia atendimento à creche e pré-escola (BRASIL, 1988). Entretanto, como supracitado, somente em 2009 houve modificação do artigo 208 antecipando a idade da educação básica, a partir de então obrigatória para crianças com 4 anos de idade (BRASIL, 2009), evidenciando a recente importância que a primeira infância vem ganhando nos últimos 10 anos. Tendo em vista esta mudança, em 2014 foi aprovada a lei do Plano Nacional de Educação (PNE), que, além da universalização da pré-escola até 2016, previa a oferta de vagas para atender, no mínimo, 50\% das crianças entre 0 e 3 anos.

Nesse sentido, o Brasil vem se alinhando com uma tendência mundial de promover a consolidação da educação infantil de qualidade. Exemplo disso são os Objetivos de Desenvolvimento Sustentável (ODS), desenvolvidos pela Organização das Nações Unidas (ONU) em 2016, que consistem em metas subdivididas em 17 grandes áreas visando a melhoria da qualidade de vida para as gerações atual e futuras. No ramo da educação, o ODS 4.2 versa sobre a garantia, até 2030, do acesso para todas as meninas e meninos à educação infantil de qualidade com o objetivo de que estes estejam preparados para a educação primária (ONU, 2016).

Por outro lado, a Base Nacional Comum Curricular (BNCC), documento de 2017 redigido pelo governo com o propósito de ser a base para o desenvolvimento de currículos de todas as escolas do Brasil, inclui não só as diretrizes para a educação infantil, como também aborda, em cada um de seus campos de aprendizagem, a questão das habilidades socioemocionais, sempre levando em consideração o desenvolvimento do indivíduo perante as diversas facetas sociedade (BRASIL, 2017).

Por fim, esses documentos apontam a importância da consolidação da educação infantil como uma etapa importante para o desenvolvimento da criança, levando em conta o desenvolvimento de habilidades cognitivas e não cognitivas que irão acompanhar o indivíduo para o resto de sua vida. Nesse sentido, entender como essa etapa tem influenciado as crianças ao longo de tempo é um tópico de extrema relevância no Brasil, sobretudo considerando as inúmeras reformas que foram feitas ao longo dos últimos 10 anos e a recente ampliação da oferta desta etapa de ensino. Se faz imprescindível verificar como e quais creches impactam de maneira positiva os resultados das crianças, já que ampliar um modelo de creche que é nocivo para o futuro destas não é algo desejável. Reforça-se a importância do uso de ferramentas que possibilitem a mensuração da qualidade do ambiente escolar nesta etapa de educação, haja vista que ainda não se discute a nível governamental um modelo de mensuração nacional. 



\section{Instrumentos socioemocionais}

Esta breve seção tem como objetivo descrever os instrumentos utilizados para coletar as informações acerca das habilidades não-cognitivas. A subseção 3.1 descreve o instrumento utilizado em Sertãozinho (SP), enquanto a 3.2 descreve o utilizado no Ceará, ambos medem os cinco grandes domínios de personalidade.

\subsection{Big Five Inventory (BFI)}

O Big Five Inventory (BFI) é um instrumento psicológico que objetiva mensurar os cinco grande domínios de personalidade (mais conhecidos como Big Five). Inicialmente proposto por John, Donahue e Kentle (1991) em língua inglesa e, posteriormente, adaptado para o espanhol por Benet-Martinez e John (1998) e para o português por Andrade (2008), o BFI é uma medida de auto-relato composta por 44 afirmações curtas respondidas através de uma escala Likert de cinco níveis, indo de discordo totalmente a concordo totalmente.

O BFI já foi comparado com outros dois importantes instrumentos na mensuração destes cinco domínios: Trait Descriptive Adjectives (TDA) e NEO Five-Factor Inventory (NEO-FFI). O NEO-FFI é considerado como o instrumento com as melhores características psicométricas dentre os que medem os Big Five, enquanto o TDA é o de uso mais comum entre instrumentos de um único adjetivo (JOHN; SRIVASTAVA, 1999).

Em importante trabalho desenvolvido por Schmitt et al. (2007), os autores discutem a tradução do instrumento em inglês para outras 28 línguas e sua aplicação em mais de 17 mil indivíduos de 56 nações diferentes e verificaram grande robustez na estrutura de cinco domínios do BFI, além de boa validade convergente com o NEO-FFI ${ }^{1}$. Neste trabalho, entretanto, a amostra brasileira foi bastante reduzida (menos de 100 indivíduos). A validação do instrumento para a língua portuguesa, portanto, foi discutida mais profundamente por Andrade (2008).

Por fim, vale ressaltar que, na pesquisa realizada em 2017, foi aplicada a segunda versão do BFI (BFI-2), composta por 60 itens e construída por Soto e John (2017). Entretanto, a fim de manter a perfeita comparabilidade entre os dados de 2012 e 2017, a primeira versão do BFI também foi mantida em 2017. Para o cálculo dos scores socioemocionais deste trabalho, portanto, foram utilizados somente os itens da primeira versão do BFI, garantindo esta comparabilidade entre os anos.

1 A validade convergente pode ser entendida como a relação entre duas medidas diferentes de um mesmo construto Pasquali (2017). 


\subsection{SENNA 2}

O Social and Emotional Non-cognitive Nationwide Assessment (SENNA) é "um teste de avaliação de traços de personalidade em crianças e adolescentes" que tem como pretensão ser simples o suficiente para ser aplicado em larga escala e, ao mesmo tempo, ter boas propriedades descritivas acerca das características socioemocionais (SANTOS; PRIMI, 2014), de modo que se torna possível apoiar e desenvolver políticas públicas a partir dos dados coletado pelo instrumento, bem como produzir conhecimento científico para a área. Para a confecção de tal instrumento, foram mapeados e analisados instrumentos psicológicos já existentes, de modo que oito $^{2}$ destes foram escolhidos para serem testados no ambiente escolar. Considerando-se que nenhum dos oito foi capaz de medir as habilidades dentro do espectro desejado e que a aplicação conjunta destes seria inaceitavelmente longa, optou-se pela construção de um novo instrumento que os agrupasse, este viria a ser o SENNA. Todos estes possuíam construtos que "podiam ser entendidos como facetas dos próprios cinco grandes domínios de personalidade, dada a maneira como se relacionam estatisticamente com medidas desses domínios" (SANTOS; PRIMI, 2014) e que, portanto, poderiam ser organizados de acordo com os cinco grandes domínios de personalidade. Desse modo, ainda que seja um instrumento diferente do Big Five Inventory, o SENNA, ao medir socioemocional, também agrupa-se nos cinco domínios de personalidade.

A metodologia aplicada para analisar os itens dos oito instrumentos selecionados foi a de Blocos Balanceados Incompletos ${ }^{3}$ (SAILER, 2005). O instrumento foi validado a partir de uma amostra de 3023 alunos. Os itens foram agrupados por meio de análise fatorial exploratória ${ }^{4}$ das escalas dentro dos cinco domínios. Existem versões do instrumento para indivíduos do $5^{\circ}$ ano do ensino fundamental, bem como para indivíduos dos $1^{\circ}$ e $3^{\circ}$ anos do Ensino Médio.

Para a coleta de dados do Ceará, foi utilizada uma segunda versão do instrumento, conhecida como SENNA 2. O instrumento foi aplicado em sua versão curta, que possui 59 itens. A grande diferença da primeira versão do instrumento para a segunda, é que, além de gerar os scores para os cinco grandes domínios, também geram resultados de autoeficácia e identidade. Em linhas gerais, o questionário de autoeficácia visa captar aquilo que o aluno é capaz de fazer, enquanto o questionário de identidade visa captar aquilo que o aluno considera sobre si mesmo. No presente trabalho, sempre que for citado o instrumento SENNA, entende-se que está referenciando ao SENNA 2.

2 Foram eles: Inventário dos Cinco Fatores (BFI), Inventário dos Cinco Fatores para Crianças (BFC), Questionário de Capacidades e Dificuldades (SDQ), Escala lócus de controle de Norwick-Strickland, Questionário de Autoeficácia para Crianças, Escala de Garra (Grit), Autoavaliações nucleares (Core) e Escala de autoestima de Rosemberg. Destes, apenas os dois primeiros estavam dentro das cinco subescalas do BFI: abertura para novas experiências, conscienciosidade, extroversão, amabilidade e estabilidade emocional.

3 O método de Blocos Balanceados Incompletos consiste em excluir itens específicos do instrumento em um questionário, mas inseri-los em outro questionário. Desse modo, há um conjunto de combinações possíveis que é utilizado, resultando em diversas versões do instrumento. Assim, é possível testar diversos itens em diferentes amostras, não sendo necessário aplicar um questionário muito extenso para um único indivíduo.

4 Análise fatorial exploratória tem como objetivo verificar se existe uma estrutura implícita dentro das variáveis que compõem o instrumento. 


\section{Base de Dados}

O objetivo deste trabalho é realizar um estudo empírico com a finalidade de verificar o impacto da frequência à creche sobre o desenvolvimento de habilidades não-cognitivas durante a vida educacional dos indivíduos. Entretanto, ao contrário das tradicionais habilidades cognitivas, as habilidades não-cognitivas não possuem mensuração a nível nacional ${ }^{1}$. Nesse sentido, para lidar com a escassez de dados que impossibilita a realização de estudos em larga escala nessa área, o presente trabalho optou por fazer uso de duas bases de dados diferentes: uma coletada no estado do Ceará e uma coletada em Sertãozinho, município do interior de São Paulo.

A base de dados do Ceará, apresentada em 4.1, é fruto de uma aplicação realizada em um único ponto no tempo do instrumento SENNA em conjunto com o Sistema Permanente de Avaliação da Educação Básica do Ceará (SPAECE). Por sua vez, a base de dados de Sertãozinho, apresentada em 4.2, abrange quase todas as escolas do município e possui aplicações em três anos distintos, viabilizando o acompanhamento dos alunos ao longo dos anos.

Vale destacar que as amostras utilizadas são, por natureza, bastante distintas. À título de exemplo, o Ceará, localizado na região Nordeste do país, é o oitavo estado mais populoso do país e o próprio SPAECE atinge cerca de 500 mil alunos por ano, considerando-se todas as séries de ensino (SPAECE, 2018). Sertãozinho, por sua vez, é uma cidade localizada no interior de São Paulo com pouco mais de 100 mil habitantes (IBGE, 2019a).

Além disso, há também uma diferença importante no nível de renda e na qualidade de vida das duas localidades. Para fins de comparação, em 2017, o PIB per capita de Sertãozinho era de 43 mil reais e do Ceará de 16 mil reais e seus IDH eram, respectivamente, 0,761 e 0,682 em 2010 (IBGE, 2019a; IBGE, 2019b). Nesse sentido, é importante considerar também que a própria aplicação do SPAECE é realizada apenas na rede pública estadual de educação, enquanto os dados de Sertãozinho espalham-se por quase todas as escolas do município, incluindo as privadas (que, geralmente, já possuem características bastante singulares quando comparadas à rede pública em todo o país).

Por fim, educacionalmente falando, ainda que o estado do Ceará seja conhecido por abrigar casos importantes de sucesso (Sobral, reconhecidamente), Sertãozinho possuía, também em 2017, o Índice de Desenvolvimento da Educação Básica (IDEB), que mistura o desempenho dos alunos na Prova Brasil e as taxas de aprovação das escolas, mais alto que o Ceará nos anos finais do ensino fundamental (7,2 contra 6,1) e também nos anos iniciais (5,6 contra 4,9).

1 Exemplos de questionários que mensuram habilidades cognitivas são a Prova Brasil (desenvolvida pelo Instituto Nacional de Estudos e Pesquisas Educacionais Anísio Teixeira - Inep/MEC) a nível nacional e o PISA (Programa Internacional de Avaliação de Estudantes) a nível internacional. Ainda, alguns estados realizam medidas de proficiência próprias, a exemplo do Ceará com o SPAECE e São Paulo com o Sistema de Avaliação do Rendimento Escolar do Estado de São Paulo (SARESP). 
Desse modo, ainda que a existência dessas bases de dados permitam a realização de um estudo bastante abrangente e com diferentes abordagens do tema, comparações e generalizações dos resultados aqui apresentados precisam ser feitas com cautela. Nas subseções seguintes discute-se mais profundamente as características de cada uma das amostras utilizadas.

\subsection{Ceará}

A base de dados utilizada provém de uma aplicação conjunta do instrumento SENNA e do Sistema Permanente de Avaliação da Educação Básica do Ceará (SPAECE) em escolas públicas nos 184 municípios do Ceará no ano de 2015. A aplicação do SENNA foi realizada apenas com alunos do $1^{\circ}$ ano do ensino médio, seja este regular ${ }^{2}$, Ensino de Jovens Adultos (EJA) presencial ou ensino médio integrado.

Além dos resultados não-cognitivos, resultados do SPAECE, prova aplicada para os alunos das instituições municipais e estaduais do Ceará que visa monitorar e avaliar a educação pública, foram obtidos. A aplicação do SPAECE teve início em 1992, mas só a partir de 2001 começou a ser aplicada para todos os municípios do estado do Ceará. O SPAECE é composto por provas de Língua Portuguesa e Matemática, além de questionários contextuais do aluno (SPAECE, 2018).

Excluem-se os alunos do EJA desta análise, tendo em vista que estes, por se encontrarem em uma etapa da vida diferente dos demais indivíduos participantes da pesquisa, têm características também diferentes, de modo que a modelagem de suas variáveis de resultados necessitariam de um abordagem que foge do escopo deste trabalho. Vale ressaltar que também foram excluídos da análise indivíduos que não possuíam código de aluno, indivíduos que possuíam o código de aluno duplicado, indivíduos que não possuíam resposta para a variável de creche, isto é, se havia frequentado ou não creche, pois esta é a variável de interesse do presente trabalho, indivíduos que não possuíam a informação de socioemocional e indivíduos que possuíam idade menor que 13 anos, tendo em vista que estes podem ser considerados como outliers.

Por meio da Tabela 1 é possível notar que pouco menos da metade dos indivíduos são do sexo masculino (47,8\%), com idade média de 16 anos, em sua maioria pardos ou negros $(64,8 \%)$. Menos de $30 \%$ reprovou ao menos uma vez. Mais da metade dos indivíduos $(53,6 \%)$ frequentou creche pública, mas cerca de $38 \%$ não frequentaram nenhum tipo de creche. Uma heterogeneidade interessante a ser explorada é a diferença de qualidade entre as creches, dado que esta variável possui quatro categorias: não frequentou, pública, privada com bolsa e privada sem bolsa. No entanto, para a manutenção de comparabilidade das análises de dados do Ceará e de Sertãozinho e, dado que em Sertãozinho as mesmas categorias não existem, tal heterogeneidade será explorada como um exercício adicional do presente trabalho. Quando se trata da pré-escola,

\footnotetext{
2 Isto é, aquele que compõe a última etapa da educação básica, sem estar associado com formação profissionali-
} zante ou voltado para a formação de adultos que não concluíram esta etapa de ensino anteriormente. 
reduz-se o número de indivíduos $(19,5 \%)$ que nunca frequentou essa etapa de ensino.

A Tabela 2 reporta características socioeconômicas dos alunos. É possível verificar uma baixa escolaridade das mães, tendo em vista que 17,3\% nunca estudaram ou não completaram o Ensino Fundamental I e 25\% completaram apenas o Ensino Fundamental I. As 16,4\% de respostas tidas como "não sabe", referentes aos alunos que não sabiam responder o nível de escolaridade de suas respectivas mães, foram mantidas, pois podem estar relacionadas com alguma característica da família. Enquanto apenas 39,3\% dos alunos mora com o pai, 79,2\% mora com a mãe e apenas $34,4 \%$ moram com ambos. $61 \%$ da amostra possui algum beneficiário do Bolsa Família em sua residência. Por fim, quando se tratam das características da moradia, a maioria das casas possui energia elétrica $(95,3 \%)$, televisão $(90,7 \%)$, geladeira $(90,3 \%)$ e água encanada $(88,7 \%)$.

Tabela 1 - Características dos alunos - Ceará

\begin{tabular}{lccc}
\hline \hline & Média ou \% & D.p. & $\mathrm{N}$ \\
\cline { 2 - 4 } Homem & $47,8 \%$ & 0,5 & 96880 \\
Idade & 15,975 & 1,182 & 95360 \\
Cor & & & \\
$\quad$ Pardos e negros & $64,8 \%$ & 0,478 & 95325 \\
$\quad$ Brancos e amarelos & $30,8 \%$ & 0,462 & 95325 \\
$\quad$ Indígena & $4,4 \%$ & 0,206 & 95325 \\
Creche & & & \\
$\quad$ Não frequentou & $37,6 \%$ & 0,485 & 97586 \\
$\quad$ Pública & $53,6 \%$ & 0,499 & 97586 \\
$\quad$ Privada com bolsa & $3,2 \%$ & 0,176 & 97586 \\
$\quad$ Privada sem bolsa & $5,5 \%$ & 0,228 & 97586 \\
Pré-escola & & & \\
$\quad$ Não frequentou & $19,5 \%$ & 0,396 & 95886 \\
$\quad$ Pública & $64,6 \%$ & 0,478 & 95886 \\
$\quad$ Privada com bolsa & $3,6 \%$ & 0,187 & 95886 \\
$\quad$ Privada sem bolsa & $12,3 \%$ & 0,329 & 95886 \\
Reprovação & & & \\
$\quad$ Uma vez & $26,7 \%$ & 0,443 & 94641 \\
$\quad$ Mais de uma vez & $10,2 \%$ & 0,303 & 94641 \\
\hline \hline
\end{tabular}

As variáveis não-cognitivas utilizadas foram calculadas por meio de Teoria de Resposta ao Item (TRI). Resumidamente, o TRI consiste em modelar padrões de respostas individuais ao especificar como os traços latentes ${ }^{3}$ interagem com as características do item, como, por exemplo, a dificuldade do mesmo. O objetivo principal da utilização desse método é separar as características dos respondentes dos parâmetros associados ao próprio item, a fim de que ambos possam ser estudados separadamente (CHALMERS et al., 2012). Após o tratamento da base de dados, os scores foram padronizados, isto é, retirou-se a média e dividiu-se pelo desvio-padrão,

3 Entende-se por traços latentes aqueles que não são observáveis diretamente. Um exemplo de traço latente é a própria habilidade do indivíduo. 
Tabela 2 - Características socioeconômicas dos alunos - Ceará

\begin{tabular}{lccc}
\hline \hline & Média ou \% & D.p. & $\mathrm{N}$ \\
\cline { 2 - 4 } Educação da mãe & & & \\
Nunca estudou ou não & $17,3 \%$ & 0,379 & 92077 \\
completou Fundamental I & & & \\
Fundamental I & $25,0 \%$ & 0,433 & 92077 \\
Fundamental II & $17,1 \%$ & 0,376 & 92077 \\
Ensino Médio & $18,6 \%$ & 0,389 & 92077 \\
Ensino Superior & $3,7 \%$ & 0,189 & 92077 \\
Pós-Graduação & $1,9 \%$ & 0,138 & 92077 \\
Não sabe & $16,4 \%$ & 0,37 & 92077 \\
Mora com o pai & $39,3 \%$ & 0,489 & 97586 \\
Mora com a mãe & $79,2 \%$ & 0,406 & 97586 \\
Mora com ambos & $34,4 \%$ & 0,475 & 97586 \\
Bolsa Família & $61,0 \%$ & 0,488 & 96058 \\
Características da moradia & & & \\
Rua asfaltada & $63,3 \%$ & 0,482 & 92153 \\
Energia Elétrica & $95,3 \%$ & 0,212 & 96512 \\
Água encanada & $88,7 \%$ & 0,317 & 96840 \\
Coleta de lixo & $75,5 \%$ & 0,43 & 96723 \\
Empregada doméstica & $11,9 \%$ & 0,324 & 96479 \\
Carro & $30,1 \%$ & 0,459 & 95092 \\
Geladeira & $90,3 \%$ & 0,296 & 96495 \\
Máquina de lavar & $56,5 \%$ & 0,496 & 96509 \\
Computador & $41,3 \%$ & 0,492 & 96457 \\
Microondas & $38,9 \%$ & 0,488 & 95959 \\
Televisão & $90,7 \%$ & 0,291 & 96357 \\
\hline \hline
\end{tabular}

cálculo devidamente explicitado na Seção 5. Nesse sentido, todos os cinco domínios possuem média igual a 0 e desvio-padrão igual 1. Portanto, optou-se por não reportar uma tabela com estatísticas descritivas, já que esta seria pouco informativa.

Visando explorar o comportamento das habilidades socioemocionais, foram comparadas as médias destas de acordo com a idade do indivíduo por frequência ou não à creche, reportadas nas Figuras 1, 2, 3, 4 e 5. Além disso, como exercício adicional, foram comparadas também as médias dessas habilidades em relação a categoria de creche que o aluno frequentou (Pública, Privada com bolsa ou Privada sem bolsa) e os resultados estão reportados nas Figuras 11, 12, 13, 14 e 15 no Apêndice A. Ainda, vale ressaltar que a análise se dá em um único ano escolar - o primeiro ano do ensino médio - de modo que as variações de idade dizem respeito a alunos adiantados ou atrasados. Nesse sentido, os gráficos não reportam o desenvolvimento socioemocional típico das idades, mas sim a habilidade média para os indivíduos naquela idade e que possuem histórico de reprovação ou que estão adiantados na etapa escolar.

Nota-se que para a maioria das idades e habilidades, crianças que frequentaram creche possuem scores mais altos quando comparadas com crianças que não frequentaram creche. 
Essa relação não é clara apenas para o domínio de Estabilidade emocional, onde as médias são bem parecidas entre os dois grupos e entre as diferentes idades. Ainda, no que se refere à Conscienciosidade, observa-se que, aos 20 anos, os scores aumentam substancialmente tanto para quem frequentou creche quanto para quem não frequentou.

Figura 1 - Abertura para novas experiências por idade para crianças que frequentaram e não frequentaram creche

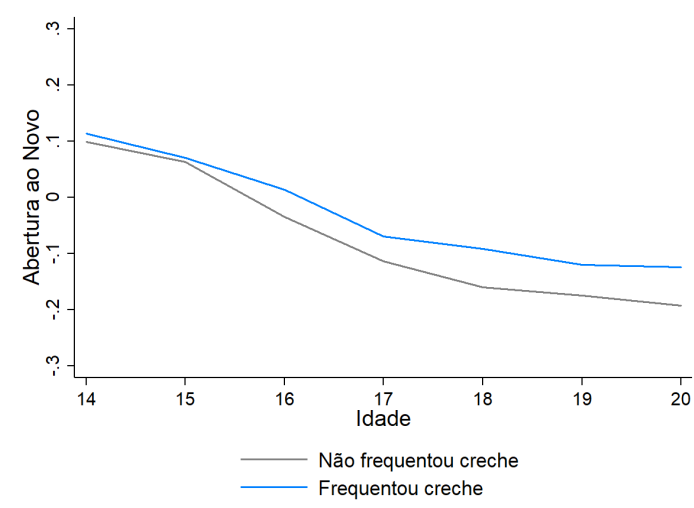

Figura 3 - Extroversão por idade para crianças que frequentaram e não frequentaram creche

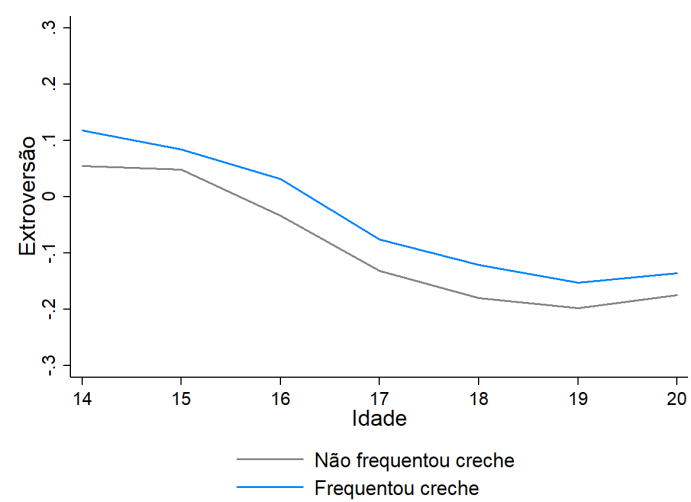

Figura 2-Conscienciosidade por idade para crianças que frequentaram e não frequentaram creche

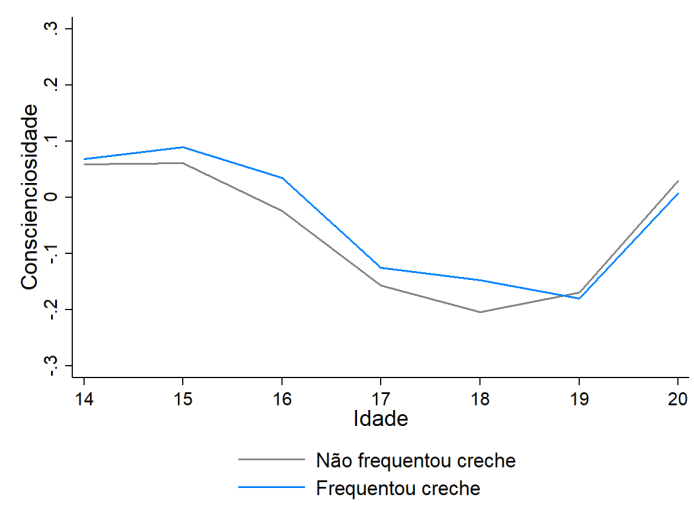

Figura 4 - Amabilidade por idade para crianças que frequentaram e não frequentaram creche

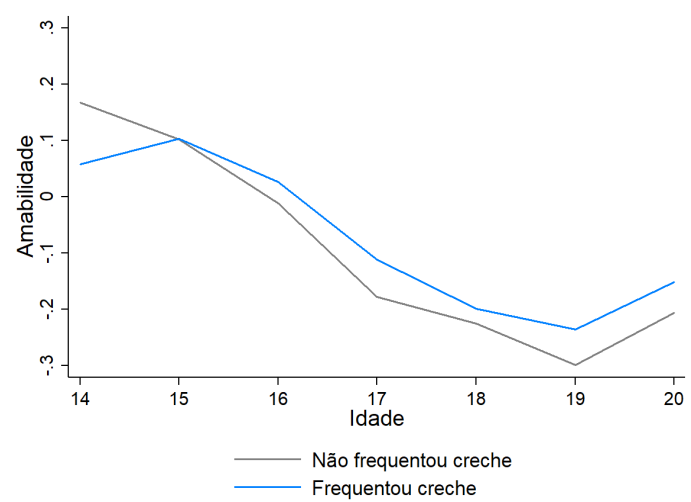


Figura 5 - Estabilidade emocional por idade para crianças que frequentaram e não frequentaram creche

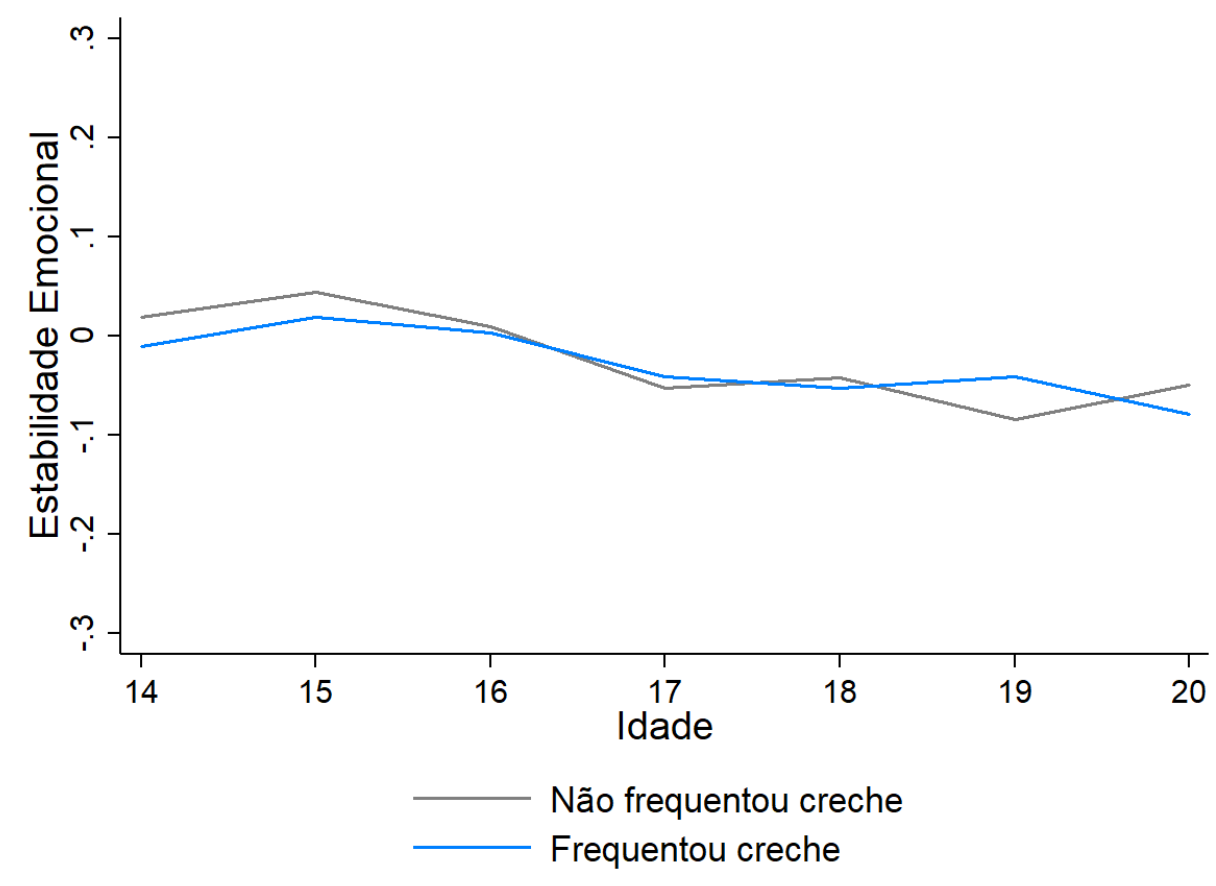

É possível notar as diferenças de status socioeconômico da família por meio da tabela 31 no Apêndice A, onde as mesmas estatísticas descritivas reportadas nas Tabelas 1 e 2 são separadas para cada categoria de creche. Há permanência da categoria de creche na de pré-escola, já que $80,2 \%$ das crianças que frequentaram creche pública permaneceram em pré-escola pública e $67,5 \%$ das crianças que frequentaram creche privada sem bolsa permaneceram na mesma condição quando matriculadas na pré-escola. Verificam-se índices de reprovações mais altos para indivíduos que frequentaram creche privada com bolsa. As mães mais escolarizadas são as de filhos que frequentaram creche particular sem bolsa, enquanto a maior taxa de mães que nunca estudaram ou não completaram o Ensino Fundamental I provém da categoria de alunos que frequentaram creche com bolsa. Cerca de $65 \%$ dos alunos que frequentaram creches públicas possuem alguém em seu domicílio que recebe o benefício do programa Bolsa Família, enquanto apenas $37,2 \%$ dos indivíduos que frequentaram creche privada sem bolsa o possuem, indicando um melhor status socioeconômico para indivíduos dentro desta última categoria. Por fim, crianças que frequentaram creche sem bolsa têm, no geral, características de moradia melhores do que os indivíduos pertencentes às outras três categorias.

Ainda que a idade média já tenha sido reportada pela Tabela 1, optou-se por mostrar a distribuição das idade, ilustrada na Tabela 3. A maioria dos indivíduos possui 15 ou 16 anos, idade adequada para indivíduos que nunca reprovaram nenhuma série escolar.

Por fim, desconfia-se de que creches apontadas como "particular com bolsa" sejam creches conveniadas. Define-se como creche conveniada uma creche particular, mas que possui 
Tabela 3 - Distribuição da variável idade - Ceará

\begin{tabular}{lcc}
\hline \hline Idade & $\mathrm{N}$ & $\%$ \\
\hline 14 & 2303 & 2,42 \\
15 & 36694 & 38,48 \\
16 & 33301 & 34,92 \\
17 & 13513 & 14,17 \\
18 & 5428 & 5,69 \\
19 & 1960 & 2,06 \\
20 & 2161 & 2,27 \\
\hline Total & 95360 & 100,00 \\
\hline \hline
\end{tabular}

convênio com a prefeitura. Esta política vem sendo adotada devido a incapacidade do Estado de atender a ampla demanda de creches, pode-se pensar como uma "terceirização" da instituição, mas que deve atuar seguindo as normas das creches públicas. Essa informação foi verificada a partir dos microdados do Censo Escolar de 2002, pois, considerando que a idade média dos indivíduos é de, aproximadamente, 16 anos, em 2002 estes teriam 3 anos, idade do último ano de atendimento de creche. A identificação de creche conveniada só foi inserida nos microdados recentemente, de modo que, em 2002, essa variável não está disponível. Entretanto, tentando suprir a ausência dessa informação, verificou-se disparidades acerca da propriedade ${ }^{4}$ onde atua a escola e a dependência administrativa da mesma (Municipal, Estadual, Federal ou Particular). Obteve Creches municipais, estaduais ou federais que atuassem em propriedade particular ou creches particulares que atuassem em propriedade pública foram consideradas como conveniadas. Então, foram obtidas o número de matrículas para cada uma dessas instituições e suas respectivas porcentagens com relação ao total.

Tabela 4 - Comparação do SPAECE com o Censo Escolar de 2002 por tipo de creche - Ceará

\begin{tabular}{lcc|lcc}
\hline \hline \multicolumn{2}{c|}{ SPAECE } & \multicolumn{3}{c}{ Censo Escolar 2002 } \\
\hline \multirow{2}{*}{ Tipo de creche } & \multirow{2}{*}{ Participantes } & $\%$ & $\begin{array}{l}\text { Dependência } \\
\text { administrativa }\end{array}$ & Matrículas & $\%$ \\
\hline Pública & 52339 & $86 \%$ & Pública & 52877 & $61 \%$ \\
Particular com bolsa & 3130 & $5 \%$ & Conveniada & 11108 & $13 \%$ \\
Particular sem bolsa & 5376 & $9 \%$ & Particular & 23327 & $27 \%$ \\
\hline Total & 60845 & $100 \%$ & Total & 87312 & $100 \%$ \\
\hline \hline
\end{tabular}

A tabela 4 mostra os dados, a nível de aluno, da base de dados do Ceará e os dados, também a nível de aluno, obtidos por meio do Censo Escolar de 2002. Verifica-se que as porcentagens seguem a mesma ordem de grandeza, isto é, a maior parte dos alunos frequentou creches públicas, seguida de creche particular e, por fim, as que supomos ser conveniadas. Note

4 A propriedade dos imóveis foi verificada a partir das variáveis "PROP_MUN", "PROP_EST", "PROP_FED", "PROP_PAR", que indicam se a entidade proprietária do imóvel é municipal, estadual, federal ou particular, respectivamente. Estas informações estão contidas no dicionário do Censo Escolar de 2002. 
ainda que, como na base do Ceará se analisam apenas alunos provenientes de escolas públicas, é natural que se espere que a maior parte destes tenha frequentado creche também pública. Nesse sentido, temos indícios de que creches particulares com bolsa de fato possam ser creches conveniadas.

\subsection{Sertãozinho (SP)}

A base de dados longitudinal para o município de Sertãozinho (SP), é fruto de um esforço conjunto do Laboratório de Estudos e Pesquisas em Economia Social (LEPES) ${ }^{5}$ da Universidade de São Paulo com o Metas Sociais ${ }^{6,7}$. Foram realizadas três coletas ao longo do tempo, 2008, 2012 e 2017, com o intuito de acompanhar o desenvolvimento dos indivíduos.

Em 2008 ocorreu a primeira aplicação da Provinha Brasil ${ }^{8}$ em Sertãozinho, que, excepcionalmente esse ano, incluiu a totalidade das escolas públicas e privadas do município, com o objetivo de coletar informações acerca da alfabetização das crianças do $2^{\circ}$ ano $\left(1^{a}\right.$ série) do ensino fundamental (FELÍCIO; TERRA; ZOGHBI, 2012). Conjuntamente, foi aplicado um questionário socioeconômico direcionado para os responsáveis dos alunos. Contudo, não foi aplicado nenhum instrumento socioemocional para o primeiro ano da coleta, inviabilizando a utilização deste ano na análise.

Para os dados de 2012, aplicaram-se as provas cognitivas de Língua Portuguesa e Matemática para todos os alunos dos $6^{\circ}$ ano $\left(5^{\mathrm{a}}\right.$ série $)$ e $5^{\circ}$ ano ( $4^{\mathrm{a}}$ série $)$ do ensino fundamental, tendo em vista que alunos promovidos estariam na primeira e alunos que possuíssem uma reprovação estariam na segunda. Entretanto, alguns alunos participantes da coleta de 2008 possuíam duas reprovações e, portanto, encontravam-se no $4^{\circ}$ ano ( $3^{\mathrm{a}}$ série). Como esses constituíam pequena parcela da amostra, as provas de caráter cognitivo foram aplicadas somente para estes alunos participantes da pesquisa em 2008, não sendo necessária a aplicação dos testes cognitivos em todo o $4^{\mathrm{o}}$ ano ( $3^{\mathrm{a}}$ série).

Foram feitos dois tipos de provas cognitivas: uma para os alunos que estavam no $6^{\circ}$ ano e, portanto, não tinham nenhuma reprovação e outra para os alunos que já haviam reprovado pelo menos uma vez e, portanto, encontravam-se no $4^{\circ}$ e $5^{\circ}$ ano. Ademais, dois questionários socioeconômicos foram coletados, um preenchido pelo próprio aluno e o outro pelo seu respectivo responsável. Por fim, foram aplicados testes não cognitivos direcionados a todos os alunos dos $4^{\circ}, 5^{\circ}$ e $6^{\circ}$ ano, os quais permitiram mensurar os cinco grandes domínios de personalidade.

Em 2012, trinta e uma escolas participaram da pesquisa, dentre elas públicas e privadas.

\footnotetext{
Para maiores informações: <http://lepes.fearp.usp.br/>.

Para maiores informações: <https://www.metassociais.com.br/>.

7 O Metas Sociais foi responsável pela pesquisa no ano de 2008, enquanto o LEPES foi responsável pelas coletas de 2012 e 2017.

8 A Provinha Brasil é uma avaliação de proficiência em português e matemática voltada para crianças matriculadas no $2^{\circ}$ ano ( $1^{\mathrm{a}}$ série) do ensino fundamental de escolas públicas (INEP, 2018).
} 
De acordo com os dados do Censo Escolar de 2012 extraídos da página do INEP, é possível concluir que apenas três escolas do município não participaram da pesquisa nesse ano, dado que existiam trinta e quatro escolas de ensino regular atuantes para os anos escolares de interesse.

Na terceira onda da pesquisa, que ocorreu em 2017, novamente, optou-se pela coleta de dados de todos os indivíduos que estavam matriculados do $9^{\circ}$ ano ( $8^{\mathrm{a}}$ série) do ensino fundamental até o $2^{\circ}$ ano do ensino médio, independente da participação nas coletas anteriores. Nem todos os alunos compareceram nos dias em que os questionários foram aplicados, sendo esta uma fonte de perda amostral. Ainda, alguns dos alunos que participaram da pesquisa nas coletas anteriores encontravam-se em outros anos de ensino, as provas foram aplicadas para eles, de tal sorte que não se tornassem uma fonte de atrito na amostra.

Foram realizadas provas de Língua Portuguesa e Matemática, além de terem sido aplicados dois tipos de questionários que visam a mensuração de habilidades socioemocionais, um questionário de cadastro e um de informação contextual. As provas de matemática e de português foram elaboradas com base nas questões do site do INEP, de modo que se torna possível a comparação com a Prova Brasil. Os questionários de habilidades socioemocionais eram de dois tipos: o primeiro utilizava o BFI; e o segundo utilizava lócus de controle e a escala Social Skills Rating System (SSRS) $)^{9}$ O questionário de cadastro envolvia perguntas sobre cor, gênero e informação escolar.

Ademais, foram aplicados questionários de violência para os alunos e questionários direcionados para os pais. O questionário dos pais continha perguntas sobre sua satisfação com a escola que seu filho(a) estava matriculado, expectativa sobre o futuro do jovem, informações socioeconômicas e estrutura familiar.

Novamente, apenas os dados coletados em 2012 e em 2017 foram utilizados ${ }^{10}$, havendo atrito amostral de 43,8\%, reportado na Tabela 5. O atrito amostral é definido como indivíduos que participaram da pesquisa em 2012, mas não foram encontrados ou participaram de maneira parcial em 2017. Ainda que tenha acontecido um grande esforço para acompanhar alunos que saíram da escola, exceto aqueles que mudaram de cidade, a perda amostral pode ser considerada alta. Isto ocorre porque, em 2017, a pesquisa foi repartida em três dias de aplicação, de modo que é possível que, ainda que um aluno tenha participado de parte da pesquisa, isto é, participou de apenas um dia ou dois, não necessariamente ele respondeu aos questionários que continham as informações necessárias para a base de dados utilizada neste trabalho ${ }^{11}$. Ainda, existe a

9 Esta escala se subdivide em 3 subescalas, a primeira é similar a competência social, a segunda é a de problemas de comportamento e a terceira é de competência acadêmica.

10 Por conta da dificuldade que se tem de acompanhar os mesmos alunos ao longo do tempo, dos alunos da amostra de 2008, apenas 792 permaneceram na base até 2017, sendo este mais um dos motivos pelo qual se realizou a opção de excluir os dados de 2008 da amostra utilizada.

11 Dos dados de 2012, utilizou-se a identificação do aluno, parte do questionário de pais e as respostas dos itens socioemocionais. Para 2017, utilizaram-se os dados de cadastro, dados contextuais, parte do questionário de pais e respostas dos itens socioemocionais relativos aos cinco grandes domínios de personalidade. Ademais, foram excluídos da amostra 8 indivíduos que possuíam 20 anos ou mais, pois foram considerados como outliers, isto é, indivíduos muito diferentes dos demais e que contaminariam a análise realizada. 
possibilidade do aluno ter comparecido aos três dias de pesquisa, porém não ter respondido a todos os questionários necessários.

Tabela 5 - Atrito amostral dos alunos presentes em 2012 e 2017 - Sertãozinho

\begin{tabular}{lcc}
\hline \hline & 2012 & 2017 \\
\hline $\mathrm{N}^{0}$ de observações & 2962 & 1664 \\
Atrito & & 1298 \\
& & $(43,8 \%)$ \\
\hline \hline
\end{tabular}

Um problema em comum dos dados coletados em 2012 e 2017 é a baixa taxa de resposta dos pais aos questionários, de modo que variáveis como escolaridade da mãe, frequência à creche e à pré-escola possuem alto índice de missings. Buscando corrigir esse problema, foram propostas correções para essas duas variáveis. No que tange a escolaridade da mãe, utilizou-se a seguinte regra: a informação respondida pelos pais foi considerada a mais confiável, entretanto, caso os pais não tivessem respondido ao questionário, considerou-se a resposta do aluno. Em caso de não resposta dos alunos e dos pais, a variável foi deixada como missing. No caso de frequência à creche, optou-se por considerar a resposta dada pelos pais em 2012, tendo em vista que, pelo fato de as crianças serem muito pequenas quando frequentaram a creche, podem não se lembrar da informação correta, gerando erro de medida na variável. Caso os pais não tivessem respondido ao questionário em 2012, foram consideradas as respostas dos alunos em 2017. Para a correção da variável de pré-escola, realizou-se o mesmo procedimento. Por meio da Tabela 6 é possível notar que 229 crianças estavam com a resposta errada quando se trata de frequência à creche. Para a variável de pré-escola, pode-se ver através da Tabela 7, que 125 respostas mudaram com a correção da variável. Ainda, 71 indivíduos da amostra possuíam informações conflitantes, por exemplo, alguns indivíduos haviam respondido que frequentaram e não frequentaram creche. Como creche é a variável principal do exercício, esses indivíduos foram retirados da análise, o que explica a diferença do número total de observações da Tabela 5 para as tabelas 6 e 7 .

Tabela 6 - Diferença de resposta da variável de creche - Sertãozinho

\begin{tabular}{lcc|c}
\hline \hline \multirow{2}{*}{ Creche corrigida } & \multicolumn{3}{c}{ Creche respondida pelos alunos em 2017 } \\
\cline { 2 - 4 } & Não frequentou & Frequentou & Total \\
\hline Não frequentou & 613 & 47 & 660 \\
Frequentou & 182 & 751 & 933 \\
\hline Total & 795 & 798 & 1593 \\
\hline \hline
\end{tabular}

Ainda, foi realizada uma correção na variável de idade, pois, ao compará-la em 2012 e 2017, alguns indivíduos possuíam valor diferente de cinco anos, tempo de intervalo das pesquisas. Nesses casos, verificou-se se havia discrepância entre o ano de nascimento reportado pelo aluno em 2012 e em 2017. Caso houvesse, foi considerado como correto o ano de nascimento reportado 
Tabela 7 - Diferença de resposta da variável de pré-escola - Sertãozinho

\begin{tabular}{lccccc}
\hline \hline \multirow{2}{*}{ Pré-escola corrigida } & \multicolumn{4}{c}{ Pré-escola respondida pelos alunos em 2017 } \\
\cline { 2 - 6 } & Não frequentou & Frequentou & Informação faltante & Total \\
\hline Não frequentou & 73 & 20 & 0 & 93 \\
Frequentou & 89 & 1381 & 16 & 1486 \\
Informação faltante & 0 & 0 & 14 & 14 \\
\hline Total & 162 & 1401 & 30 & 1593 \\
\hline \hline
\end{tabular}

Tabela 8 - Idade dos indivíduos da amostra para os anos de 2012 e 2017 - Sertãozinho

\begin{tabular}{lcccc}
\hline \hline & \multicolumn{3}{c}{2012} & \multicolumn{2}{c}{2017} \\
\cline { 2 - 5 } Idade & $\%$ do total & $\mathrm{N}^{0}$ de observações & $\%$ do total & $\mathrm{N}^{0}$ de observações \\
\hline 10 & $27,5 \%$ & 438 & $0,0 \%$ & 0 \\
11 & $47,3 \%$ & 753 & $0,0 \%$ & 0 \\
12 & $20,5 \%$ & 327 & $0,0 \%$ & 0 \\
13 & $4,1 \%$ & 65 & $0,0 \%$ & 0 \\
14 & $0,6 \%$ & 10 & $0,0 \%$ & 0 \\
15 & $0,0 \%$ & 0 & $1,6 \%$ & 26 \\
16 & $0,0 \%$ & 0 & $38,9 \%$ & 619 \\
17 & $0,0 \%$ & 0 & $46,5 \%$ & 741 \\
18 & $0,0 \%$ & 0 & $10,6 \%$ & 168 \\
19 & $0,0 \%$ & 0 & $2,5 \%$ & 39 \\
\hline Total & $100 \%$ & 1,593 & $100 \%$ & 1,593 \\
\hline \hline
\end{tabular}

pelos pais em 2012, supondo que essa era uma resposta mais confiável do que a dos próprios alunos em ambos os anos. Caso a variável não possuísse resposta no questionário de pais, considerou-se a idade reportada pelo aluno em 2017, supondo-se que esta era mais confiável do que a de 2012, quando os alunos eram mais jovens. A Tabela 8 mostra as idades após as correções.

É possível notar uma persistência da discordância entre as idades e o intervalo da pesquisa, por exemplo: em 2012, 27,5\% dos respondentes possuíam 10 anos, enquanto, em 2017, apenas 1,6\% possuíam 15 anos. Para entender o porquê desse acontecimento, reportou-se a Tabela 9, que mostra a distribuição de idades por ano da pesquisa. Pode-se atribuir a discrepância ao desenho da pequisa: em 2012 o questionário foi aplicado em dois períodos no tempo. No primeiro semestre do ano, os alunos responderam a provas cognitivas e questionários contextuais, também foram apicados questionários para os pais. No segundo semestre, os alunos responderam a questionários não-cognitivos, havendo uma segunda rodada de questionários para alunos e pais. Neste último semestre também foram coletadas respostas de diretores e professores. Nesse sentido, a diferença na distribuição das idades está relacionada apenas com o mês de aplicação da pesquisa. A reaplicação dos questionários de alunos e pais no segundo semestre se deu a uma alta taxa de não-resposta.

No que tange as habilidades socioemocionais, é necessário tomar cuidado ao analisar os 
Tabela 9 - Idade em 2012 e 2017 - Sertãozinho

\begin{tabular}{lccccc|c}
\hline \hline Idade do aluno & \multicolumn{7}{c}{ Idade do aluno em 2017} \\
\cline { 2 - 7 } em 2012 & 15 & 16 & 17 & 18 & 19 & Total \\
\hline 10 & 26 & 412 & 0 & 0 & 0 & 438 \\
11 & 0 & 207 & 546 & 0 & 0 & 753 \\
12 & 0 & 0 & 195 & 132 & 0 & 327 \\
13 & 0 & 0 & 0 & 36 & 29 & 65 \\
14 & 0 & 0 & 0 & 0 & 10 & 10 \\
\hline Total & 26 & 619 & 741 & 168 & 39 & 1,593 \\
\hline \hline
\end{tabular}

dados, pois serão utilizadas duas variações destas variáveis, onde ambas envolvem a padronização e correção por aquiescência, de modo que a diferença reside apenas no ano base da padronização. Para utilização destas variáveis nos modelos de Mínimos Quadrados Ordinários, será realizada uma padronização para cada ano. Nos modelos em painel, a padronização será realizada com relação ao ano de 2012, que tem suas estatísticas descritivas mostradas pela Tabela 10. A diferenciação as metodologias será explicada na Seção 5 com maiores detalhes. Note que todas as médias de 2012, na Tabela 10, são nulas e todos os desvios-padrão são iguais a 1. Isso ocorre porque, para a padronização, foi utilizado como ano base o ano de 2012, assim seria possível comparar os resultados de ambos os anos. Justamente por esse fato, não é informativo reportar as estatísticas descritivas que possuem ano base em 2012 e em 2017, pois estas têm médias nulas para cada uma das habilidades e desvios-padrão iguais a 1.

Tabela 10 - Estatísticas dos socioemocionais com ano base em 2012 - Sertãozinho

\begin{tabular}{lcccccc}
\hline \hline & Média & D.p. & Mínimo & Mediana & Máximo & $\mathrm{N}$ \\
\cline { 2 - 7 } & \multicolumn{7}{c}{2012} \\
Abertura para novas experiências & 0,00 & 1,00 & $-3,71$ & 0,00 & 2,40 & 1589 \\
Conscienciosidade & 0,00 & 1,00 & $-3,51$ & 0,02 & 2,46 & 1589 \\
Extroversão & 0,00 & 1,00 & $-4,06$ & $-0,03$ & 2,74 & 1588 \\
Amabilidade & 0,00 & 1,00 & $-3,46$ & 0,04 & 1,76 & 1589 \\
Estabilidade Emocional & 0,00 & 1,00 & $-3,36$ & 0,02 & 3,19 & 1588 \\
\cline { 2 - 7 } & & \multicolumn{7}{c}{2017} & & \\
Abertura para novas experiênciaas & $-0,14$ & 0,94 & $-3,82$ & $-0,13$ & 2,18 & 1592 \\
Conscienciosidade & $-0,37$ & 0,98 & $-4,20$ & $-0,41$ & 2,32 & 1593 \\
Extroversão & $-0,17$ & 1,17 & $-3,74$ & $-0,20$ & 2,64 & 1593 \\
Amabilidade & $-0,48$ & 0,97 & $-4,06$ & $-0,48$ & 2,41 & 1593 \\
Estabilidade Emocional & $-0,31$ & 1,23 & $-3,13$ & $-0,29$ & 2,98 & 1592 \\
\hline \hline
\end{tabular}

Ainda, para entender melhor os resultados posteriores, optou-se por mostrar os gráficos da trajetória socioemocional por idade e com ano base em 2012, separando os subgrupos dos alunos que fizeram creche e dos que não a fizeram, reportados nas figuras 6, 7, 8, 9 e 10. Estes gráficos ilustram uma espécie de trajetória socioemocional ao longo do tempo, dado que frequentaram creche. Frequentar a creche é um tratamento que ocorre no instante inicial da vida, podendo ter efeitos diversos a depender da idade do indivíduo. Como as regressões reportam 
os resultados na média, a informação do estágio acaba sendo reprimida, isto é, ainda que não haja, na média, algum resultado socioemocional de creche, pode ser que no início da vida, este resultado tenha sido positivo e ao final tenha sido negativo, tornando o efeito médio nulo.

Figura 6 - Abertura para novas experiências por idade para crianças que frequentaram e não frequentaram creche
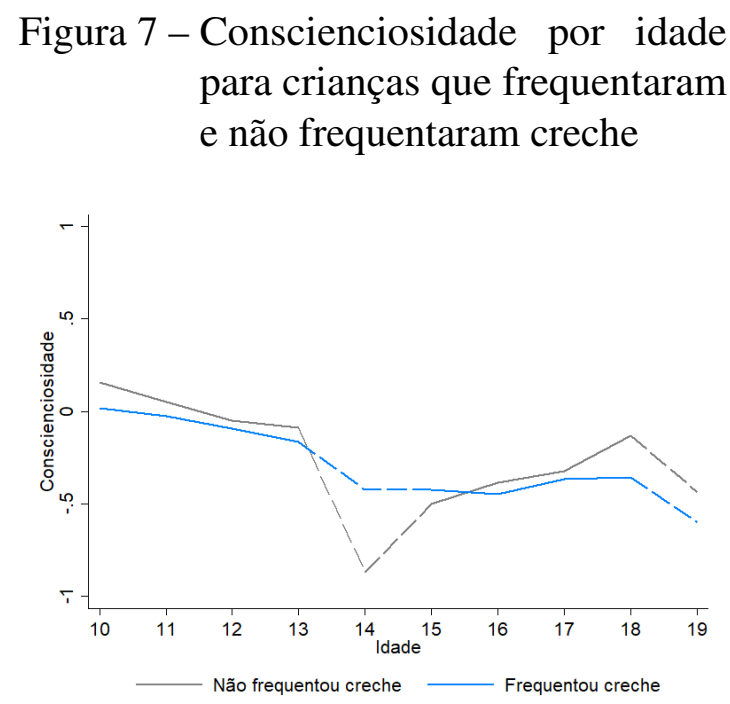

Nota: Ano base 2012.

Figura 9 - Amabilidade por idade para crianças que frequentaram e não frequentaram creche

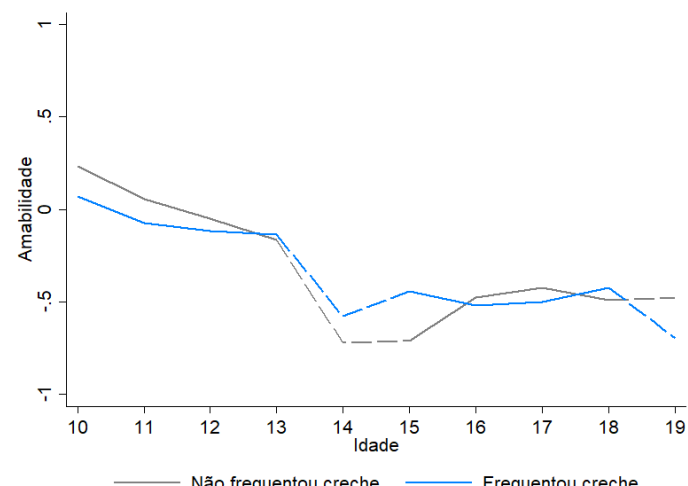

Nota: Ano base 2012.

Nota: Ano base 2012.

O tracejado dos gráficos denota idades que representam uma pequena parcela da amostra. Observa-se um comportamento disruptivo para 13, 14, 15 e 19 anos, que correspondem a 4,1\%, $0,6 \%, 1,6 \%$ e $2,5 \%$ da amostra, respectivamente. Vale ressaltar que a intenção dos gráficos é verificar a trajetória socioemocional para além destas idades. A partir das trajetórias observadas, é possível esperar que creche tenha algum efeito sob a medida de extroversão, dado que, ao longo de toda a trajetória, crianças que frequentaram creche possuem essa habilidade superior com relação às crianças que não frequentaram. Pode-se esperar também que crianças que frequentaram creche possuam medidas de conscienciosidade e amabilidade menores, quando 
Figura 10 - Estabilidade emocional por idade para crianças que frequentaram e não frequentaram creche

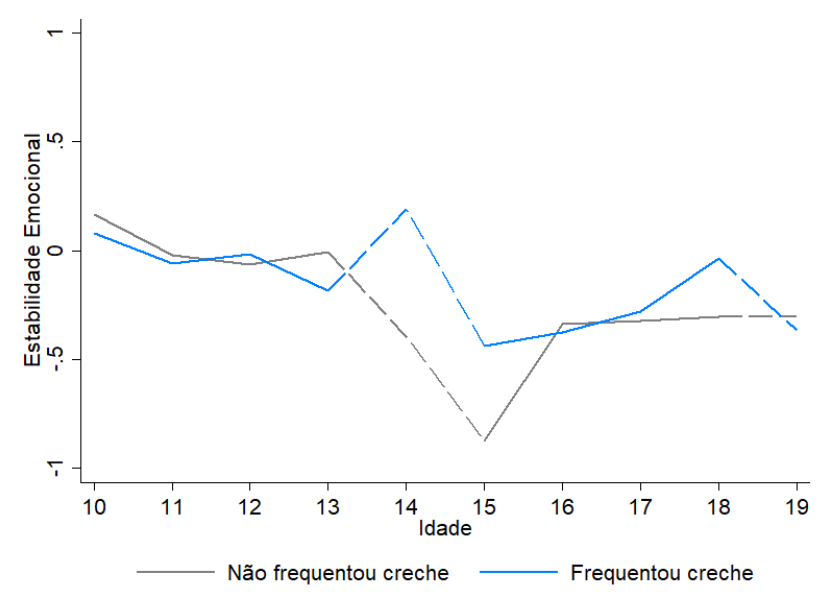

comparadas às que não frequentaram. Para abertura para novas experiências e estabilidade emocional, não há um efeito claro, dado que em diversos pontos elas se cruzam.

Complementar aos gráficos, a Tabela 11 mostra o teste de diferença de médias para os grupos de indivíduos que frequentaram creche e os que não a frequentaram. A tabela apresenta os resultados baseados nas seguintes hipóteses nula e alternativa:

$$
\begin{aligned}
& H_{0}: \overline{H S E}_{\text {creche }}=\overline{H S E}_{\text {não creche }} \\
& H_{1}: \overline{H S E}_{\text {creche }} \neq \overline{H S E}_{\text {não creche }}
\end{aligned}
$$

onde $\overline{H S E}$ representa a média de uma das cinco habilidades socioemocionais em questão. Um p-valor alto indica que a hipótese nula de que a média da habilidade socioemocional de quem fez creche é estatisticamente igual a de quem não fez. Nesse sentido, pode-se esperar que, posteriormente, ao estimar o modelo, as habilidades abertura para novas experiências e estabilidade emocional não apresentem resultados significantes, enquanto as demais, provavelmente, apresentarão.

Tabela 11 - Teste de diferença de média por socioemocional para frequentadores e não frequentadores de creche

\begin{tabular}{lcccc}
\hline \hline & $\begin{array}{c}\text { Média para quem } \\
\text { não fez creche }\end{array}$ & $\begin{array}{c}\text { Média para quem } \\
\text { fez creche }\end{array}$ & $\begin{array}{c}\text { Diferença } \\
\text { de médias }\end{array}$ & P-valor \\
\cline { 2 - 5 } Abertura para novas experiências & $-0,056$ & $-0,076$ & $-0,020$ & 0,578 \\
Conscienciosidade & $-0,144$ & $-0,217$ & $-0,074^{* *}$ & 0,042 \\
Extroversão & $-0,141$ & $-0,050$ & $0,091^{* *}$ & 0,020 \\
Amabilidade & $-0,194$ & $-0,274$ & $-0,080^{* *}$ & 0,029 \\
Estabilidade Emocional & $-0,157$ & $-0,153$ & 0,004 & 0,928 \\
\hline \hline
\end{tabular}

Nota: A diferença é dada pela média de quem frequentou creche subtraída da média de quem não frequentou creche.

Por meio da tabela 12 possível notar que algumas variáveis foram definidas como invari- 
antes no tempo, tais como sexo e cor. Para estas variáveis, foram consideradas as respostas dadas pelos alunos em 2017, sendo considerada esta mais confiável do que a de 2012, principalmente no que tange a cor, tendo em vista que muitos dos alunos podem não entender muito bem como se definir quanto a sua cor. Com relação as variáveis de creche e pré-escola, devido as correções realizadas já explicitadas, essa variável também é invariante no tempo.

Tabela 12 - Estatísticas de características sociais e educacionais para os sobreviventes de 2012 e 2017

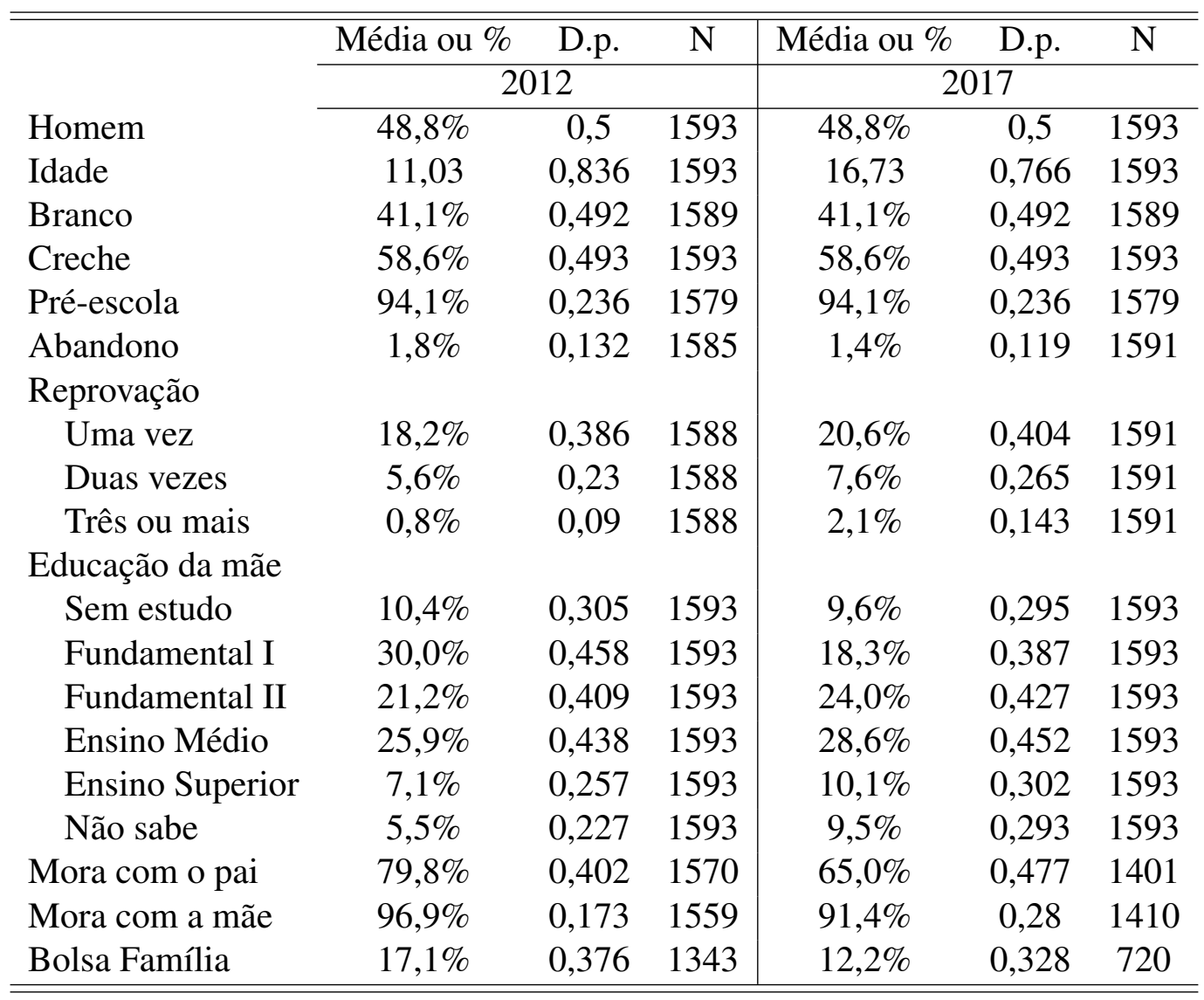

Como características principais dos indivíduos da base de dados, vê-se que pouco menos da metade são do sexo masculino $(48,8 \%)$ e brancos $(41,1 \%)$. Mais da metade dos alunos frequentaram creche $(58,6 \%)$ e quase todos frequentaram pré-escola $(94,1 \%)$. De 2012 para 2017, é possível notar um aumento na escolarização das mães.

A variável de abandono provavelmente apresenta algum erro de medida, tendo em vista que em 2012 1,8\% dos alunos haviam abandonado ao menos uma vez a escola e em 2017 esse percentual cai para $1,4 \%$. Provavelmente isso ocorre por falta de entendimento das crianças em 2012 do conceito de abandono. Quando se trata da reprovação, percebe-se um aumento da variável de 2012 para 2017, o que é natural, tendo em vista que, em 2017, os alunos aumentaram o tempo de sobrevivência dentro da escola, estando suscetíveis a um maior número de "fracassos". Por fim, o percentual de beneficiários do programa Bolsa Família cai de 2012 para 2017, o que pode indicar um aumento da renda familiar em 2017. Entretanto, uma parcela muito menor de 
pessoas respondeu a essa variável no último ano da pesquisa. 


\section{Metodologia}

\subsection{Variáveis de resultado}

Com relação ao cálculo utilizado para a mensuração do socioemocional, optou-se pela utilização do score padronizado. Por padronizado, define-se:

$$
H S E_{i}^{*}=\frac{H S E_{i}-\overline{H S E}}{\text { d.p. }\left(H S E_{i}\right)}
$$

onde $H S E_{i}$ é a habilidade socioemocional em questão do indivíduo $i, \overline{H S E}$ e d.p. $\left(H S E_{i}\right)$ são média e desvio-padrão desta habilidade, respectivamente. Desse modo, a variável estará medida em desvios-padrão.

Como explicitado na seção 4.2, serão utilizados dois tipos de padronização para a base de dados de Sertãozinho, de modo que a aplicação de cada um dos tipos dependerá da metodologia utilizada. Para a utilização do modelo de Mínimos Quadrados Ordinários, tendo em vista que serão realizadas regressões individuais para cada um dos anos, entendeu-se que a interpretação das habilidades não-cognitivas seriam melhores definidas ao realizar dois cálculos de padronização: um para o ano de 2012, isto é, utilizando-se da média da variável socioemocional em questão e seu desvio-padrão em 2012 e; um para o ano de 2017, similar ao descrito anteriormente. Já para a aplicação da metodologia de dados em painel, optou-se por analisar as variáveis padronizadas em um ano base, o de 2012. Assim, como os indivíduos são analisados ao longo do tempo, é possível observar a evolução do socioemocional entre esses dois anos e contrastar os resultados obtidos em cada ano da pesquisa. Sendo assim, para os dados em painel, foram utilizadas as estatísticas de 2012 para o referido cálculo, possibilitando a comparação dos scores obtidos nos diferentes anos. Isso explica o fato de na Tabela 10 as médias de 2012 serem iguais a zero e os desvios-padrão iguais a 1.

Ademais, o questionário não-cognitivo se encontra estruturado através de uma escala Likert de cinco níveis, indo de "Discordo Totalmente" a "Concordo Totalmente". Em questionários dessa natureza pode haver uma tendência a se concordar ou discordar de uma afirmativa, independente de seu conteúdo, criando scores artificialmente altos ou baixos ${ }^{1}$, o chamado viés de aquiescência (FURR, 2017). Portanto, aplica-se o uso da correção desse viés. O uso desta correção é uma diferença primordial com relação ao trabalho realizado por Santos (2015), apontado na seção 2 .

1 Este viés pode fazer com que os construtos socioemocionais estejam sub ou superestimados, dado que o indivíduo está criando traços de personalidade artificialmente. É um viés comum em questionários em que o respondente tem dificuldade no entendimento dos itens ou que possui itens ambíguos, ou ainda porque o ambiente de testagem apresenta distrações. 


\subsection{Modelos econométricos}

O objetivo do estudo é verificar o impacto de se realizar creche sob o desenvolvimento das habilidades socioemocionais. Define-se como grupo de tratamento os indivíduos que frequentaram creche e como grupo de controle, os que não a frequentaram. Serão utilizadas três metodologias, em busca de robustez dos resultados: Mínimos Quadrados Ordinários (MQO) com a inclusão de variáveis de controle, painel de Primeiras Diferenças e painel de Efeitos Aleatórios.

O modelo de MQO a ser estimado está representado como segue:

$$
H S E_{i t}=\alpha_{t}+\sum_{k=1}^{3} \gamma_{k} \text { Creche }_{i k}+X_{i t} \Phi+u_{i t}
$$

onde $H S E_{i t}$ representa uma das cinco habilidades não cognitivas para o ano em questão, dado que será realizado um exercício para cada uma das cinco habilidades socioemocionais; Creche $_{k}$ é uma variável indicadora do tipo de creche que o aluno frequentou, isto é, Creche $_{i 1}=$ 1 indica que o aluno $i$ frequentou creche do tipo pública, Creche $e_{i 2}=1$ indica que o aluno $i$ frequentou creche particular com bolsa, Creche $_{i 3}=1$ indica que o aluno $i$ frequentou creche particular sem bolsa e todas iguais a zero indicam que o aluno não frequentou creche; $\mathrm{X}$ é uma matriz de variáveis observáveis que serão utilizadas como variáveis de controle, explicitadas a seguir; por fim, $u$ é um vetor de variáveis não-observadas independentes das variáveis incluídas no modelo.

O interesse do presente trabalho reside em estimar os parâmetros $\gamma_{1}, \gamma_{2}$ e $\gamma_{3}$ para cada uma das habilidades socioemocionais, que medem o efeito de se frequentar creche em habilidades não cognitivas, além de discriminar quais tipos de creche são as que mais afetam a variável dependente. No caso da base de dados de Sertãozinho, devido a correção realizada na variável de creche, não será possível diferenciar creches públicas e privadas, de modo que será incluída uma única variável indicadora que assumirá valor 1 quando o indivíduo tiver frequentado creche e 0 , caso contrário.

Para que a estimação do modelo em (5.1) seja feita por MQO de maneira consistente é necessário que as variáveis explicativas sejam independentes do termo de erro. Ainda, é possível realizar a hipótese de que, controlando por outros fatores, ter feito creche é exógeno a outras variáveis que não estão no modelo e que também afetam o desenvolvimento de habilidades socioemocionais. Nesse sentido, para obter estimativas de $\gamma_{1}, \gamma_{2}$ e $\gamma_{3}$ se faz importante a utilização de variáveis de controle, a fim de exaurir qualquer fonte de endogeneidade das variáveis de creche. O termo $X$ deve, então, conter todo tipo de variável que determine as variáveis de creche e esteja correlacionada com habilidades socioemocionais.

Vale ressaltar que as bases de dados possuem diferentes variáveis de controle, tendo em vista que são provenientes de diferentes pesquisas. Ainda que algumas variáveis estejam disponíveis na base de dados do Ceará, elas podem não estar disponíveis na base de dados 
de Sertãozinho e vice-versa. Nessa seção serão explicitados todos os possíveis controles para quaisquer das duas bases, enquanto na seção 6 serão explicitadas as variáveis utilizadas em cada uma das regressões.

Um primeiro controle a ser usado diz respeito ao fato do aluno ter feito ou não pré-escola, já que queremos isolar somente o efeito da creche e sabe-se que a educação infantil como um todo é importante para o desenvolvimento de tais habilidades. Além disso, a decisão de inserir o(a) filho(a) somente na pré-escola ou em ambas as modalidades da educação infantil pode estar relacionado com alguma característica das famílias, que é não observada, tornando-se ainda mais interessante modelar esse efeito. Algumas variáveis de controle são inseridas a fim de captar características do ambiente familiar ${ }^{2}$. A inclusão de todas essas variáveis visa captar tanto a renda familiar quanto a estrutura da mesma, características que empiricamente estão relacionadas com variáveis de desenvolvimento cognitivo e não-cognitivo. Incluem-se também características individuais dos estudantes, tais como sexo, cor e idade, tendo em vista que essas são importantes para captar padrões do desenvolvimento. No caso da variável cor, ela capta também variáveis socioeconômicas, dado questões históricas da sociedade brasileira.

Outrossim, alguns controles escolares são utilizados a fim de retirar o efeito da escola que o aluno frequenta no momento da pesquisa, por exemplo, bem como controles de fluxo (reprovações e abandono), pois é sabido que tais variáveis tem relação com o desenvolvimento não-cognitivo do indivíduo. No mesmo sentido, controla-se a distância do aluno para a escola, um possível indicador de indivíduos que moram mais afastados de regiões com maior presença de creches (partindo do princípio que creches e escolas estão em regiões próximas e que o aluno mora no mesmo local de quando tinha idade para entrar em creche). Por fim, o nível educacional da mãe (ou mulher responsável pelo aluno) também é utilizado como variável de controle, pois, além de representar o quanto a mãe estudou, mostra algum indicativo da renda familiar. Esse controle é bastante importante pois mães com maior nível educacional podem ter maior tendência a colocarem os filhos em creches, o que poderia viesar nossa análise. Ou ainda, mães de baixo status socioeconômico poderiam antecipar a entrada do filho na escola em prol do seu retorno ao mercado de trabalho.

Como um segundo exercício, pretende-se realizar a estimação de um modelo de dados em painel que visa verificar o efeito de fading out com os dados de Sertãozinho, dado que tal exercício não é possível na base de dados do Ceará, que só possui um ponto no tempo. Vale ressaltar que os dados de Sertãozinho estão organizados na forma de painel balanceado, isto é, têm-se os mesmos períodos no tempo para as mesmas observações. O modelo a seguir segue a metodologia utilizada em Fonseca (2015). A opção pela estimação deste modelo é que ele permite entender a dinâmica do efeito de creche sobre o socioemocional ao longo do tempo Note ainda que, por ser um modelo similar ao de primeiras-diferenças, todas as variáveis que são

2 Aqui incluem-se variáveis que dizem respeito ao número de pessoas que moram juntas, se a criança possui a presença dos pais no domicílio, presença de aparelhos eletro-eletrônicos no domicílio, presença de água encanada, rua asfaltada, carro, parente beneficiário do bolsa família. 
fixas no tempo também são eliminadas, e, portanto, características do indivíduo como sexo e cor serão omitidas do modelo. Como ter frequentado a creche também é uma variável fixa no tempo, realizou-se uma interação desta com o tempo, modificando a interpretação do coeficiente, que passa a significar a tendência linear.

Estima-se:

$$
H S E_{2017 i}-H S E_{2012 i}=\Delta_{\text {Painel }} \text { Creche } * t+\left(X_{2017}-X_{2012}\right) \phi+\left(\varepsilon_{2017}-\varepsilon_{2012}\right),
$$

onde o coeficiente $\Delta_{\text {Painel }}$ têm a interpretação do efeito de decaimento, também conhecido como efeito fading out, de ter frequentado creche (FONSECA, 2015). Isto é, esse coeficiente reporta a durabilidade de creche sobre o desenvolvimento socioemocional dos alunos. Ao utilizar tal método, é possível analisar a dinâmica da variável de creche sobre as habilidades socioemocionais, pois permite-se que o coeficiente de inclinação da variável principal varie ao longo do tempo, captando possíveis efeitos relacionados ao padrão desenvolvimental.

Por fim, o modelo em painel de efeitos aleatórios a ser estimado é:

$$
H S E_{i t}=\beta \text { Creche }_{i}+x_{i t}^{\prime} \delta+c_{i}+\varepsilon_{i t},
$$

onde $\beta$ é o coeficiente de interesse que dará o efeito de se ter frequentado creche sobre a habilidade socioemocional em questão; $x^{\prime}$ é uma matriz de variáveis de controle, os mesmos utilizados para os modelos de mínimos quadrados ordinários; $c_{i}$ são variáveis fixas no tempo, mas não observáveis ${ }^{3}$ e que, portanto, não serão estimadas no modelo e; $\varepsilon_{i t}$ é o termo de erro.

Assume-se a hipótese de que os efeitos individuais não-observáveis são aleatórios e distribuídos independentemente dos regressores, isto é, $\operatorname{cov}\left(c_{i}, x_{i t}\right)=0$. A vantagem deste método é que podem-se incluir variáveis que são fixas no tempo.

$3 c_{i}$ também é conhecido como efeito aleatório individual (WOOLDRIDGE, 2010). 


\section{Resultados}

\subsection{Ceará}

A partir do modelo de Mínimos Quadrados Ordinários explicitado na seção anterior, foram estimadas as regressões onde se definiu a variável explicada como uma das cinco habilidades socioemocionais: abertura para novas experiências, conscienciosidade, extroversão, amabilidade e estabilidade emocional, descritas na Seção 2. Destarte, os resultados reportados se dividirão em cinco tabelas, uma para cada competência não cognitiva. Além disso, discutir-se-ão os resultados referentes aos dados de Ceará aproveitando-se das diferentes categorias de creche disponíveis (Pública, Privada com bolsa ou Privada sem bolsa), a fim de tratar das possíveis heterogeneidades no impacto da creche sobre as habilidades socioemocionais. Não obstante, os resultados comparáveis à Sertãozinho (com apenas uma variável dummy para creche) estão reportados na tabela 32 no Apêndice A.

Todas as tabelas seguirão a mesma especificação: 1) o primeiro modelo é o mais simples possível, onde apenas são utilizadas as variáveis categóricas de creche como regressores; 2) são inseridas as variáveis categóricas de pré-escola, que seguem as mesmas categorias de creche, onde não frequentou pré-escola é a variável omitida para base de comparação; 3) são inseridos controles escolares: as variáveis de etapa da turma ${ }^{1}$, de tempo de trajeto da casa até a escola ${ }^{2}$, se o indivíduo reprovou uma vez, se o indivíduo reprovou mais de uma vez, se a pessoa faltou à escola três vezes ou mais no último mês e dummies para a escola; 4) são adicionados controles residenciais: se a casa possui rua asfaltada, energia elétrica, água encanada, coleta de lixo, serviço de empregada doméstica ou diarista, televisão, geladeira, micro-ondas, máquina de lavar-roupas, computador, se alguém na moradia possui carro, é beneficiário do programa Bolsa Família e o total de pessoas que habitam a residência; 5) são inseridos controles sociais: sexo, cor e idade; 6 ) adicionam-se variáveis de controles familiares: se o indivíduo mora com a mãe, se o indivíduo mora com o pai e se o indivíduo mora com ambos; 7) por fim, a última especificação adiciona nível de escolaridade da mãe, que varia de nunca estudou ou não completou o Ensino Fundamental I até pós-graduação completa, passando pela resposta "não sei”.

A partir das tabelas 13,14, 15, 16 e 17, é possível notar que, excluindo-se a competência de estabilidade emocional, frequentar creche pública relativamente a situação de não frequentar possui um impacto positivo e significante em habilidades socioemocionais para todas as especificações do modelo, em que o impacto de maior magnitude é dado na habilidade de extroversão (cerca de 0,07 desvios-padrão). Para abertura para novas experiências, frequentar a creche parece

Se a turma pertencia ao ensino médio regular ou ensino médio integrado.

2 Essa variável possui quatro categorias: até 15 minutos, entre 15 e 30 minutos, entre 30 minutos e 1 hora e mais de 1 hora. 
ser importante, independente da natureza desta. Nota-se ainda que, para este domínio, frequentar creche privada sem bolsa tem uma magnitude maior (0,14 desvios-padrão) com relação aos demais tipos de creche, indicando uma melhor qualidade desta quando comparada as demais categorias. Para conscienciosidade, não é encontrado efeito estatisticamente significativo quando o indivíduo frequentou creche particular (com ou sem bolsa), já que a significância deste se perde a partir da segunda especificação. Uma baixa magnitude de creche pública é verificada para essa habilidade, 0,033 desvios-padrão.

Para extroversão, frequentar creche particular com bolsa não tem efeito estatisticamente significante, entretanto frequentar creche particular sem bolsa aumenta 0,13 desvios-padrão nessa habilidade quando comparado com crianças que não frequentaram nenhum tipo de creche, enquanto a magnitude é consideravelmente menor para os indivíduos que frequentaram creche pública ( 0,07 desvios-padrão). Para amabilidade, frequentar creche privada com bolsa reduz 0,078 desvios-padrão em comparação aos indivíduos que não frequentaram nenhum tipo de creche. Já a creche pública aumenta em 0,04 desvios-padrão esta habilidade. Por fim, frequentar creche não possui efeito estatisticamente significativo sobre estabilidade emocional.

Tabela 13 - Estimação de MQO - Abertura para novas experiências - Ceará

\begin{tabular}{lccccccc}
\hline \hline & $(1)$ & $(2)$ & $(3)$ & $(4)$ & $(5)$ & $(6)$ & $(7)$ \\
\hline Creche pública & $0,014^{* *}$ & $0,032^{* * *}$ & $0,046^{* * *}$ & $0,043^{* * *}$ & $0,041^{* * *}$ & $0,041^{* * *}$ & $0,042^{* * *}$ \\
& $(0,007)$ & $(0,007)$ & $(0,008)$ & $(0,009)$ & $(0,009)$ & $(0,009)$ & $(0,009)$ \\
Creche privada sem bolsa & $0,274^{* * *}$ & $0,139^{* * *}$ & $0,148^{* * *}$ & $0,143^{* * *}$ & $0,133^{* * *}$ & $0,134^{* * *}$ & $0,137^{* * *}$ \\
& $(0,016)$ & $(0,017)$ & $(0,017)$ & $(0,019)$ & $(0,020)$ & $(0,020)$ & $(0,020)$ \\
& & & & & & & \\
Creche privada com bolsa & $-0,024$ & $-0,017$ & 0,015 & $0,048^{*}$ & $0,045^{*}$ & $0,047^{*}$ & $0,053^{* *}$ \\
& $(0,017)$ & $(0,017)$ & $(0,020)$ & $(0,025)$ & $(0,026)$ & $(0,026)$ & $(0,027)$ \\
& & & & & & & \\
Pré-escola & Não & Sim & Sim & Sim & Sim & Sim & Sim \\
Controles escolares & Não & Não & Sim & Sim & Sim & Sim & Sim \\
Controles de moradia & Não & Não & Não & Sim & Sim & Sim & Sim \\
Controles sociais & Não & Não & Não & Não & Sim & Sim & Sim \\
Controles familiares & Não & Não & Não & Não & Não & Sim & Sim \\
Educação da mãe & Não & Não & Não & Não & Não & Não & Sim \\
\hline Observações & 97586 & 95886 & 89339 & 76033 & 73647 & 73647 & 72007 \\
$R^{2}$ ajustado & 0,004 & 0,012 & 0,041 & 0,044 & 0,046 & 0,047 & 0,052 \\
\hline \hline
\end{tabular}

Erros-padrão em parênteses. Todas as regressões utilizam erros-padrão robustos a heterocedasticidade.

${ }^{*} p<0.10,{ }^{* *} p<0.05,{ }^{* * *} p<0.01$

Especificação dos controles:

Pré-escola: se frequentou pré-escola pública, privada com bolsa ou sem bolsa; Controles escolares: tempo de trajeto até a escola, se reprovou uma vez, se reprovou duas vezes ou mais, se o aluno faltou 3 vezes ou mais à escola no último mês, dummies para a escola e para código de etapa (EM regular ou EM integrado); Controles de Moradia: se a rua é asfaltada, se a residência possui energia elétrica, água encanada, coleta de lixo, empregada doméstica ou faxineira trabalhando, geladeira, máquina de lavar-roupas, micro-ondas e TV com cores, quantidade de moradores na residência, se alguém na residência possui carro, presença de morador com bolsa família; Controles sociais: idade, sexo e cor; Controles familiares: se mora com a mãe, se mora com o pai e se mora com ambos; Educação da mãe: Nunca estudou ou não completou o Ensino Fundamental I até Pós-graduação completa.

Nota-se que para todos os domínios a magnitude dos efeitos se altera consideravelmente 
da especificação na coluna (1) para a especificação na coluna (2), indicando que a inclusão de variáveis de controle de pré-escola é importante para o modelo. Entre as especificações das colunas (3) a (7) não se verifica um padrão de mudança ao adicionar os controles.

Tabela 14 - Estimação de MQO - Conscienciosidade - Ceará

\begin{tabular}{lccccccc}
\hline \hline & $(1)$ & $(2)$ & $(3)$ & $(4)$ & $(5)$ & $(6)$ & $(7)$ \\
\hline Creche pública & $0,054^{* * *}$ & $0,041^{* * *}$ & $0,039^{* * *}$ & $0,027^{* * *}$ & $0,030^{* * *}$ & $0,033^{* * *}$ & $0,033^{* * *}$ \\
& $(0,007)$ & $(0,007)$ & $(0,008)$ & $(0,008)$ & $(0,009)$ & $(0,009)$ & $(0,009)$ \\
Creche privada sem bolsa & $-0,007$ & $-0,031^{* *}$ & $-0,020$ & 0,009 & 0,014 & 0,016 & 0,016 \\
& $(0,014)$ & $(0,015)$ & $(0,015)$ & $(0,017)$ & $(0,017)$ & $(0,017)$ & $(0,018)$ \\
& & & & & & & \\
Creche privada com bolsa & $-0,151^{* * *}$ & $-0,124^{* * *}$ & $-0,087^{* * *}$ & $-0,030$ & $-0,019$ & $-0,015$ & $-0,018$ \\
& $(0,016)$ & $(0,017)$ & $(0,019)$ & $(0,024)$ & $(0,025)$ & $(0,025)$ & $(0,025)$ \\
& & & & & & & \\
Pré-escola & Não & Sim & Sim & Sim & Sim & Sim & Sim \\
Controles escolares & Não & Não & Sim & Sim & Sim & Sim & Sim \\
Controles de moradia & Não & Não & Não & Sim & Sim & Sim & Sim \\
Controles sociais & Não & Não & Não & Não & Sim & Sim & Sim \\
Controles familiares & Não & Não & Não & Não & Não & Sim & Sim \\
Educação da mãe & Não & Não & Não & Não & Não & Não & Sim \\
\hline Observações & 97586 & 95886 & 89339 & 76033 & 73647 & 73647 & 72007 \\
$R^{2}$ ajustado & 0,002 & 0,004 & 0,072 & 0,082 & 0,090 & 0,091 & 0,094 \\
\hline \hline
\end{tabular}

Erros-padrão em parênteses.

${ }^{*} p<0.10,{ }^{* *} p<0.05,{ }^{* * *} p<0.01$

Todas as regressões utilizam erros-padrão robustos a heterocedasticidade.

Ver nota de rodapé da Tabela 13 para descrição detalhada dos controles.

Tabela 15 - Estimação de MQO - Extroversão - Ceará

\begin{tabular}{lccccccc}
\hline \hline & $(1)$ & $(2)$ & $(3)$ & $(4)$ & $(5)$ & $(6)$ & $(7)$ \\
\hline Creche pública & $0,038^{* * *}$ & $0,058^{* * *}$ & $0,068^{* * *}$ & $0,068^{* * *}$ & $0,067^{* * *}$ & $0,067^{* * *}$ & $0,069^{* * *}$ \\
& $(0,007)$ & $(0,007)$ & $(0,008)$ & $(0,008)$ & $(0,009)$ & $(0,009)$ & $(0,009)$ \\
Creche privada sem bolsa & $0,256^{* * *}$ & $0,137^{* * *}$ & $0,151^{* * *}$ & $0,141^{* * *}$ & $0,133^{* * *}$ & $0,133^{* * *}$ & $0,134^{* * *}$ \\
& $(0,016)$ & $(0,017)$ & $(0,018)$ & $(0,020)$ & $(0,020)$ & $(0,020)$ & $(0,021)$ \\
& & & & & & & \\
Creche privada com bolsa & $-0,065^{* * *}$ & $-0,044^{* *}$ & $-0,005$ & 0,027 & 0,027 & 0,028 & 0,025 \\
& $(0,017)$ & $(0,017)$ & $(0,020)$ & $(0,025)$ & $(0,026)$ & $(0,026)$ & $(0,027)$ \\
& & & & & & & \\
Pré-escola & Não & Sim & Sim & Sim & Sim & Sim & Sim \\
Controles escolares & Não & Não & Sim & Sim & Sim & Sim & Sim \\
Controles de moradia & Não & Não & Não & Sim & Sim & Sim & Sim \\
Controles sociais & Não & Não & Não & Não & Sim & Sim & Sim \\
Controles familiares & Não & Não & Não & Não & Não & Sim & Sim \\
Educação da mãe & Não & Não & Não & Não & Não & Não & Sim \\
\hline Observações & 97586 & 95886 & 89339 & 76033 & 73647 & 73647 & 72007 \\
$R^{2}$ ajustado & 0,003 & 0,009 & 0,030 & 0,033 & 0,033 & 0,033 & 0,039 \\
\hline \hline
\end{tabular}

Erros-padrão em parênteses.

${ }^{*} p<0.10,{ }^{* *} p<0.05,{ }^{* * *} p<0.01$

Todas as regressões utilizam erros-padrão robustos a heterocedasticidade.

Ver nota de rodapé da Tabela 13 para descrição detalhada dos controles. 
Tabela 16 - Estimação de MQO - Amabilidade - Ceará

\begin{tabular}{lccccccc}
\hline \hline & $(1)$ & $(2)$ & $(3)$ & $(4)$ & $(5)$ & $(6)$ & $(7)$ \\
\hline Creche pública & $0,039^{* * *}$ & $0,052^{* * *}$ & $0,054^{* * *}$ & $0,039^{* * *}$ & $0,038^{* * *}$ & $0,041^{* * *}$ & $0,042^{* * *}$ \\
& $(0,007)$ & $(0,007)$ & $(0,008)$ & $(0,008)$ & $(0,008)$ & $(0,008)$ & $(0,009)$ \\
Creche privada sem bolsa & $0,111^{* * *}$ & $-0,011$ & $-0,001$ & 0,016 & 0,019 & 0,021 & 0,024 \\
& $(0,014)$ & $(0,015)$ & $(0,016)$ & $(0,018)$ & $(0,018)$ & $(0,018)$ & $(0,018)$ \\
& & & & & & \\
Creche privada com bolsa & $-0,324^{* * *}$ & $-0,294^{* * *}$ & $-0,195^{* * *}$ & $-0,095^{* * *}$ & $-0,085^{* * *}$ & $-0,082^{* * *}$ & $-0,078^{* * *}$ \\
& $(0,016)$ & $(0,017)$ & $(0,020)$ & $(0,025)$ & $(0,026)$ & $(0,026)$ & $(0,026)$ \\
& & & & & & & \\
Pré-escola & Não & Sim & Sim & Sim & Sim & Sim & Sim \\
Controles escolares & Não & Não & Sim & Sim & Sim & Sim & Sim \\
Controles de moradia & Não & Não & Não & Sim & Sim & Sim & Sim \\
Controles sociais & Não & Não & Não & Não & Sim & Sim & Sim \\
Controles familiares & Não & Não & Não & Não & Não & Sim & Sim \\
Educação da mãe & Não & Não & Não & Não & Não & Não & Sim \\
\hline Observações & 97586 & 95886 & 89339 & 76033 & 73647 & 73647 & 72007 \\
$R^{2}$ ajustado & 0,005 & 0,012 & 0,059 & 0,064 & 0,077 & 0,078 & 0,079 \\
\hline \hline
\end{tabular}

Erros-padrão em parênteses.

${ }^{*} p<0.10,{ }^{* *} p<0.05,{ }^{* * *} p<0.01$

Todas as regressões utilizam erros-padrão robustos a heterocedasticidade.

Ver nota de rodapé da Tabela 13 para descrição detalhada dos controles.

Tabela 17 - Estimação de MQO - Estabilidade Emocional - Ceará

\begin{tabular}{lccccccc}
\hline \hline & $(1)$ & $(2)$ & $(3)$ & $(4)$ & $(5)$ & $(6)$ & $(7)$ \\
\hline Creche pública & $-0,011^{*}$ & $-0,006$ & 0,010 & 0,006 & 0,003 & 0,005 & 0,008 \\
& $(0,007)$ & $(0,007)$ & $(0,008)$ & $(0,009)$ & $(0,009)$ & $(0,009)$ & $(0,009)$ \\
Creche privada sem bolsa & $0,040^{* *}$ & 0,007 & 0,014 & 0,014 & $-0,001$ & 0,001 & $-0,001$ \\
& $(0,016)$ & $(0,017)$ & $(0,018)$ & $(0,020)$ & $(0,020)$ & $(0,020)$ & $(0,020)$ \\
& & & & & & & \\
Creche privada com bolsa & $-0,072^{* * *}$ & $-0,053^{* * *}$ & $-0,030$ & $-0,005$ & $-0,027$ & $-0,024$ & $-0,027$ \\
& $(0,016)$ & $(0,017)$ & $(0,019)$ & $(0,024)$ & $(0,025)$ & $(0,025)$ & $(0,026)$ \\
& & & & & & & \\
Pré-escola & Não & Sim & Sim & Sim & Sim & Sim & Sim \\
Controles escolares & Não & Não & Sim & Sim & Sim & Sim & Sim \\
Controles de moradia & Não & Não & Não & Sim & Sim & Sim & Sim \\
Controles sociais & Não & Não & Não & Não & Sim & Sim & Sim \\
Controles familiares & Não & Não & Não & Não & Não & Sim & Sim \\
Educação da mãe & Não & Não & Não & Não & Não & Não & Sim \\
\hline Observações & 97586 & 95886 & 89339 & 76033 & 73647 & 73647 & 72007 \\
$R^{2}$ ajustado & 0,000 & 0,001 & 0,017 & 0,019 & 0,071 & 0,072 & 0,073 \\
\hline \hline
\end{tabular}

Erros-padrão em parênteses.

${ }^{*} p<0.10,{ }^{* *} p<0.05,{ }^{* * *} p<0.01$

Todas as regressões utilizam erros-padrão robustos a heterocedasticidade.

Ver nota de rodapé da Tabela 13 para descrição detalhada dos controles. 
Tabela 18 - Estimação de MQO - Extensões - Ceará

\begin{tabular}{|c|c|c|c|c|c|}
\hline & $\begin{array}{c}(1) \\
\text { Abertura }\end{array}$ & $\begin{array}{c}(2) \\
\text { Conscienciosidade }\end{array}$ & $\begin{array}{c}(3) \\
\text { Extroversão }\end{array}$ & $\begin{array}{c}\text { (4) } \\
\text { Amabilidade }\end{array}$ & $\begin{array}{c}\text { (5) } \\
\text { Estabilidade }\end{array}$ \\
\hline Creche pública & $\begin{array}{c}0,042^{* * *} \\
(0,009)\end{array}$ & $\begin{array}{c}0,033^{* * *} \\
(0,009)\end{array}$ & $\begin{array}{c}0,069^{* * *} \\
(0,009)\end{array}$ & $\begin{array}{c}0,042^{* * *} \\
(0,009)\end{array}$ & $\begin{array}{c}0,008 \\
(0,009)\end{array}$ \\
\hline Creche privada sem bolsa & $\begin{array}{c}0,137^{* * *} \\
(0,020)\end{array}$ & $\begin{array}{c}0,016 \\
(0,018)\end{array}$ & $\begin{array}{c}0,134^{* * *} \\
(0,021)\end{array}$ & $\begin{array}{c}0,024 \\
(0,018)\end{array}$ & $\begin{array}{l}-0,001 \\
(0,020)\end{array}$ \\
\hline Creche privada com bolsa & $\begin{array}{l}0,053^{* *} \\
(0,027)\end{array}$ & $\begin{array}{l}-0,018 \\
(0,025)\end{array}$ & $\begin{array}{c}0,025 \\
(0,027)\end{array}$ & $\begin{array}{c}-0,078^{* * *} \\
(0,026)\end{array}$ & $\begin{array}{l}-0,027 \\
(0,026)\end{array}$ \\
\hline Pré-escola pública & $\begin{array}{l}0,092^{* * *} \\
(0,010)\end{array}$ & $\begin{array}{c}0,061^{* * *} \\
(0,010)\end{array}$ & $\begin{array}{c}0,055^{* * *} \\
(0,010)\end{array}$ & $\begin{array}{c}0,041^{* * *} \\
(0,010)\end{array}$ & $\begin{array}{c}0,037^{* * *} \\
(0,010)\end{array}$ \\
\hline Pré-escola privada sem bolsa & $\begin{array}{c}0,185^{* * *} \\
(0,016)\end{array}$ & $\begin{array}{c}0,045^{* * *} \\
(0,015)\end{array}$ & $\begin{array}{c}0,148^{* * *} \\
(0,016)\end{array}$ & $\begin{array}{c}0,084^{* * *} \\
(0,015)\end{array}$ & $\begin{array}{c}0,047^{* * *} \\
(0,016)\end{array}$ \\
\hline Pré-escola privada com bolsa & $\begin{array}{c}0,138^{* * *} \\
(0,023)\end{array}$ & $\begin{array}{c}0,029 \\
(0,021)\end{array}$ & $\begin{array}{c}0,079^{* * *} \\
(0,022)\end{array}$ & $\begin{array}{c}0,009 \\
(0,022)\end{array}$ & $\begin{array}{l}-0,011 \\
(0,022)\end{array}$ \\
\hline Reprovação & & & & & \\
\hline Uma vez & $\begin{array}{c}-0,122^{* * *} \\
(0,010)\end{array}$ & $\begin{array}{c}-0,205^{* * *} \\
(0,010)\end{array}$ & $\begin{array}{c}-0,108^{* * *} \\
(0,010)\end{array}$ & $\begin{array}{c}-0,162^{* * *} \\
(0,010)\end{array}$ & $\begin{array}{c}-0,112^{* * *} \\
(0,010)\end{array}$ \\
\hline Mais de uma vez & $\begin{array}{c}-0,149^{* * *} \\
(0,016)\end{array}$ & $\begin{array}{c}-0,316^{* * *} \\
(0,015)\end{array}$ & $\begin{array}{c}-0,126^{* * *} \\
(0,016)\end{array}$ & $\begin{array}{c}-0,182^{* * *} \\
(0,016)\end{array}$ & $\begin{array}{c}-0,148^{* * *} \\
(0,015)\end{array}$ \\
\hline Faltou três vezes ou mais & $\begin{array}{c}-0,114^{* * *} \\
(0,008)\end{array}$ & $\begin{array}{c}-0,343^{* * *} \\
(0,008)\end{array}$ & $\begin{array}{c}-0,098^{* * *} \\
(0,008)\end{array}$ & $\begin{array}{c}-0,116^{* * *} \\
(0,008)\end{array}$ & $\begin{array}{c}-0,156^{* * *} \\
(0,008)\end{array}$ \\
\hline Bolsa Família & $\begin{array}{c}-0,031^{* * *} \\
(0,008)\end{array}$ & $\begin{array}{l}-0,003 \\
(0,008)\end{array}$ & $\begin{array}{c}-0,021^{* *} \\
(0,008)\end{array}$ & $\begin{array}{c}-0,026^{* * *} \\
(0,008)\end{array}$ & $\begin{array}{l}-0,004 \\
(0,008)\end{array}$ \\
\hline Homem & $\begin{array}{c}0,105^{* * *} \\
(0,008)\end{array}$ & $\begin{array}{c}-0,162^{* * *} \\
(0,008)\end{array}$ & $\begin{array}{c}0,024^{* * *} \\
(0,008)\end{array}$ & $\begin{array}{c}-0,250^{* * *} \\
(0,007)\end{array}$ & $\begin{array}{c}0,477^{* * *} \\
(0,008)\end{array}$ \\
\hline Brancos e amarelos & $\begin{array}{c}0,036^{* * *} \\
(0,008)\end{array}$ & $\begin{array}{c}0,033^{* * *} \\
(0,008)\end{array}$ & $\begin{array}{c}-0,020^{* *} \\
(0,008)\end{array}$ & $\begin{array}{c}0,002 \\
(0,008)\end{array}$ & $\begin{array}{l}-0,009 \\
(0,008)\end{array}$ \\
\hline Indígena & $\begin{array}{c}0,016 \\
(0,019)\end{array}$ & $\begin{array}{c}-0,087^{* * *} \\
(0,017)\end{array}$ & $\begin{array}{c}-0,052^{* * *} \\
(0,018)\end{array}$ & $\begin{array}{l}-0,044^{* *} \\
(0,018)\end{array}$ & $\begin{array}{l}-0,029 \\
(0,019)\end{array}$ \\
\hline Mora com a mãe & $\begin{array}{c}-0,036^{* * *} \\
(0,012)\end{array}$ & $\begin{array}{l}-0,017 \\
(0,011)\end{array}$ & $\begin{array}{c}-0,038^{* * *} \\
(0,012)\end{array}$ & $\begin{array}{l}-0,020^{*} \\
(0,012)\end{array}$ & $\begin{array}{l}0,019^{*} \\
(0,012)\end{array}$ \\
\hline Mora com o pai & $\begin{array}{l}-0,026 \\
(0,021)\end{array}$ & $\begin{array}{c}-0,052^{* * *} \\
(0,020)\end{array}$ & $\begin{array}{l}-0,033 \\
(0,021)\end{array}$ & $\begin{array}{l}-0,033^{*} \\
(0,020)\end{array}$ & $\begin{array}{l}0,041^{* *} \\
(0,020)\end{array}$ \\
\hline Mora com ambos & $\begin{array}{c}0,062^{* * *} \\
(0,022)\end{array}$ & $\begin{array}{c}0,123^{* * *} \\
(0,021)\end{array}$ & $\begin{array}{c}0,062^{* * *} \\
(0,022)\end{array}$ & $\begin{array}{c}0,106^{* * *} \\
(0,021)\end{array}$ & $\begin{array}{c}0,016 \\
(0,022)\end{array}$ \\
\hline Educação da mãe & & & & & \\
\hline Fundamental I & $\begin{array}{c}0,019 \\
(0,012)\end{array}$ & $\begin{array}{c}0,020 \\
(0,012)\end{array}$ & $\begin{array}{c}0,042^{* * *} \\
(0,012)\end{array}$ & $\begin{array}{c}0,038^{* * *} \\
(0,012)\end{array}$ & $\begin{array}{c}0,019 \\
(0,012)\end{array}$ \\
\hline Fundamental II & $\begin{array}{c}0,063^{* * *} \\
(0,014)\end{array}$ & $\begin{array}{c}0,003 \\
(0,013)\end{array}$ & $\begin{array}{c}0,098^{* * *} \\
(0,014)\end{array}$ & $\begin{array}{c}0,039^{* * *} \\
(0,013)\end{array}$ & $\begin{array}{l}0,030^{* *} \\
(0,013)\end{array}$ \\
\hline Ensino Médio & $\begin{array}{c}0,093^{* * *} \\
(0,014)\end{array}$ & $\begin{array}{c}0,013 \\
(0,014)\end{array}$ & $\begin{array}{c}0,128^{* * *} \\
(0,014)\end{array}$ & $\begin{array}{c}0,052^{* * *} \\
(0,014)\end{array}$ & $\begin{array}{c}0,049^{* * *} \\
(0,014)\end{array}$ \\
\hline Ensino Superior & $\begin{array}{c}0,139^{* * *} \\
(0,024)\end{array}$ & $\begin{array}{l}-0,004 \\
(0,021)\end{array}$ & $\begin{array}{c}0,147^{* * *} \\
(0,023)\end{array}$ & $\begin{array}{l}0,045^{* *} \\
(0,022)\end{array}$ & $\begin{array}{c}0,086^{* * *} \\
(0,023)\end{array}$ \\
\hline Pós Graduação & $\begin{array}{c}0,156^{* * *} \\
(0,031)\end{array}$ & $\begin{array}{c}0,017 \\
(0,030)\end{array}$ & $\begin{array}{c}0,190^{* * *} \\
(0,033)\end{array}$ & $\begin{array}{c}0,019 \\
(0,028)\end{array}$ & $\begin{array}{c}-0,028 \\
(0,029)\end{array}$ \\
\hline Não sabe & $\begin{array}{c}-0,129^{* * *} \\
(0,013)\end{array}$ & $\begin{array}{c}-0,123^{* * *} \\
(0,013)\end{array}$ & $\begin{array}{c}-0,083^{* * *} \\
(0,013)\end{array}$ & $\begin{array}{c}-0,055^{* * *} \\
(0,013)\end{array}$ & $\begin{array}{c}-0,067^{* * *} \\
(0,013)\end{array}$ \\
\hline Controles escolares & Sim & Sim & Sim & Sim & Sim \\
\hline Controles de moradia & Sim & Sim & Sim & Sim & Sim \\
\hline Controles sociais & Sim & Sim & Sim & Sim & Sim \\
\hline Observações & 72007 & 72007 & 72007 & 72007 & 72007 \\
\hline$R^{2}$ ajustado & 0,052 & 0,094 & 0,039 & 0,079 & 0,073 \\
\hline
\end{tabular}

Erros-padrão entre parênteses. Todas as regressões utilizam erros-padrão robustos a heterocedasticidade.

${ }^{*} p<0.10,{ }^{* *} p<0.05,{ }^{* * *} p<0.01$

Ver nota de rodapé da Tabela 13 para descrição detalhada dos controles. 
A tabela 18 resume a especificação da coluna (7) de todas as tabelas de resultados anteriores e mostra a magnitude e significância de algumas variáveis de controle. A tabela 32 segue a mesma estrutura. Algumas das variáveis de controle ainda se encontram omitidas, tendo em vista a extensa quantidade destas. Dummies para a escola, idade, variáveis de características da moradia, como rua asfaltada, água encanada, entre outras, são alguns exemplos das variáveis que não foram reportadas, ainda que estejam presentes como variáveis de controle. Observa-se que mães com pós-graduação possuem efeito positivo e significante para as habilidades de abertura para novas experiências e extroversão, de 0,156 e 0,19 desvios-padrão, respectivamente, quando comparadas às mães que não completaram o ensino fundamental I ou nunca estudaram. Note que para todas as habilidades a resposta "não sei" quando se trata da escolaridade da mãe possui efeito significativo e negativo, destacam-se os efeitos sobre as habilidades abertura para novas experiências e conscienciosidade, que possuem efeito de $-0,13$ e $-0,12$, respectivamente. Para conscienciosidade, a escolaridade da mãe não possui efeito significativo, com exceção da resposta "não sei".

Meninas possuem scores maiores nas habilidades de conscienciosidade e amabilidade em comparação com indivíduos do sexo masculino. Possuir algum familiar recipiente do programa Bolsa Família tem efeito negativo e significante para as habilidades de abertura, conscienciosidade e amabilidade. Indivíduos de cor branca ou amarela possuem scores significantes e maiores em abertura e conscienciosidade quando comparados com os que se declaram negros ou pardos. Reprovar uma ou mais vezes, bem como ter faltado três vezes ou mais no último mês têm efeito significativo e negativo. Ademais, morar somente com o pai ou somente com a mãe parece ter efeito negativo sobre quase todas as habilidades, exceto para a habilidade de estabilidade emocional, enquanto morar com ambos os pais tem efeito positivo em todas as habilidades.

\subsection{Sertãozinho}

Tendo em vista que a base de dados de Sertãozinho possui a peculiaridade de acompanhar os alunos ao longo do tempo, serão aplicadas múltiplas estratégias a fim de não só captar a correlação da creche com habilidades não-cognitivas, de acordo com o seu estágio de desenvolvimento, mas também entender a aceleração da creche ao longo do tempo. Isto é, pode ser que, em um estágio inicial, a habilidade média "estática" dos indivíduos que frequentaram creche seja diferente da habilidade dos que não frequentaram, mas, em um segundo momento, pode ocorrer um efeito catching $u p^{3}$ ou fading out, de modo que, considerando essa dinâmica, a diferença inicialmente constatada pode se perder, aumentar ou permanecer constante ao longo do tempo. Para modelar esta dinâmica, estima-se o modelo de fading out, explicado na Seção 5.

3 Define-se como catching up quando se observa uma diferença inicial em um determinado construto ou habilidade para diferentes grupos, mas, em um segundo momento, essa diferença desaparece, pois o grupo que antes não a possuía, "alcança" o primeiro grupo. Isso evidencia mudanças não persistentes do construto ou habilidade determinado grupo. 
As tabelas 19, 20, 21, 22 e 23 reportam os resultados das estimativas de MQO por ano da pesquisa. $\mathrm{O}$ uso dos controles segue a mesma ordem em todas as regressões e as especificações seguem como descritas: 1) na mesma lógica do modelo da Subseção 6.1, o primeiro modelo contém apenas a variável categórica de creche como regressor; 2) é inserida a variável categórica de pré-escola; 3) são inseridos os controles sociais de sexo, cor, idade e idade ao quadrado; 4) são inseridas variáveis categóricas que indicam se o aluno mora com a mãe, com o pai ou com ambos; 5) são inseridos controles com variáveis categóricas para a escolaridade da mãe ${ }^{4}$; 6) são inseridas as variáveis de fluxo de abandono, reprovou uma vez, duas e três vezes ou mais. As tabelas completas das regressões encontram-se no Apêndice A.

Tabela 19 - Estimação de MQO por ano - Abertura para novas experiências - Sertãozinho

\begin{tabular}{|c|c|c|c|c|c|c|}
\hline & \multicolumn{6}{|c|}{2012} \\
\hline & (1) & (2) & (3) & (4) & (5) & (6) \\
\hline \multirow[t]{2}{*}{ Creche } & $-0,043$ & $-0,046$ & $-0,030$ & $-0,017$ & $-0,018$ & $-0,017$ \\
\hline & $(0,051)$ & $(0,052)$ & $(0,051)$ & $(0,052)$ & $(0,052)$ & $(0,052)$ \\
\hline Pré-escola & Não & Sim & Sim & Sim & Sim & Sim \\
\hline Controles sociais & Não & Não & Sim & Sim & Sim & Sim \\
\hline Controles familiares & Não & Não & Não & Sim & Sim & Sim \\
\hline Educação da mãe & Não & Não & Não & Não & Sim & Sim \\
\hline Controles de fluxo & Não & Não & Não & Não & Não & Sim \\
\hline Observações & 1589 & 1575 & 1571 & 1526 & 1526 & 1515 \\
\hline \multirow[t]{3}{*}{$R^{2}$ ajustado } & $-0,000$ & 0,003 & 0,023 & 0,021 & 0,023 & 0,023 \\
\hline & \multicolumn{6}{|c|}{2017} \\
\hline & $(1)$ & $(2)$ & (3) & (4) & $(5)$ & $(6)$ \\
\hline \multirow[t]{2}{*}{ Creche } & 0,004 & 0,002 & 0,003 & $-0,014$ & $-0,007$ & $-0,001$ \\
\hline & $(0,051)$ & $(0,051)$ & $(0,051)$ & $(0,055)$ & $(0,055)$ & $(0,056)$ \\
\hline Pré-escola & Não & Sim & Sim & Sim & Sim & Sim \\
\hline Controles sociais & Não & Não & Sim & Sim & Sim & Sim \\
\hline Controles familiares & Não & Não & Não & Sim & Sim & Sim \\
\hline Educação da mãe & Não & Não & Não & Não & Sim & Sim \\
\hline Controles de fluxo & Não & Não & Não & Não & Não & Sim \\
\hline Observações & 1592 & 1578 & 1574 & 1384 & 1384 & 1382 \\
\hline$R^{2}$ ajustado & $-0,001$ & $-0,001$ & 0,000 & 0,002 & 0,011 & 0,013 \\
\hline
\end{tabular}

Erros-padrão em parênteses. Todas as regressões utilizam erros-padrão robustos a heterocedasticidade.

${ }^{*} p<0.10,{ }^{* *} p<0.05,{ }^{* * *} p<0.01$

4 Sem estudo, Fundamental I, Fundamental II, Ensino Médio, Ensino Superior e Não sei, como ilustrado pela Tabela 12. A categoria omitida é "sem estudo". 
Tabela 20 - Estimação de MQO por ano - Conscienciosidade - Sertãozinho

\begin{tabular}{lcccccc}
\hline \hline & \multicolumn{7}{c}{2012} & & \\
& \multicolumn{7}{c}{$(1)$} & $(2)$ & $(3)$ & $(4)$ & $(5)$ & $(6)$ \\
\hline Creche & $-0,082$ & $-0,084$ & $-0,071$ & $-0,055$ & $-0,058$ & $-0,063$ \\
& $(0,051)$ & $(0,051)$ & $(0,051)$ & $(0,053)$ & $(0,053)$ & $(0,053)$ \\
& & & & & & \\
Pré-escola & Não & Sim & Sim & Sim & Sim & Sim \\
Controles sociais & Não & Não & Sim & Sim & Sim & Sim \\
Controles familiares & Não & Não & Não & Sim & Sim & Sim \\
Educação da mãe & Não & Não & Não & Não & Sim & Sim \\
Controles de fluxo & Não & Não & Não & Não & Não & Sim \\
\hline Observações & 1589 & 1575 & 1571 & 1526 & 1526 & 1515 \\
$R^{2}$ ajustado & 0,001 & 0,003 & 0,020 & 0,018 & 0,016 & 0,018 \\
\hline & \multicolumn{7}{c}{2017} & & \\
\cline { 2 - 7 } & $(1)$ & $(2)$ & $(3)$ & $(4)$ & $(5)$ & $(6)$ \\
\hline Creche & $-0,067$ & $-0,072$ & $-0,074$ & $-0,050$ & $-0,049$ & $-0,040$ \\
& $(0,052)$ & $(0,052)$ & $(0,052)$ & $(0,056)$ & $(0,056)$ & $(0,056)$ \\
& & & & & & \\
Pré-escola & Não & Sim & Sim & Sim & Sim & Sim \\
Controles sociais & Não & Não & Sim & Sim & Sim & Sim \\
Controles familiares & Não & Não & Não & Sim & Sim & Sim \\
Educação da mãe & Não & Não & Não & Não & Sim & Sim \\
Controles de fluxo & Não & Não & Não & Não & Não & Sim \\
\hline Observações & 1593 & 1579 & 1575 & 1385 & 1385 & 1383 \\
$R^{2}$ ajustado & 0,000 & 0,000 & $-0,001$ & $-0,001$ & $-0,001$ & 0,003 \\
\hline \hline
\end{tabular}

Erros-padrão em parênteses. Todas as regressões utilizam erros-padrão robustos a heterocedasticidade.

${ }^{*} p<0.10,{ }^{* *} p<0.05,{ }^{* * *} p<0.01$ 
Tabela 21 - Estimação de MQO por ano - Extroversão - Sertãozinho

\begin{tabular}{|c|c|c|c|c|c|c|}
\hline & \multicolumn{6}{|c|}{2012} \\
\hline & (1) & (2) & (3) & (4) & (5) & (6) \\
\hline \multirow[t]{2}{*}{ Creche } & 0,080 & 0,077 & $0,091^{*}$ & $0,086^{*}$ & $0,092^{*}$ & $0,094^{*}$ \\
\hline & $(0,051)$ & $(0,051)$ & $(0,051)$ & $(0,052)$ & $(0,051)$ & $(0,052)$ \\
\hline Pré-escola & Não & Sim & Sim & Sim & Sim & Sim \\
\hline Controles sociais & Não & Não & Sim & Sim & Sim & Sim \\
\hline Controles familiares & Não & Não & Não & Sim & Sim & Sim \\
\hline Educação da mãe & Não & Não & Não & Não & Sim & Sim \\
\hline Controles de fluxo & Não & Não & Não & Não & Não & Sim \\
\hline Observações & 1588 & 1574 & 1570 & 1526 & 1526 & 1515 \\
\hline \multirow[t]{3}{*}{$R^{2}$ ajustado } & 0,001 & 0,003 & 0,011 & 0,010 & 0,021 & 0,025 \\
\hline & \multicolumn{6}{|c|}{2017} \\
\hline & (1) & (2) & (3) & (4) & (5) & (6) \\
\hline \multirow[t]{2}{*}{ Creche } & $0,088^{*}$ & $0,089^{*}$ & 0,082 & 0,051 & 0,051 & 0,048 \\
\hline & $(0,051)$ & $(0,051)$ & $(0,051)$ & $(0,055)$ & $(0,055)$ & $(0,055)$ \\
\hline Pré-escola & Não & Sim & Sim & Sim & Sim & Sim \\
\hline Controles sociais & Não & Não & Sim & Sim & Sim & Sim \\
\hline Controles familiares & Não & Não & Não & Sim & Sim & Sim \\
\hline Educação da mãe & Não & Não & Não & Não & Sim & Sim \\
\hline Controles de fluxo & Não & Não & Não & Não & Não & Sim \\
\hline Observações & 1593 & 1579 & 1575 & 1385 & 1385 & 1383 \\
\hline$R^{2}$ ajustado & 0,001 & 0,003 & 0,009 & 0,009 & 0,009 & 0,011 \\
\hline
\end{tabular}

Erros-padrão em parênteses. Todas as regressões utilizam erros-padrão robustos a heterocedasticidade.

${ }^{*} p<0.10,{ }^{* *} p<0.05,{ }^{* * *} p<0.01$ 
Tabela 22 - Estimação de MQO por ano - Amabilidade - Sertãozinho

\begin{tabular}{|c|c|c|c|c|c|c|}
\hline & \multicolumn{6}{|c|}{2012} \\
\hline & (1) & (2) & (3) & (4) & (5) & (6) \\
\hline \multirow[t]{2}{*}{ Creche } & $-0,118^{* *}$ & $-0,117^{* *}$ & $-0,095^{*}$ & $-0,076$ & $-0,077$ & $-0,079$ \\
\hline & $(0,051)$ & $(0,051)$ & $(0,051)$ & $(0,051)$ & $(0,052)$ & $(0,052)$ \\
\hline Pré-escola & Não & Sim & Sim & Sim & Sim & Sim \\
\hline Controles sociais & Não & Não & Sim & Sim & Sim & Sim \\
\hline Controles familiares & Não & Não & Não & Sim & Sim & Sim \\
\hline Educação da mãe & Não & Não & Não & Não & Sim & Sim \\
\hline Controles de fluxo & Não & Não & Não & Não & Não & Sim \\
\hline Observações & 1589 & 1575 & 1571 & 1526 & 1526 & 1515 \\
\hline \multirow[t]{3}{*}{$R^{2}$ ajustado } & 0,003 & 0,002 & 0,028 & 0,024 & 0,023 & 0,024 \\
\hline & \multicolumn{6}{|c|}{2017} \\
\hline & (1) & $(2)$ & (3) & (4) & (5) & (6) \\
\hline \multirow[t]{2}{*}{ Creche } & $-0,044$ & $-0,041$ & $-0,042$ & $-0,028$ & $-0,025$ & $-0,019$ \\
\hline & $(0,051)$ & $(0,051)$ & $(0,051)$ & $(0,055)$ & $(0,055)$ & $(0,055)$ \\
\hline Pré-escola & Não & Sim & Sim & Sim & Sim & Sim \\
\hline Controles sociais & Não & Não & Sim & Sim & Sim & Sim \\
\hline Controles familiares & Não & Não & Não & Sim & Sim & Sim \\
\hline Educação da mãe & Não & Não & Não & Não & Sim & Sim \\
\hline Controles de fluxo & Não & Não & Não & Não & Não & Sim \\
\hline Observações & 1593 & 1579 & 1575 & 1385 & 1385 & 1383 \\
\hline$R^{2}$ ajustado & $-0,000$ & $-0,000$ & $-0,000$ & 0,001 & 0,004 & 0,007 \\
\hline
\end{tabular}

Erros-padrão em parênteses. Todas as regressões utilizam erros-padrão robustos a heterocedasticidade. ${ }^{*} p<0.10,{ }^{* *} p<0.05,{ }^{* * *} p<0.01$ 
Tabela 23 - Estimação de MQO por ano - Estabilidade Emocional - Sertãozinho

\begin{tabular}{|c|c|c|c|c|c|c|}
\hline & \multicolumn{6}{|c|}{2012} \\
\hline & (1) & (2) & (3) & (4) & (5) & (6) \\
\hline \multirow[t]{2}{*}{ Creche } & $-0,035$ & $-0,028$ & $-0,037$ & $-0,014$ & $-0,016$ & $-0,014$ \\
\hline & $(0,051)$ & $(0,051)$ & $(0,051)$ & $(0,052)$ & $(0,052)$ & $(0,053)$ \\
\hline Pré-escola & Não & Sim & Sim & Sim & Sim & Sim \\
\hline Controles sociais & Não & Não & Sim & Sim & Sim & Sim \\
\hline Controles familiares & Não & Não & Não & Sim & Sim & Sim \\
\hline Educação da mãe & Não & Não & Não & Não & Sim & Sim \\
\hline Controles de fluxo & Não & Não & Não & Não & Não & Sim \\
\hline Observações & 1588 & 1574 & 1570 & 1526 & 1526 & 1515 \\
\hline \multirow[t]{3}{*}{$R^{2}$ ajustado } & $-0,000$ & $-0,001$ & 0,008 & 0,012 & 0,010 & 0,008 \\
\hline & \multicolumn{6}{|c|}{2017} \\
\hline & (1) & (2) & (3) & (4) & (5) & (6) \\
\hline \multirow[t]{2}{*}{ Creche } & 0,034 & 0,045 & 0,014 & 0,036 & 0,035 & 0,038 \\
\hline & $(0,051)$ & $(0,051)$ & $(0,048)$ & $(0,051)$ & $(0,051)$ & $(0,051)$ \\
\hline Pré-escola & Não & Sim & Sim & Sim & Sim & Sim \\
\hline Controles sociais & Não & Não & Sim & Sim & Sim & Sim \\
\hline Controles familiares & Não & Não & Não & Sim & Sim & Sim \\
\hline Educação da mãe & Não & Não & Não & Não & Sim & Sim \\
\hline Controles de fluxo & Não & Não & Não & Não & Não & Sim \\
\hline Observações & 1592 & 1578 & 1574 & 1384 & 1384 & 1382 \\
\hline$R^{2}$ ajustado & $-0,000$ & 0,002 & 0,164 & 0,160 & 0,160 & 0,158 \\
\hline
\end{tabular}

Erros-padrão em parênteses. Todas as regressões utilizam erros-padrão robustos a heterocedasticidade.

${ }^{*} p<0.10,{ }^{* *} p<0.05,{ }^{* * *} p<0.01$

É possível observar que o efeito de creche possui diferença de magnitude e sinal para as habilidades de abertura para novas experiências e estabilidade emocional nos dois anos da pesquisa, ainda que esse efeito não seja significativo. Isto pode indicar um padrão desenvolvimental das habilidades, pois sabe-se que na adolescência (10 a 20 anos) há uma variação maior no desenvolvimento destas habilidades socioemocionais (SOTO et al., 2011), sugerindo que esse é um período de formação mais intensa dos traços de personalidade dos indivíduos. Como era esperado, de acordo com o teste de diferença de médias reportado na tabela 11, as competências de abertura para novas experiências e estabilidade emocional não apresentaram significância estatística para nenhuma das especificações. Extroversão, reportada na Tabela 21, é a única que apresenta resultado positivo e significante para creche, ainda que a significância só ocorra para o ano de 2012. Crianças que frequentaram creche, relativamente as que não frequentaram, têm, em média, 0,09 desvios-padrão a mais na habilidade de extroversão em 2012. Possivelmente este resultado pode estar associado ao fato de que estas crianças começam a socializar mais cedo com outras de mesma idade. Em amabilidade, observa-se um coeficiente estatisticamente significativo e negativo para indivíduos que frequentaram creche. Entretanto, essa significância 
se perde no momento em que são inseridos os controles familiares.

As tabelas 24 e 25 reportam os resultados do modelo de fading out. Por meio da Tabela 24 se verifica que os coeficientes da interação de creche com o tempo em todas as habilidades socioemocionais são negativos e estatisticamente significantes, dando a entender que, em 2017, haveria um efeito fading out de ter frequentado creche, quando comparado com 2012. Já na Tabela 25 utilizam-se os controles de idade e idade ao quadrado. Nota-se que o coeficiente de creche interagido com o ano perde significância e muda de sinal para todas as habilidades, indicando que o efeito da idade, que, nesse caso, pode estar também associado a repetência em alguma medida, está associado a esse efeito fading out. Finalmente, a habilidade de extroversão não possui efeito significante para nenhuma das variáveis do modelo, o que indicaria a inexistência de efeito fading out para essa habilidade, tendo em visto um coeficiente de interação muito próximo de zero.

Tabela 24 - Estimações de fading out - Sertãozinho

\begin{tabular}{lccccc}
\hline \hline & $(1)$ & $(2)$ & $(3)$ & $(4)$ & $(5)$ \\
& Abertura & Conscienciosidade & Extroversão & Amabilidade & Estabilidade \\
\hline Creche*Ano & $-0,023^{* * *}$ & $-0,073^{* * *}$ & $-0,033^{* * *}$ & $-0,090^{* * *}$ & $-0,056^{* * *}$ \\
& $(0,008)$ & $(0,008)$ & $(0,009)$ & $(0,008)$ & $(0,009)$ \\
& & & & \\
Constante & $26,697^{* * *}$ & $86,488^{* * *}$ & $38,508^{* * *}$ & $106,207^{* * *}$ & $65,349^{* * *}$ \\
& $(9,472)$ & $(9,511)$ & $(10,259)$ & $(9,930)$ & $(11,107)$ \\
\hline Observações & 3181 & 3182 & 3181 & 3182 & 3180 \\
\hline \hline Erros-padrão em parênteses. & & & & \\
${ }^{*} p<0.10,{ }^{* *} p<0.05,{ }^{* * *} p<0.01$ &
\end{tabular}

Tabela 25 - Estimações de fading out - Sertãozinho

\begin{tabular}{lccccc}
\hline \hline & $(1)$ & $(2)$ & $(3)$ & $(4)$ & $(5)$ \\
& Abertura & Conscienciosidade & Extroversão & Amabilidade & Estabilidade \\
\hline Creche*Ano $^{*}$ & 0,0069 & 0,0013 & 0,0014 & 0,0129 & 0,0127 \\
& $(0,0123)$ & $(0,0122)$ & $(0,0134)$ & $(0,0125)$ & $(0,0143)$ \\
Idade & $-0,4315^{* * *}$ & $-0,3931^{* * *}$ & $-0,0980$ & $-0,4052^{* * *}$ & $-0,5002^{* * *}$ \\
& $(0,0970)$ & $(0,0960)$ & $(0,1056)$ & $(0,0987)$ & $(0,1128)$ \\
& & & & & \\
Idade $^{2}$ & $0,0146^{* * *}$ & $0,0118^{* * *}$ & 0,0025 & $0,0113^{* * *}$ & $0,0159^{* * *}$ \\
& $(0,0035)$ & $(0,0035)$ & $(0,0038)$ & $(0,0036)$ & $(0,0041)$ \\
& & & & & \\
Constante & $-5,1977$ & 1,3214 & $-0,8314$ & $-12,1713$ & $-11,3838$ \\
& $(14,4488)$ & $(14,2943)$ & $(15,7392)$ & $(14,7011)$ & $(16,8070)$ \\
\hline Observações & 3181 & 3182 & 3181 & 3182 & 3180 \\
\hline \hline
\end{tabular}

Erros-padrão em parênteses.

${ }^{*} p<0.10,{ }^{* *} p<0.05,{ }^{* * *} p<0.01$ 
Por fim, os modelos de efeitos aleatórios se encontram nas tabelas 26, 27, 28, 29 e 30. Para abertura para novas experiências e estabilidade emocional, não se encontra efeito estatisticamente significante. Para conscienciosidade e amabilidade, encontram-se efeitos negativos e significantes, exceto quando são adicionados controles relativos a presença dos pais na residência. Para a habilidade de extroversão verificam-se coeficientes positivos e estatisticamente significativos de se ter frequentado a creche. Ainda, a variável indicadora de sexo parece ser importante para explicar padrões para indivíduos de sexos diferentes. Em quase todas as habilidades, com exceção de estabilidade emocional, ser do sexo masculino reduz o score médio da habilidade socioemocional. 
Tabela 26 - Modelo de efeitos aleatórios para Abertura para novas experiências - Sertãozinho

\begin{tabular}{|c|c|c|c|c|c|}
\hline & (1) & (2) & (3) & (4) & (5) \\
\hline \multirow[t]{2}{*}{ Creche } & $-0,019$ & $-0,021$ & $-0,013$ & $-0,008$ & $-0,009$ \\
\hline & $(0,039)$ & $(0,039)$ & $(0,039)$ & $(0,039)$ & $(0,040)$ \\
\hline \multirow[t]{2}{*}{ Pré-escola } & & $0,149^{*}$ & 0,130 & 0,110 & $0,170^{* *}$ \\
\hline & & $(0,083)$ & $(0,083)$ & $(0,082)$ & $(0,085)$ \\
\hline \multirow[t]{2}{*}{ Homem } & & & $-0,132^{* * *}$ & $-0,134^{* * *}$ & $-0,135^{* * *}$ \\
\hline & & & $(0,038)$ & $(0,038)$ & $(0,040)$ \\
\hline \multirow[t]{2}{*}{ Branco } & & & $-0,010$ & $-0,033$ & $-0,044$ \\
\hline & & & $(0,064)$ & $(0,065)$ & $(0,067)$ \\
\hline \multirow[t]{2}{*}{ Pardo } & & & $-0,103^{*}$ & $-0,107^{*}$ & $-0,124^{*}$ \\
\hline & & & $(0,062)$ & $(0,063)$ & $(0,065)$ \\
\hline \multirow[t]{2}{*}{ Amarelo } & & & 0,081 & 0,066 & 0,020 \\
\hline & & & $(0,148)$ & $(0,147)$ & $(0,146)$ \\
\hline \multirow[t]{2}{*}{ Indígena } & & & 0,109 & 0,129 & 0,221 \\
\hline & & & $(0,232)$ & $(0,228)$ & $(0,242)$ \\
\hline \multirow[t]{2}{*}{ Idade } & & & $-0,390^{* * *}$ & $-0,394^{* * *}$ & $-0,371^{* * *}$ \\
\hline & & & $(0,090)$ & $(0,090)$ & $(0,097)$ \\
\hline \multirow[t]{2}{*}{ Idade $^{2}$} & & & $0,013^{* * *}$ & $0,013^{* * *}$ & $0,012^{* * *}$ \\
\hline & & & $(0,003)$ & $(0,003)$ & $(0,003)$ \\
\hline \multirow[t]{2}{*}{ Fundamental I } & & & & 0,110 & 0,088 \\
\hline & & & & $(0,069)$ & $(0,072)$ \\
\hline \multirow[t]{2}{*}{ Fundamental II } & & & & $0,181^{* *}$ & $0,176^{* *}$ \\
\hline & & & & $(0,071)$ & $(0,074)$ \\
\hline \multirow[t]{2}{*}{ Ensino Médio } & & & & $0,125^{*}$ & 0,091 \\
\hline & & & & $(0,069)$ & $(0,072)$ \\
\hline \multirow[t]{2}{*}{ Ensino Superior } & & & & $0,289^{* * *}$ & $0,262^{* * *}$ \\
\hline & & & & $(0,086)$ & $(0,088)$ \\
\hline \multirow[t]{2}{*}{ Não sei } & & & & 0,115 & 0,045 \\
\hline & & & & $(0,084)$ & $(0,094)$ \\
\hline \multirow[t]{2}{*}{ Mora com o pai } & & & & & $-0,020$ \\
\hline & & & & & $(0,156)$ \\
\hline \multirow[t]{2}{*}{ Mora com a mãe } & & & & & 0,025 \\
\hline & & & & & $(0,117)$ \\
\hline \multirow[t]{2}{*}{ Mora com ambos } & & & & & 0,079 \\
\hline & & & & & $(0,162)$ \\
\hline \multirow[t]{2}{*}{ Constante } & $-0,057^{*}$ & $-0,194^{* *}$ & $2,701^{* * *}$ & $2,629^{* * *}$ & $2,381^{* * *}$ \\
\hline & $(0,030)$ & $(0,082)$ & $(0,608)$ & $(0,611)$ & $(0,661)$ \\
\hline Observações & 3181 & 3153 & 3145 & 3145 & 2910 \\
\hline
\end{tabular}

Erros-padrão em parênteses. ${ }^{*} p<0.10,{ }^{* *} p<0.05,{ }^{* * *} p<0.01$

Todas as regressões utilizam erros-padrão robustos a heterocedasticidade. 
Tabela 27 - Modelo de efeitos aleatórios para Conscienciosidade - Sertãozinho

\begin{tabular}{|c|c|c|c|c|c|}
\hline & (1) & $(2)$ & (3) & (4) & (5) \\
\hline \multirow[t]{2}{*}{ Creche } & $-0,074^{*}$ & $-0,077^{*}$ & $-0,071^{*}$ & $-0,071^{*}$ & $-0,055$ \\
\hline & $(0,040)$ & $(0,041)$ & $(0,041)$ & $(0,041)$ & $(0,042)$ \\
\hline \multirow[t]{2}{*}{ Pré-escola } & & $0,142^{*}$ & 0,115 & 0,118 & $0,182^{* *}$ \\
\hline & & $(0,084)$ & $(0,084)$ & $(0,085)$ & $(0,087)$ \\
\hline \multirow[t]{2}{*}{ Homem } & & & $-0,121^{* * *}$ & $-0,118^{* * *}$ & $-0,119^{* * *}$ \\
\hline & & & $(0,040)$ & $(0,040)$ & $(0,041)$ \\
\hline \multirow[t]{2}{*}{ Branco } & & & $-0,004$ & 0,000 & 0,015 \\
\hline & & & $(0,068)$ & $(0,069)$ & $(0,071)$ \\
\hline \multirow[t]{2}{*}{ Pardo } & & & $-0,020$ & $-0,019$ & $-0,027$ \\
\hline & & & $(0,067)$ & $(0,068)$ & $(0,069)$ \\
\hline \multirow[t]{2}{*}{ Amarelo } & & & 0,189 & 0,191 & 0,139 \\
\hline & & & $(0,165)$ & $(0,165)$ & $(0,159)$ \\
\hline \multirow[t]{2}{*}{ Indígena } & & & 0,211 & 0,205 & 0,242 \\
\hline & & & $(0,234)$ & $(0,235)$ & $(0,258)$ \\
\hline \multirow[t]{2}{*}{ Idade } & & & $-0,359^{* * *}$ & $-0,355^{* * *}$ & $-0,336^{* * *}$ \\
\hline & & & $(0,095)$ & $(0,095)$ & $(0,100)$ \\
\hline \multirow[t]{2}{*}{ Idade $^{2}$} & & & $0,011^{* * *}$ & $0,011^{* * *}$ & $0,010^{* * *}$ \\
\hline & & & $(0,003)$ & $(0,003)$ & $(0,004)$ \\
\hline \multirow[t]{2}{*}{ Fundamental I } & & & & $-0,051$ & $-0,059$ \\
\hline & & & & $(0,067)$ & $(0,071)$ \\
\hline \multirow[t]{2}{*}{ Fundamental II } & & & & $-0,043$ & $-0,058$ \\
\hline & & & & $(0,067)$ & $(0,071)$ \\
\hline \multirow[t]{2}{*}{ Ensino Médio } & & & & $-0,053$ & $-0,078$ \\
\hline & & & & $(0,066)$ & $(0,069)$ \\
\hline \multirow[t]{2}{*}{ Ensino Superior } & & & & $-0,064$ & $-0,079$ \\
\hline & & & & $(0,086)$ & $(0,090)$ \\
\hline \multirow[t]{2}{*}{ Não sei } & & & & $-0,116$ & $-0,218^{* *}$ \\
\hline & & & & $(0,083)$ & $(0,093)$ \\
\hline \multirow[t]{2}{*}{ Mora com o pai } & & & & & 0,038 \\
\hline & & & & & $(0,153)$ \\
\hline \multirow[t]{2}{*}{ Mora com a mãe } & & & & & 0,104 \\
\hline & & & & & $(0,105)$ \\
\hline \multirow[t]{2}{*}{ Mora com ambos } & & & & & $-0,040$ \\
\hline & & & & & $(0,159)$ \\
\hline \multirow[t]{2}{*}{ Constante } & $-0,143^{* * *}$ & $-0,275^{* * *}$ & $2,648^{* * *}$ & $2,661^{* * *}$ & $2,403^{* * *}$ \\
\hline & $(0,032)$ & $(0,085)$ & $(0,643)$ & $(0,646)$ & $(0,682)$ \\
\hline Observações & 3182 & 3154 & 3146 & 3146 & 2911 \\
\hline
\end{tabular}

Erros-padrão em parênteses. ${ }^{*} p<0.10,{ }^{* *} p<0.05,{ }^{* * *} p<0.01$

Todas as regressões utilizam erros-padrão robustos a heterocedasticidade. 
Tabela 28 - Modelo de efeitos aleatórios para Extroversão - Sertãozinho

\begin{tabular}{|c|c|c|c|c|c|}
\hline & $(1)$ & (2) & (3) & $(4)$ & (5) \\
\hline \multirow[t]{2}{*}{ Creche } & $0,092^{* *}$ & $0,091^{* *}$ & $0,095^{* *}$ & $0,099^{* *}$ & $0,082^{*}$ \\
\hline & $(0,044)$ & $(0,044)$ & $(0,044)$ & $(0,044)$ & $(0,046)$ \\
\hline \multirow[t]{2}{*}{ Pré-escola } & & $0,222^{* *}$ & $0,206^{* *}$ & $0,179^{* *}$ & $0,211^{* *}$ \\
\hline & & $(0,090)$ & $(0,091)$ & $(0,090)$ & $(0,092)$ \\
\hline \multirow[t]{2}{*}{ Homem } & & & $-0,094^{* *}$ & $-0,097^{* *}$ & $-0,086^{*}$ \\
\hline & & & $(0,044)$ & $(0,043)$ & $(0,045)$ \\
\hline \multirow[t]{2}{*}{ Branco } & & & $-0,091$ & $-0,112$ & $-0,108$ \\
\hline & & & $(0,070)$ & $(0,071)$ & $(0,074)$ \\
\hline \multirow[t]{2}{*}{ Pardo } & & & $-0,151^{* *}$ & $-0,145^{* *}$ & $-0,148^{* *}$ \\
\hline & & & $(0,068)$ & $(0,067)$ & $(0,071)$ \\
\hline \multirow[t]{2}{*}{ Amarelo } & & & $-0,236$ & $-0,252$ & $-0,294^{*}$ \\
\hline & & & $(0,171)$ & $(0,167)$ & $(0,164)$ \\
\hline \multirow[t]{2}{*}{ Indígena } & & & $-0,171$ & $-0,149$ & $-0,157$ \\
\hline & & & $(0,201)$ & $(0,198)$ & $(0,209)$ \\
\hline \multirow[t]{2}{*}{ Idade } & & & $-0,080$ & $-0,085$ & $-0,060$ \\
\hline & & & $(0,104)$ & $(0,103)$ & $(0,108)$ \\
\hline \multirow[t]{2}{*}{ Idade $^{2}$} & & & 0,002 & 0,002 & 0,001 \\
\hline & & & $(0,004)$ & $(0,004)$ & $(0,004)$ \\
\hline \multirow[t]{2}{*}{ Fundamental I } & & & & $-0,108$ & $-0,086$ \\
\hline & & & & $(0,075)$ & $(0,078)$ \\
\hline \multirow[t]{2}{*}{ Fundamental II } & & & & 0,016 & 0,037 \\
\hline & & & & $(0,077)$ & $(0,081)$ \\
\hline \multirow[t]{2}{*}{ Ensino Médio } & & & & 0,064 & 0,081 \\
\hline & & & & $(0,078)$ & $(0,081)$ \\
\hline \multirow[t]{2}{*}{ Ensino Superior } & & & & $0,172^{*}$ & $0,179^{*}$ \\
\hline & & & & $(0,103)$ & $(0,106)$ \\
\hline \multirow[t]{2}{*}{ Não sei } & & & & 0,013 & $-0,003$ \\
\hline & & & & $(0,100)$ & $(0,114)$ \\
\hline \multirow[t]{2}{*}{ Mora com o pai } & & & & & $-0,179$ \\
\hline & & & & & $(0,187)$ \\
\hline \multirow[t]{2}{*}{ Mora com a mãe } & & & & & $-0,232^{*}$ \\
\hline & & & & & $(0,130)$ \\
\hline \multirow[t]{2}{*}{ Mora com ambos } & & & & & 0,134 \\
\hline & & & & & $(0,194)$ \\
\hline \multirow[t]{2}{*}{ Constante } & $-0,142^{* * *}$ & $-0,346^{* * *}$ & 0,561 & 0,641 & 0,721 \\
\hline & $(0,035)$ & $(0,091)$ & $(0,701)$ & $(0,700)$ & $(0,746)$ \\
\hline Observações & 3181 & 3153 & 3145 & 3145 & 2911 \\
\hline
\end{tabular}

Erros-padrão em parênteses. ${ }^{*} p<0.10,{ }^{* *} p<0.05,{ }^{* * *} p<0.01$

Todas as regressões utilizam erros-padrão robustos a heterocedasticidade. 
Tabela 29 - Modelo de efeitos aleatórios para Amabilidade - Sertãozinho

\begin{tabular}{|c|c|c|c|c|c|}
\hline & $(1)$ & (2) & (3) & (4) & (5) \\
\hline \multirow[t]{2}{*}{ Creche } & $-0,080^{* *}$ & $-0,078^{* *}$ & $-0,068^{*}$ & $-0,067^{*}$ & $-0,056$ \\
\hline & $(0,039)$ & $(0,039)$ & $(0,039)$ & $(0,039)$ & $(0,040)$ \\
\hline \multirow[t]{2}{*}{ Pré-escola } & & 0,096 & 0,063 & 0,063 & 0,070 \\
\hline & & $(0,078)$ & $(0,077)$ & $(0,078)$ & $(0,081)$ \\
\hline \multirow[t]{2}{*}{ Homem } & & & $-0,094^{* *}$ & $-0,091^{* *}$ & $-0,089^{* *}$ \\
\hline & & & $(0,038)$ & $(0,039)$ & $(0,040)$ \\
\hline \multirow[t]{2}{*}{ Branco } & & & 0,080 & 0,079 & 0,082 \\
\hline & & & $(0,067)$ & $(0,067)$ & $(0,070)$ \\
\hline \multirow[t]{2}{*}{ Pardo } & & & 0,055 & 0,053 & 0,045 \\
\hline & & & $(0,066)$ & $(0,066)$ & $(0,069)$ \\
\hline \multirow[t]{2}{*}{ Amarelo } & & & 0,111 & 0,113 & 0,094 \\
\hline & & & $(0,146)$ & $(0,145)$ & $(0,146)$ \\
\hline \multirow[t]{2}{*}{ Indígena } & & & 0,209 & 0,206 & 0,193 \\
\hline & & & $(0,176)$ & $(0,175)$ & $(0,186)$ \\
\hline \multirow[t]{2}{*}{ Idade } & & & $-0,396^{* * *}$ & $-0,391^{* * *}$ & $-0,338^{* * *}$ \\
\hline & & & $(0,098)$ & $(0,098)$ & $(0,103)$ \\
\hline \multirow[t]{2}{*}{ Idade $^{2}$} & & & $0,011^{* * *}$ & $0,011^{* * *}$ & $0,009^{* *}$ \\
\hline & & & $(0,004)$ & $(0,004)$ & $(0,004)$ \\
\hline \multirow[t]{2}{*}{ Fundamental I } & & & & 0,032 & 0,014 \\
\hline & & & & $(0,072)$ & $(0,075)$ \\
\hline \multirow[t]{2}{*}{ Fundamental II } & & & & 0,026 & $-0,005$ \\
\hline & & & & $(0,070)$ & $(0,074)$ \\
\hline \multirow[t]{2}{*}{ Ensino Médio } & & & & 0,021 & $-0,007$ \\
\hline & & & & $(0,071)$ & $(0,074)$ \\
\hline \multirow[t]{2}{*}{ Ensino Superior } & & & & $-0,008$ & $-0,031$ \\
\hline & & & & $(0,089)$ & $(0,091)$ \\
\hline \multirow[t]{2}{*}{ Não sei } & & & & $-0,058$ & $-0,146$ \\
\hline & & & & $(0,084)$ & $(0,096)$ \\
\hline \multirow[t]{2}{*}{ Mora com o pai } & & & & & 0,054 \\
\hline & & & & & $(0,177)$ \\
\hline \multirow[t]{2}{*}{ Mora com a mãe } & & & & & 0,127 \\
\hline & & & & & $(0,129)$ \\
\hline \multirow[t]{2}{*}{ Mora com ambos } & & & & & $-0,025$ \\
\hline & & & & & $(0,182)$ \\
\hline \multirow[t]{2}{*}{ Constante } & $-0,194^{* * *}$ & $-0,284^{* * *}$ & $2,961^{* * *}$ & $2,904^{* * *}$ & $2,433^{* * *}$ \\
\hline & $(0,030)$ & $(0,077)$ & $(0,658)$ & $(0,661)$ & $(0,699)$ \\
\hline Observações & 3182 & 3154 & 3146 & 3146 & 2911 \\
\hline
\end{tabular}

Erros-padrão em parênteses. ${ }^{*} p<0.10,{ }^{* *} p<0.05,{ }^{* * *} p<0.01$

Todas as regressões utilizam erros-padrão robustos a heterocedasticidade. 
Tabela 30 - Modelo de efeitos aleatórios para Estabilidade Emocional - Sertãozinho

\begin{tabular}{|c|c|c|c|c|c|}
\hline & (1) & $(2)$ & (3) & (4) & $(5)$ \\
\hline \multirow[t]{2}{*}{ Creche } & 0,004 & 0,014 & $-0,009$ & $-0,011$ & 0,011 \\
\hline & $(0,044)$ & $(0,044)$ & $(0,042)$ & $(0,042)$ & $(0,044)$ \\
\hline \multirow[t]{2}{*}{ Pré-escola } & & $-0,179^{*}$ & $-0,102$ & $-0,090$ & $-0,092$ \\
\hline & & $(0,097)$ & $(0,094)$ & $(0,094)$ & $(0,100)$ \\
\hline \multirow[t]{2}{*}{ Homem } & & & $0,581^{* * *}$ & $0,580^{* * *}$ & $0,554^{* * *}$ \\
\hline & & & $(0,042)$ & $(0,042)$ & $(0,044)$ \\
\hline \multirow[t]{2}{*}{ Branco } & & & $-0,091$ & $-0,085$ & $-0,093$ \\
\hline & & & $(0,072)$ & $(0,072)$ & $(0,075)$ \\
\hline \multirow[t]{2}{*}{ Pardo } & & & $-0,047$ & $-0,051$ & $-0,046$ \\
\hline & & & $(0,070)$ & $(0,069)$ & $(0,072)$ \\
\hline \multirow[t]{2}{*}{ Amarelo } & & & 0,093 & 0,098 & 0,067 \\
\hline & & & $(0,192)$ & $(0,189)$ & $(0,181)$ \\
\hline \multirow[t]{2}{*}{ Indígena } & & & 0,037 & 0,031 & 0,112 \\
\hline & & & $(0,239)$ & $(0,241)$ & $(0,231)$ \\
\hline \multirow[t]{2}{*}{ Idade } & & & $-0,446^{* * *}$ & $-0,445^{* * *}$ & $-0,479^{* * *}$ \\
\hline & & & $(0,103)$ & $(0,103)$ & $(0,109)$ \\
\hline \multirow[t]{2}{*}{ Idade $^{2}$} & & & $0,014^{* * *}$ & $0,014^{* * *}$ & $0,015^{* * *}$ \\
\hline & & & $(0,004)$ & $(0,004)$ & $(0,004)$ \\
\hline \multirow[t]{2}{*}{ Fundamental I } & & & & 0,116 & 0,111 \\
\hline & & & & $(0,076)$ & $(0,080)$ \\
\hline \multirow[t]{2}{*}{ Fundamental II } & & & & 0,018 & 0,010 \\
\hline & & & & $(0,077)$ & $(0,081)$ \\
\hline \multirow[t]{2}{*}{ Ensino Médio } & & & & 0,022 & 0,012 \\
\hline & & & & $(0,078)$ & $(0,081)$ \\
\hline \multirow[t]{2}{*}{ Ensino Superior } & & & & $-0,021$ & $-0,020$ \\
\hline & & & & $(0,099)$ & $(0,103)$ \\
\hline \multirow[t]{2}{*}{ Não sei } & & & & 0,058 & 0,034 \\
\hline & & & & $(0,096)$ & $(0,109)$ \\
\hline \multirow[t]{2}{*}{ Mora com o pai } & & & & & $0,335^{*}$ \\
\hline & & & & & $(0,177)$ \\
\hline \multirow[t]{2}{*}{ Mora com a mãe } & & & & & $0,258^{* *}$ \\
\hline & & & & & $(0,130)$ \\
\hline \multirow[t]{2}{*}{ Mora com ambos } & & & & & $-0,257$ \\
\hline & & & & & $(0,183)$ \\
\hline \multirow[t]{2}{*}{ Constante } & $-0,157^{* * *}$ & 0,005 & $3,045^{* * *}$ & $2,972^{* * *}$ & $2,905^{* * *}$ \\
\hline & $(0,034)$ & $(0,098)$ & $(0,699)$ & $(0,701)$ & $(0,748)$ \\
\hline Observações & 3180 & 3152 & 3144 & 3144 & 2910 \\
\hline
\end{tabular}

Erros-padrão em parênteses. ${ }^{*} p<0.10,{ }^{* *} p<0.05,{ }^{* * *} p<0.01$

Todas as regressões utilizam erros-padrão robustos a heterocedasticidade. 


\section{Conclusão}

Habilidades socioemocionais são ao menos tão importantes quanto habilidades cognitivas para explicar resultados futuros (DUCKWORTH; SELIGMAN, 2005) e é sabido que estas se desenvolvem majoritariamente na primeira infância devido a plasticidade cerebral (KNUDSEN et al., 2006). O presente trabalho procurou investigar o impacto de se frequentar creche sobre o desenvolvimento das habilidades não cognitivas em estágios posteriores da vida (ensino fundamental e médio para os alunos de Sertãozinho e ensino médio para os alunos do Ceará).

Verificou-se que fazer creche afeta positivamente a habilidade de extroversão, resultado encontrado nas duas análises realizadas. Para os dados de Sertãozinho, não há fading out desse efeito na transição entre o ensino fundamental e o ensino médio. Para a habilidade de estabilidade emocional, não foram encontrados resultados estatisticamente significativos. Quando se tratam das habilidades de conscienciosidade e amabilidade, verifica-se discrepância quanto ao sinal: enquanto em Sertãozinho frequentar creche reduziria os scores médios destas habilidades, no Ceará haveria impacto positivo de se frequentar creche pública em ambas as habilidades, ainda que as creches supostamente conveniadas reduzam este score. Encontra-se efeito positivo e significativo de se frequentar qualquer tipo de creche em abertura para novas experiências, ainda que alunos de creches privadas sem bolsa tenham scores médios mais altos quando comparado aos demais. Em Sertãozinho, não se encontra significância sobre esta habilidade.

Os resultados para Sertãozinho acima mencionados são diferentes dos encontrados em Santos (2015), que faz uso da base da mesma base de dados restrita aos anos de 2008 e 2012. O autor não encontra resultados estatisticamente significantes. Ainda, a magnitude do resultado de conscienciosidade para o modelo de MQO de Sertãozinho de 2012 é similar à magnitude encontrada pelo autor.

Como os resultados encontrados a partir das análises de ambas as bases de dados apontaram, principalmente, para a relação de creche com a habilidade de extroversão, é interessante ressaltar que esta habilidade não apresenta monotonicidade quando relacionada com resultados educacionais, mas que existem indícios de que esta pode afetar a decisão de permanecer mais tempo na escola (SANTOS; PRIMI, 2014). Nesse sentido, pode-se dizer que esta é uma das habilidades mais interessantes a serem exploradas, dentro da taxonomia dos cinco grandes domínios.

Quando se tratam de dados de microeconomia aplicada, é extremamente difícil obter resultados com validade externa. Em geral, há um trade-off entre validade externa e qualidade da informação obtida, pois, dificilmente, as informações terão um nível maior de detalhes quando aplicadas em larga escala. Nesse sentido, pode-se dizer que essa é uma das grandes limitações do trabalho. Sertãozinho é um município do interior de São Paulo com alto PIB per capita quando 
comparado a demais municípios do Brasil ${ }^{1}$. Os resultados do Ceará, por serem aplicados em uma escala maior, possuem mais confiabilidade no que tange a validade externa, entretanto possuem a limitação de serem uma cross-section.

Ainda, há o agravante de ser pouco clara a relação de causalidade quando se tratam de habilidades socioemocionais. As relações e canais pelos quais as habilidades não cognitivas são afetadas pelos demais fatores são complexas. Entretanto, o fato deste trabalho documentar algo tão pouco explorado no contexto brasileiro já é importante por si só, além de remeter a duas questões importantes para as políticas públicas: implementação de avaliação nacional da educação infantil, tendo em vista as heterogeneidades de resultados encontrados a depender do tipo de creche frequentada, e implementação de avaliação nacional de habilidades socioemocionais, de modo que se tornará possível entender melhor como estas habilidades estão relacionadas a importantes problemas educacionais vivenciados no Brasil, como, por exemplo, evasão e abandono.

1 Fonte: https://cidades.ibge.gov.br/brasil/sp/sertaozinho/panorama. Acesso em: 29 de abril de 2019. 


\section{Referências}

ALMLUND, M.; DUCKWORTH, A. L.; HECKMAN, J.; KAUTZ, T. Personality psychology and economics. In: Handbook of the Economics of Education. [S.1.]: Elsevier, 2011. v. 4, p. $1-181$.

ANDRADE, J. M. de. Evidências de validade do inventário dos cinco grandes fatores de personalidade para o Brasil. Tese (Doutorado) — Ph. D. thesis, Universidade de Brasília, 2008.

BARNETT, W. S. Long-term effects of early childhood programs on cognitive and school outcomes. The future of children, JSTOR, p. 25-50, 1995.

BECKER, G. S. Human capital revisited. In: Human Capital: A Theoretical and Empirical Analysis with Special Reference to Education (3rd Edition). [S.1.]: The University of Chicago Press, 1994. p. 15-28.

BECKER, G. S.; TOMES, N. Child endowments and the quantity and quality of children. Journal of political Economy, The University of Chicago Press, v. 84, n. 4, Part 2, p. S143-S162, 1976.

BELFIELD, C.; BOWDEN, A. B.; KLAPP, A.; LEVIN, H.; SHAND, R.; ZANDER, S. The economic value of social and emotional learning. Journal of Benefit-Cost Analysis, Cambridge University Press, v. 6, n. 3, p. 508-544, 2015.

BENET-MARTINEZ, V.; JOHN, O. P. Los cinco grandes across cultures and ethnic groups: Multitrait-multimethod analyses of the big five in spanish and english. Journal of personality and social psychology, American Psychological Association, v. 75, n. 3, p. 729, 1998.

BLAIR, C.; RAZZA, R. P. Relating effortful control, executive function, and false belief understanding to emerging math and literacy ability in kindergarten. Child development, Wiley Online Library, v. 78, n. 2, p. 647-663, 2007.

BRASIL. Constituição da República Federativa do Brasil. 1988. Disponível em: $<$ http://www.planalto.gov.br/ccivil_03/constituicao/Emendas/Emc/emc53.htm>. Acessado em: $11 / 01 / 2020$.

BRASIL. Lei $n^{o}$ 8.069, de 13 de julho de 1990. 1990. Disponível em: <http://www.planalto.gov. br/ccivil_03/Leis/18069.htm>. Acessado em: 11/08/2018.

BRASIL. Emenda constitucional $n^{o} 59$ de 11 de novembro de 2009. 2009. Disponível em $:<$ http://www.planalto.gov.br/ccivil_03/constituicao/Emendas/Emc/emc59.htm>. Acessado em: $11 / 01 / 2020$.

BRASIL. Lei $n^{o}$ 13.306, de 4 de julho de 2016. 2016. Disponível em: <http://www2.camara.leg. br/legin/fed/lei/2016/lei-13306-4-julho-2016-783308-publicacaooriginal-150706-pl.html>. Acessado em: 11/08/2018.

BRASIL. Base Nacional Comum Curricular. 2017. Brasília: MEC/Secretaria de Educação Básica, 2017. 
CAMPBELL, F. A.; RAMEY, C. T.; PUNGELLO, E.; SPARLING, J.; MILLER-JOHNSON, S. Early childhood education: Young adult outcomes from the abecedarian project. Applied developmental science, Taylor \& Francis, v. 6, n. 1, p. 42-57, 2002.

CAMPOS, M. M.; ESPOSITO, Y. L.; GIMENES, N. A. S. A meta 1 do Plano Nacional de Educação. v. 2024, p. 329-352, 2014.

CARNEIRO, P.; CRAWFORD, C.; GOODMAN, A. The impact of early cognitive and non-cognitive skills on later outcomes. Centre for Economics of Education, 2007.

CATTELL, R. B.; EBER, H. W.; TATSUOKA, M. M. Handbook for the sixteen personality factor questionnaire (16 PF): In clinical, educational, industrial, and research psychology, for use with all forms of the test. [S.1.]: Institute for Personality and Ability Testing, 1970.

CHALMERS, R. P. et al. mirt: A multidimensional item response theory package for the $\mathrm{r}$ environment. Journal of Statistical Software, v. 48, n. 6, p. 1-29, 2012.

CUNHA, F.; HECKMAN, J. J. Formulating, identifying and estimating the technology of cognitive and noncognitive skill formation. Journal of human resources, University of Wisconsin Press, v. 43, n. 4, p. 738-782, 2008.

DOMITROVICH, C. E.; CORTES, R. C.; GREENBERG, M. T. Improving young children's social and emotional competence: A randomized trial of the preschool "paths" curriculum. The Journal of primary prevention, Springer, v. 28, n. 2, p. 67-91, 2007.

DUCKWORTH, A. L.; SELIGMAN, M. E. Self-discipline outdoes iq in predicting academic performance of adolescents. Psychological science, SAGE Publications Sage CA: Los Angeles, CA, v. 16, n. 12, p. 939-944, 2005.

DUNCAN, G. J.; MAGNUSON, K. Investing in preschool programs. Journal of Economic Perspectives, v. 27, n. 2, p. 109-32, 2013.

DURLAK, J. A.; WEISSBERG, R. P.; DYMNICKI, A. B.; TAYLOR, R. D.; SCHELLINGER, K. B. The impact of enhancing students' social and emotional learning: A meta-analysis of school-based universal interventions. Child development, Wiley Online Library, v. 82, n. 1, p. 405-432, 2011.

FELÍCIO, F. d.; TERRA, R.; ZOGHBI, A. C. The effects of early childhood education on literacy scores using data from a new brazilian assessment tool. Estudos Econômicos (São Paulo), SciELO Brasil, v. 42, n. 1, p. 97-128, 2012.

FONSECA, G. d. C. Investigação da durabilidade do benefício gerado pela Educação Infantil. Tese (Doutorado) — Universidade de São Paulo, 2015.

FURR, R. M. Psychometrics: an introduction. [S.1.]: Sage Publications, 2017.

GOLDBERG, L. R. Language and individual differences: The search for universals in personality lexicons. Review of personality and social psychology, v. 2, n. 1, p. 141-165, 1981.

HAGEKULL, B.; BOHLIN, G. Day care quality, family and child characteristics and socioemotional development. Early childhood research Quarterly, Elsevier, v. 10, n. 4, p. 505-526, 1995. 
HECKMAN, J.; PINTO, R.; SAVELYEV, P. Understanding the mechanisms through which an influential early childhood program boosted adult outcomes. The American economic review, American Economic Association, v. 103, n. 6, p. 2052-2086, 2013.

HECKMAN, J. J.; MASTEROV, D. V. The productivity argument for investing in young children. Applied Economic Perspectives and Policy, Oxford University Press, v. 29, n. 3, p. 446-493, 2007.

HECKMAN, J. J.; RUBINSTEIN, Y. The importance of noncognitive skills: Lessons from the ged testing program. The American Economic Review, JSTOR, v. 91, n. 2, p. 145-149, 2001.

HECKMAN, J. J.; STIXRUD, J.; URZUA, S. The effects of cognitive and noncognitive abilities on labor market outcomes and social behavior. Journal of Labor economics, The University of Chicago Press, v. 24, n. 3, p. 411-482, 2006.

IBGE. IBGE Cidades. 2019. Disponível em: < https://cidades.ibge.gov.br/brasil/sp/sertaozinho/ panorama>. Acessado em 12/01/2020.

IBGE. IBGE Cidades. 2019. Disponível em: <https://cidades.ibge.gov.br/brasil/ce/panorama>. Acessado em 12/01/2020.

INEP, I. N. de Estudos e P. E. A. T. 2018. <http://portal.inep.gov.br/provinha-brasil>. Acessado em $27 / 03 / 2018$.

JOHN, O. P.; DONAHUE, E. M.; KENTLE, R. L. The big five inventory-versions $4 a$ and 54. [S.l.]: Berkeley, CA: University of California, Berkeley, Institute of Personality ..., 1991.

JOHN, O. P.; SRIVASTAVA, S. The big five trait taxonomy: History, measurement, and theoretical perspectives. Handbook of personality: Theory and research, Guilford, v. 2, n. 1999, p. 102-138, 1999.

KAM, C.-M.; GREENBERG, M. T.; WALLS, C. T. Examining the role of implementation quality in school-based prevention using the paths curriculum. Prevention Science, Springer, v. 4, n. 1, p. 55-63, 2003.

KNUDSEN, E. I.; HECKMAN, J. J.; CAMERON, J. L.; SHONKOFF, J. P. Economic, neurobiological, and behavioral perspectives on building america's future workforce. Proceedings of the National Academy of Sciences, National Acad Sciences, v. 103, n. 27, p. 10155-10162, 2006.

MISCHEL, W.; EBBESEN, E. B.; ZEISS, A. R. Cognitive and attentional mechanisms in delay of gratification. Journal of personality and social psychology, American Psychological Association, v. 21, n. 2, p. 204, 1972.

NORES, M.; BARNETT, W. S. Benefits of early childhood interventions across the world:(under) investing in the very young. Economics of education review, Elsevier, v. 29, n. 2, p. 271-282, 2010.

ONU. PNUD - Programa das Nações Unidas para o Desenvolvimento. 2016. Disponível em: $<$ https://indicators.report/targets/4-2/>. Acessado em 11/01/2020.

PASQUALI, L. Psicometria: teoria dos testes na psicologia e na educação. [S.1.]: Editora Vozes Limitada, 2017. 
ROBERTS, B. W. Back to the future: Personality and assessment and personality development. Journal of research in personality, Elsevier, v. 43, n. 2, p. 137-145, 2009.

SAILER, M. O. Design and randomization in crossover studies. 2005.

SANTOS, D.; PRIMI, R. Desenvolvimento socioemocional e aprendizado escolar: uma proposta de mensuração para apoiar políticas públicas. Relatório sobre resultados preliminares do projeto de medição de competências socioemocionais no Rio de Janeiro. São Paulo: OCDE, SEEDUC, Instituto Ayrton Senna, 2014.

SANTOS, D. D. d. Impactos do ensino infantil sobre o aprendizado: benefícios positivos, mas desiguais. Tese de Livre Docência, Universidade de São Paulo, 2015.

SCHMITT, D. P.; ALLIK, J.; MCCRAE, R. R.; BENET-MARTÍNEZ, V. The geographic distribution of big five personality traits: Patterns and profiles of human self-description across 56 nations. Journal of cross-cultural psychology, Sage Publications Sage CA: Thousand Oaks, CA, v. 38, n. 2, p. 173-212, 2007.

SCHWEINHART, L. J.; MONTIE, J.; XIANG, Z.; BARNETT, W. S.; BELFIELD, C. R.; NORES, M. Lifetime effects: The high/scope perry preschool study through age 40 (monographs of the high/scope educational research foundation, 14). Ypsilanti, MI: High Scope Educational Research Foundation, 2005.

SOTO, C. J.; JOHN, O. P. The next big five inventory (bfi-2): Developing and assessing a hierarchical model with 15 facets to enhance bandwidth, fidelity, and predictive power. Journal of personality and social psychology, American Psychological Association, v. 113, n. 1, p. 117, 2017.

SOTO, C. J.; JOHN, O. P.; GOSLING, S. D.; POTTER, J. Age differences in personality traits from 10 to 65: Big five domains and facets in a large cross-sectional sample. Journal of personality and social psychology, American Psychological Association, v. 100, n. 2, p. 330, 2011.

SPAECE. SPAECE: Sistema Permanente de Avaliação da Educação Básica do Ceará. 2018. Disponível em: <http://www.spaece.caedufjf.net/avaliacao-educacional/o-programa/>. Acessado em 15/07/2018.

TAYLOR, R. D.; OBERLE, E.; DURLAK, J. A.; WEISSBERG, R. P. Promoting positive youth development through school-based social and emotional learning interventions: A meta-analysis of follow-up effects. Child development, Wiley Online Library, v. 88, n. 4, p. 1156-1171, 2017.

TODOS, P. E. Anuário brasileiro da educação básica. São Paulo: Moderna, 2019.

WOOLDRIDGE, J. M. Econometric analysis of cross section and panel data. [S.1.]: MIT press, 2010 . 


\section{APÊNDICE A - Tabelas e gráficos}

Figura 11 - Abertura para novas experiências por idade de acordo com as categorias de creche - Ceará

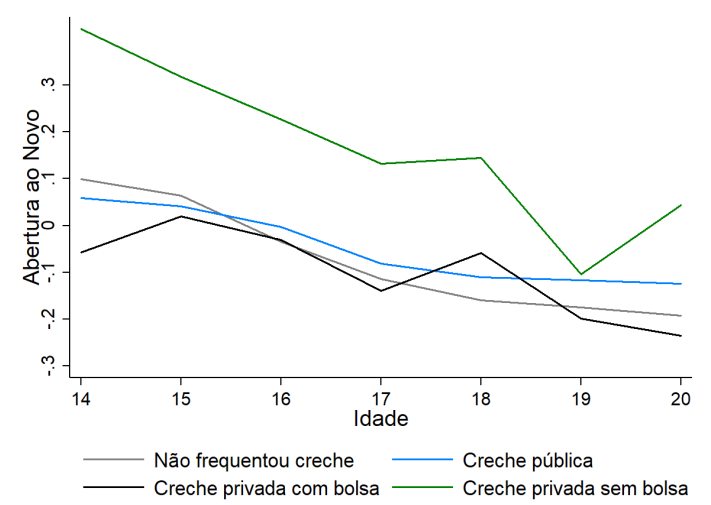

Figura 13 - Extroversão por idade de acordo com as categorias de creche - Ceará

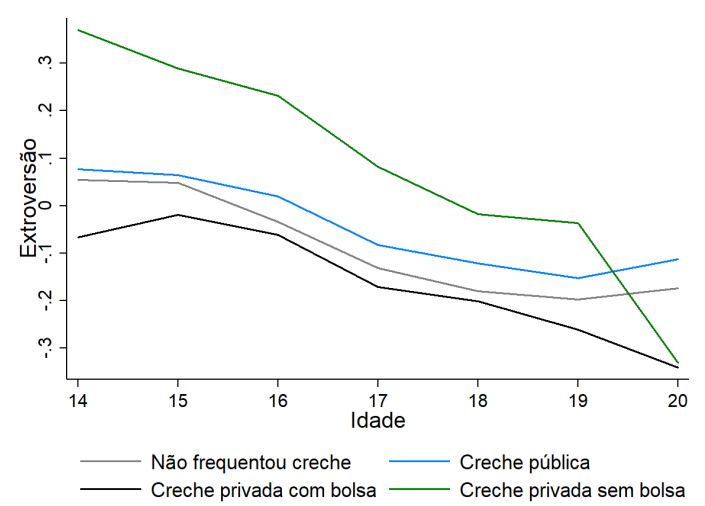

Figura 12 - Conscienciosidade por idade de acordo com as categorias de creche - Ceará

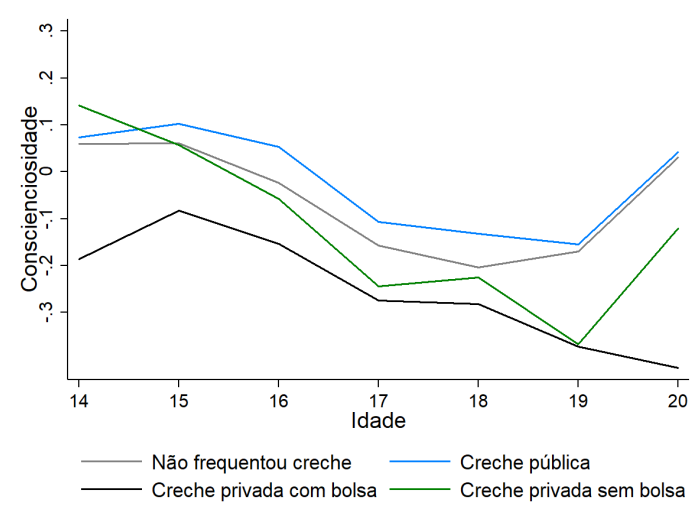

Figura 14-Amabilidade por idade de acordo com as categorias de creche - Ceará

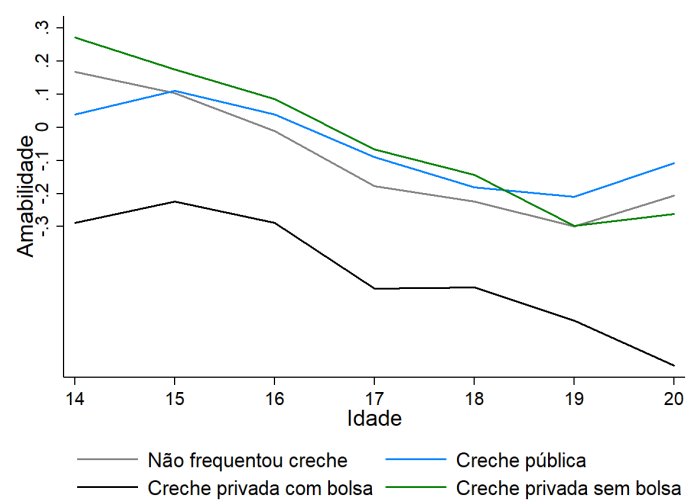


Figura 15 - Estabilidade emocional por idade de acordo com as categorias de creche - Ceará

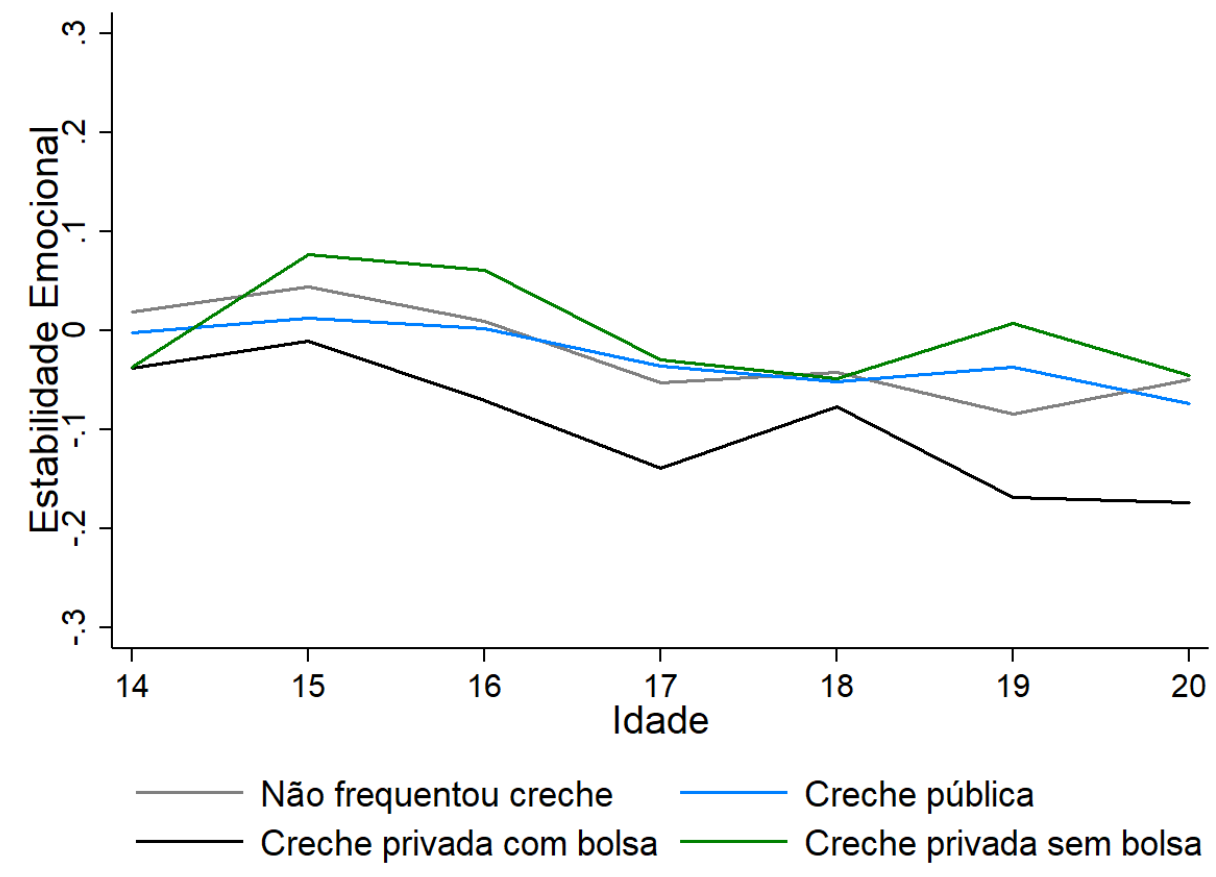


Tabela 31 - Estatísticas descritivas para os indivíduos condicionada ao tipo de creche - Ceará

\begin{tabular}{|c|c|c|c|c|c|c|c|c|c|c|c|c|}
\hline & \multicolumn{3}{|c|}{ Não frequentou creche } & \multicolumn{3}{|c|}{ Creche Pública } & \multicolumn{3}{|c|}{ Creche privada sem bolsa } & \multicolumn{3}{|c|}{ Creche privada com bolsa } \\
\hline & Média & D.p. & $\mathrm{N}$ & Média & D.p. & $\mathrm{N}$ & Média & D.p. & $\mathrm{N}$ & Média & D.p. & $\mathrm{N}$ \\
\hline Homem & $49,4 \%$ & 0,5 & 36479 & $48,8 \%$ & 0,5 & 51977 & $50,9 \%$ & 0,5 & 5332 & $54,7 \%$ & 0,498 & 3092 \\
\hline Idade & 15,998 & 1,238 & 35873 & 15,981 & 1,15 & 51257 & 15,707 & 1,042 & 5251 & 16,068 & 1,216 & 2979 \\
\hline \multicolumn{13}{|l|}{ Cor } \\
\hline Pardos e negros & $63,2 \%$ & 0,482 & 35844 & $66,8 \%$ & 0,471 & 51297 & $57,1 \%$ & 0,495 & 5239 & $63,8 \%$ & 0,481 & 2945 \\
\hline Brancos e amarelos & $32,6 \%$ & 0,469 & 35844 & $28,7 \%$ & 0,452 & 51297 & $38,8 \%$ & 0,487 & 5239 & $31,0 \%$ & 0,463 & 2945 \\
\hline Indígena & $4,3 \%$ & 0,202 & 35844 & $4,5 \%$ & 0,208 & 51297 & $4,1 \%$ & 0,198 & 5239 & $5,2 \%$ & 0,221 & 2945 \\
\hline \multicolumn{13}{|l|}{ Pré-escola } \\
\hline Não frequentou & $28,3 \%$ & 0,45 & 36015 & $14,5 \%$ & 0,352 & 51549 & $7,6 \%$ & 0,266 & 5275 & $21,7 \%$ & 0,412 & 3047 \\
\hline Pública & $50,6 \%$ & 0,5 & 36015 & $80,2 \%$ & 0,398 & 51549 & $21,2 \%$ & 0,409 & 5275 & $39,3 \%$ & 0,488 & 3047 \\
\hline Privada com bolsa & $3,6 \%$ & 0,185 & 36015 & $2,0 \%$ & 0,139 & 51549 & $3,7 \%$ & 0,188 & 5275 & $32,1 \%$ & 0,467 & 3047 \\
\hline Privada sem bolsa & $17,6 \%$ & 0,38 & 36015 & $3,3 \%$ & 0,179 & 51549 & $67,5 \%$ & 0,469 & 5275 & $7,0 \%$ & 0,254 & 3047 \\
\hline \multicolumn{13}{|l|}{ Reprovação } \\
\hline Uma vez & $27,2 \%$ & 0,445 & 35451 & $26,1 \%$ & 0,439 & 51161 & $23,6 \%$ & 0,424 & 5230 & $39,5 \%$ & 0,489 & 2799 \\
\hline Mais de uma vez & $9,9 \%$ & 0,299 & 35451 & $10,4 \%$ & 0,305 & 51161 & $8,4 \%$ & 0,277 & 5230 & $13,7 \%$ & 0,344 & 2799 \\
\hline \multicolumn{13}{|l|}{ Educação da mãe } \\
\hline $\begin{array}{l}\text { Nunca estudou ou não } \\
\text { completou Fundamental I }\end{array}$ & $17,6 \%$ & 0,381 & 34325 & $17,4 \%$ & 0,379 & 50063 & $9,4 \%$ & 0,291 & 5080 & $26,5 \%$ & 0,442 & 2609 \\
\hline Fundamental I & $23,8 \%$ & 0,426 & 34325 & $27,2 \%$ & 0,445 & 50063 & $13,4 \%$ & 0,341 & 5080 & $22,2 \%$ & 0,416 & 2609 \\
\hline Fundamental II & $16,2 \%$ & 0,368 & 34325 & $17,7 \%$ & 0,382 & 50063 & $17,1 \%$ & 0,376 & 5080 & $16,4 \%$ & 0,371 & 2609 \\
\hline Ensino Médio & $20,3 \%$ & 0,402 & 34325 & $16,0 \%$ & 0,367 & 50063 & $34,2 \%$ & 0,474 & 5080 & $15,6 \%$ & 0,363 & 2609 \\
\hline Ensino Superior & $3,9 \%$ & 0,195 & 34325 & $2,9 \%$ & 0,167 & 50063 & $9,6 \%$ & 0,294 & 5080 & $5,1 \%$ & 0,221 & 2609 \\
\hline Pós-Graduação & $2,0 \%$ & 0,14 & 34325 & $1,5 \%$ & 0,121 & 50063 & $5,4 \%$ & 0,226 & 5080 & $2,7 \%$ & 0,163 & 2609 \\
\hline Não sabe & $16,1 \%$ & 0,368 & 34325 & $17,3 \%$ & 0,379 & 50063 & $11,0 \%$ & 0,313 & 5080 & $11,3 \%$ & 0,317 & 2609 \\
\hline Mora com o pai & $41,2 \%$ & 0,492 & 36741 & $37,9 \%$ & 0,485 & 52339 & $43,5 \%$ & 0,496 & 5376 & $35,0 \%$ & 0,477 & 3130 \\
\hline Mora com a mãe & $79,5 \%$ & 0,404 & 36741 & $79,5 \%$ & 0,404 & 52339 & $79,4 \%$ & 0,404 & 5376 & $69,9 \%$ & 0,459 & 3130 \\
\hline Mora com ambos & $36,4 \%$ & 0,481 & 36741 & $33,2 \%$ & 0,471 & 52339 & $37,7 \%$ & 0,485 & 5376 & $27,6 \%$ & 0,447 & 3130 \\
\hline Bolsa Família & $59,4 \%$ & 0,491 & 36163 & $64,7 \%$ & 0,478 & 51546 & $37,2 \%$ & 0,484 & 5276 & $58,6 \%$ & 0,493 & 3073 \\
\hline \multicolumn{13}{|l|}{ Características da moradia } \\
\hline Rua asfaltada & $63,9 \%$ & 0,48 & 34152 & $61,8 \%$ & 0,486 & 50407 & $77,6 \%$ & 0,417 & 5110 & $56,9 \%$ & 0,495 & 2484 \\
\hline Energia Elétrica & $95,7 \%$ & 0,203 & 36299 & $96,2 \%$ & 0,191 & 51868 & $93,8 \%$ & 0,241 & 5312 & $76,3 \%$ & 0,425 & 3033 \\
\hline Água encanada & $88,4 \%$ & 0,32 & 36481 & $88,4 \%$ & 0,321 & 51996 & $94,8 \%$ & 0,221 & 5314 & $86,5 \%$ & 0,342 & 3049 \\
\hline Coleta de lixo & $75,5 \%$ & 0,43 & 36418 & $74,5 \%$ & 0,436 & 51926 & $86,5 \%$ & 0,341 & 5305 & $73,0 \%$ & 0,444 & 3074 \\
\hline Empregada doméstica & $12,5 \%$ & 0,331 & 36359 & $9,6 \%$ & 0,295 & 51757 & $17,5 \%$ & 0,38 & 5305 & $34,8 \%$ & 0,476 & 3058 \\
\hline Carro & $32,9 \%$ & 0,47 & 35800 & $25,0 \%$ & 0,433 & 51141 & $47,0 \%$ & 0,499 & 5155 & $56,0 \%$ & 0,496 & 2996 \\
\hline Máquina de lavar & $58,1 \%$ & 0,493 & 36339 & $52,6 \%$ & 0,499 & 51785 & $73,5 \%$ & 0,442 & 5311 & $73,9 \%$ & 0,439 & 3074 \\
\hline Computador & $43,6 \%$ & 0,496 & 36321 & $36,5 \%$ & 0,481 & 51754 & $67,4 \%$ & 0,469 & 5318 & $50,3 \%$ & 0,5 & 3064 \\
\hline Microondas & $40,8 \%$ & 0,491 & 36169 & $35,1 \%$ & 0,477 & 51441 & $59,3 \%$ & 0,491 & 5281 & $46,5 \%$ & 0,499 & 3068 \\
\hline Televisão & $89,6 \%$ & 0,305 & 36269 & $92,4 \%$ & 0,265 & 51722 & $92,2 \%$ & 0,268 & 5312 & $71,6 \%$ & 0,451 & 3054 \\
\hline Geladeira & $88,8 \%$ & 0,316 & 36326 & $92,4 \%$ & 0,264 & 51801 & $91,6 \%$ & 0,277 & 5302 & $70,8 \%$ & 0,455 & 3066 \\
\hline
\end{tabular}


Tabela 32 - Estimação de MQO - Extensões - Ceará

\begin{tabular}{|c|c|c|c|c|c|}
\hline & $\begin{array}{c}\text { (1) } \\
\text { Abertura }\end{array}$ & $\begin{array}{c}(2) \\
\text { Conscienciosidade }\end{array}$ & $\begin{array}{c}\text { (3) } \\
\text { Extroversão }\end{array}$ & $\begin{array}{c}(4) \\
\text { Amabilidade }\end{array}$ & $\begin{array}{c}\text { (5) } \\
\text { Estabilidade }\end{array}$ \\
\hline Creche & $\begin{array}{c}0,045^{* * *} \\
(0,008)\end{array}$ & $\begin{array}{c}0,031^{* * *} \\
(0,008)\end{array}$ & $\begin{array}{c}0,067^{* * *} \\
(0,008)\end{array}$ & $\begin{array}{c}0,033^{* * *} \\
(0,008)\end{array}$ & $\begin{array}{c}0,005 \\
(0,008)\end{array}$ \\
\hline Pré-escola & $\begin{array}{c}0,109^{* * *} \\
(0,010)\end{array}$ & $\begin{array}{c}0,057^{* * *} \\
(0,010)\end{array}$ & $\begin{array}{c}0,070^{* * *} \\
(0,010)\end{array}$ & $\begin{array}{c}0,045^{* * *} \\
(0,010)\end{array}$ & $\begin{array}{c}0,036^{* * *} \\
(0,010)\end{array}$ \\
\hline Reprovou uma vez & $\begin{array}{c}-0,121^{* * *} \\
(0,010)\end{array}$ & $\begin{array}{c}-0,205^{* * *} \\
(0,010)\end{array}$ & $\begin{array}{c}-0,108^{* * *} \\
(0,010)\end{array}$ & $\begin{array}{c}-0,163^{* * *} \\
(0,010)\end{array}$ & $\begin{array}{c}-0,112^{* * *} \\
(0,010)\end{array}$ \\
\hline Reprovou mais de uma vez & $\begin{array}{c}-0,148^{* * *} \\
(0,016)\end{array}$ & $\begin{array}{c}-0,317^{* * *} \\
(0,015)\end{array}$ & $\begin{array}{c}-0,126^{* * *} \\
(0,016)\end{array}$ & $\begin{array}{c}-0,184^{* * *} \\
(0,016)\end{array}$ & $\begin{array}{c}-0,149^{* * *} \\
(0,015)\end{array}$ \\
\hline Faltou três vezes ou mais & $\begin{array}{c}-0,113^{* * *} \\
(0,008)\end{array}$ & $\begin{array}{c}-0,343^{* * *} \\
(0,008)\end{array}$ & $\begin{array}{c}-0,097^{* * *} \\
(0,008)\end{array}$ & $\begin{array}{c}-0,116^{* * *} \\
(0,008)\end{array}$ & $\begin{array}{c}-0,156^{* * *} \\
(0,008)\end{array}$ \\
\hline Bolsa Família & $\begin{array}{c}-0,038^{* * *} \\
(0,008)\end{array}$ & $\begin{array}{l}-0,002 \\
(0,008)\end{array}$ & $\begin{array}{c}-0,028^{* * *} \\
(0,008)\end{array}$ & $\begin{array}{c}-0,029^{* * *} \\
(0,008)\end{array}$ & $\begin{array}{l}-0,005 \\
(0,008)\end{array}$ \\
\hline Homem & $\begin{array}{c}0,104^{* * *} \\
(0,008)\end{array}$ & $\begin{array}{c}-0,162^{* * *} \\
(0,008)\end{array}$ & $\begin{array}{c}0,023^{* * *} \\
(0,008)\end{array}$ & $\begin{array}{c}-0,251^{* * *} \\
(0,007)\end{array}$ & $\begin{array}{c}0,477^{* * *} \\
(0,008)\end{array}$ \\
\hline Brancos e amarelos & $\begin{array}{c}0,040^{* * * *} \\
(0,008)\end{array}$ & $\begin{array}{c}0,032^{* * *} \\
(0,008)\end{array}$ & $\begin{array}{c}-0,017^{* *} \\
(0,008)\end{array}$ & $\begin{array}{c}0,002 \\
(0,008)\end{array}$ & $\begin{array}{l}-0,009 \\
(0,008)\end{array}$ \\
\hline Indígena & $\begin{array}{c}0,016 \\
(0,019)\end{array}$ & $\begin{array}{c}-0,088^{* * *} \\
(0,017)\end{array}$ & $\begin{array}{c}-0,051^{* * *} \\
(0,018)\end{array}$ & $\begin{array}{c}-0,044^{* *} \\
(0,018)\end{array}$ & $\begin{array}{l}-0,029 \\
(0,019)\end{array}$ \\
\hline Mora com a mãe & $\begin{array}{c}-0,034^{* * *} \\
(0,012)\end{array}$ & $\begin{array}{l}-0,018 \\
(0,012)\end{array}$ & $\begin{array}{c}-0,036^{* * *} \\
(0,012)\end{array}$ & $\begin{array}{l}-0,020^{*} \\
(0,012)\end{array}$ & $\begin{array}{l}0,019^{*} \\
(0,012)\end{array}$ \\
\hline Mora com o pai & $\begin{array}{l}-0,023 \\
(0,021)\end{array}$ & $\begin{array}{c}-0,053^{* * *} \\
(0,020)\end{array}$ & $\begin{array}{l}-0,031 \\
(0,021)\end{array}$ & $\begin{array}{l}-0,033^{*} \\
(0,020)\end{array}$ & $\begin{array}{l}0,040^{* *} \\
(0,020)\end{array}$ \\
\hline Mora com ambos & $\begin{array}{l}0,061^{* * *} \\
(0,022)\end{array}$ & $\begin{array}{c}0,124^{* * *} \\
(0,021)\end{array}$ & $\begin{array}{c}0,062^{* * *} \\
(0,022)\end{array}$ & $\begin{array}{c}0,107^{* * *} \\
(0,021)\end{array}$ & $\begin{array}{c}0,017 \\
(0,022)\end{array}$ \\
\hline Educação da mãe & & & & & \\
\hline Fundamental I & $\begin{array}{c}0,019 \\
(0,012)\end{array}$ & $\begin{array}{c}0,020 \\
(0,012)\end{array}$ & $\begin{array}{c}0,042^{* * *} \\
(0,012)\end{array}$ & $\begin{array}{c}0,038^{* * *} \\
(0,012)\end{array}$ & $\begin{array}{c}0,019 \\
(0,012)\end{array}$ \\
\hline Fundamental II & $\begin{array}{c}0,066^{* * *} \\
(0,014)\end{array}$ & $\begin{array}{c}0,002 \\
(0,013)\end{array}$ & $\begin{array}{c}0,101^{* * *} \\
(0,014)\end{array}$ & $\begin{array}{c}0,040^{* * *} \\
(0,013)\end{array}$ & $\begin{array}{l}0,030^{* *} \\
(0,013)\end{array}$ \\
\hline Ensino Médio & $\begin{array}{c}0,106^{* * *} \\
(0,014)\end{array}$ & $\begin{array}{c}0,010 \\
(0,014)\end{array}$ & $\begin{array}{c}0,139^{* * *} \\
(0,014)\end{array}$ & $\begin{array}{c}0,055^{* * *} \\
(0,013)\end{array}$ & $\begin{array}{c}0,049^{* * *} \\
(0,014)\end{array}$ \\
\hline Ensino Superior & $\begin{array}{c}0,161^{* * *} \\
(0,024)\end{array}$ & $\begin{array}{l}-0,009 \\
(0,021)\end{array}$ & $\begin{array}{c}0,165^{* * *} \\
(0,023)\end{array}$ & $\begin{array}{l}0,048^{* *} \\
(0,022)\end{array}$ & $\begin{array}{c}0,085^{* * *} \\
(0,023)\end{array}$ \\
\hline Pós Graduação & $\begin{array}{c}0,181^{* * *} \\
(0,031)\end{array}$ & $\begin{array}{c}0,012 \\
(0,029)\end{array}$ & $\begin{array}{c}0,212^{* * *} \\
(0,033)\end{array}$ & $\begin{array}{c}0,024 \\
(0,028)\end{array}$ & $\begin{array}{l}-0,028 \\
(0,029)\end{array}$ \\
\hline Não sabe & $\begin{array}{c}-0,126^{* * *} \\
(0,013)\end{array}$ & $\begin{array}{c}-0,124^{* * *} \\
(0,013)\end{array}$ & $\begin{array}{c}-0,081^{* * *} \\
(0,013)\end{array}$ & $\begin{array}{c}-0,054^{* * *} \\
(0,013)\end{array}$ & $\begin{array}{c}-0,066^{* * *} \\
(0,013)\end{array}$ \\
\hline Observations & 72007 & 72007 & 72007 & 72007 & 72007 \\
\hline$R^{2}$ & 0,060 & 0,102 & 0,046 & 0,087 & 0,082 \\
\hline Adjusted $R^{2}$ & 0,051 & 0,094 & 0,037 & 0,079 & 0,073 \\
\hline
\end{tabular}

Erros-padrão entre parênteses. Todas as regressões utilizam erros-padrão robustos a heterocedasticidade.

${ }^{*} p<0.10,{ }^{* *} p<0.05,{ }^{* * *} p<0.01$

Ver nota de rodapé da Tabela 13 para descrição detalhada dos controles. 
Tabela 33 - Estimação de MQO para o ano de 2012 - Abertura para novas experiências - Sertãozinho

\begin{tabular}{|c|c|c|c|c|c|c|}
\hline & (1) & (2) & (3) & (4) & (5) & (6) \\
\hline \multirow[t]{2}{*}{ Creche } & $-0,043$ & $-0,046$ & $-0,030$ & $-0,017$ & $-0,018$ & $-0,017$ \\
\hline & $(0,051)$ & $(0,052)$ & $(0,051)$ & $(0,052)$ & $(0,052)$ & $(0,052)$ \\
\hline \multirow[t]{2}{*}{ Pré-escola } & & $0,247^{* *}$ & $0,194^{*}$ & $0,199^{*}$ & $0,201^{*}$ & 0,158 \\
\hline & & $(0,110)$ & $(0,111)$ & $(0,112)$ & $(0,111)$ & $(0,113)$ \\
\hline \multirow[t]{2}{*}{ Homem } & & & $-0,193^{* * *}$ & $-0,186^{* * *}$ & $-0,187^{* * *}$ & $-0,179^{* * *}$ \\
\hline & & & $(0,050)$ & $(0,052)$ & $(0,052)$ & $(0,052)$ \\
\hline \multirow[t]{2}{*}{ Branco } & & & 0,076 & 0,078 & 0,083 & 0,069 \\
\hline & & & $(0,087)$ & $(0,088)$ & $(0,089)$ & $(0,090)$ \\
\hline \multirow[t]{2}{*}{ Pardo } & & & $-0,069$ & $-0,065$ & $-0,055$ & $-0,079$ \\
\hline & & & $(0,086)$ & $(0,087)$ & $(0,088)$ & $(0,088)$ \\
\hline \multirow[t]{2}{*}{ Amarelo } & & & 0,088 & 0,077 & 0,076 & 0,075 \\
\hline & & & $(0,234)$ & $(0,235)$ & $(0,235)$ & $(0,233)$ \\
\hline \multirow[t]{2}{*}{ Indígena } & & & 0,342 & $0,454^{*}$ & $0,480^{*}$ & $0,457^{*}$ \\
\hline & & & $(0,256)$ & $(0,274)$ & $(0,273)$ & $(0,269)$ \\
\hline \multirow[t]{2}{*}{ Idade } & & & $-0,382$ & $-0,477$ & $-0,588$ & $-0,939$ \\
\hline & & & $(0,577)$ & $(0,582)$ & $(0,583)$ & $(0,591)$ \\
\hline \multirow[t]{2}{*}{ Idade $^{2}$} & & & 0,012 & 0,017 & 0,022 & 0,040 \\
\hline & & & $(0,025)$ & $(0,026)$ & $(0,026)$ & $(0,026)$ \\
\hline \multirow[t]{2}{*}{ Mora com o pai } & & & & 0,167 & 0,169 & 0,045 \\
\hline & & & & $(0,303)$ & $(0,303)$ & $(0,303)$ \\
\hline \multirow[t]{2}{*}{ Mora com a mãe } & & & & 0,203 & 0,209 & 0,095 \\
\hline & & & & $(0,254)$ & $(0,257)$ & $(0,256)$ \\
\hline \multirow[t]{2}{*}{ Mora com ambos } & & & & $-0,101$ & $-0,103$ & 0,014 \\
\hline & & & & $(0,310)$ & $(0,310)$ & $(0,311)$ \\
\hline \multirow[t]{2}{*}{ Fundamental I } & & & & & $-0,011$ & $-0,010$ \\
\hline & & & & & $(0,092)$ & $(0,092)$ \\
\hline \multirow[t]{2}{*}{ Fundamental II } & & & & & 0,072 & 0,065 \\
\hline & & & & & $(0,099)$ & $(0,100)$ \\
\hline \multirow[t]{2}{*}{ Ensino Médio } & & & & & $-0,088$ & $-0,102$ \\
\hline & & & & & $(0,096)$ & $(0,097)$ \\
\hline \multirow[t]{2}{*}{ Ensino Superior } & & & & & 0,152 & 0,126 \\
\hline & & & & & $(0,122)$ & $(0,122)$ \\
\hline \multirow[t]{2}{*}{ Não sei } & & & & & 0,048 & 0,009 \\
\hline & & & & & $(0,135)$ & $(0,137)$ \\
\hline \multirow[t]{2}{*}{ Abandono } & & & & & & $-0,020$ \\
\hline & & & & & & $(0,163)$ \\
\hline \multirow[t]{2}{*}{ Reprovou uma vez } & & & & & & $-0,140^{*}$ \\
\hline & & & & & & $(0,076)$ \\
\hline \multirow[t]{2}{*}{ Reprovou duas vezes } & & & & & & $-0,327^{* * *}$ \\
\hline & & & & & & $(0,118)$ \\
\hline \multirow[t]{2}{*}{ Reprovou três vezes ou mais } & & & & & & 0,021 \\
\hline & & & & & & $(0,189)$ \\
\hline \multirow[t]{2}{*}{ Constante } & 0,025 & $-0,203^{*}$ & 2,714 & 2,898 & 3,494 & 5,384 \\
\hline & $(0,040)$ & $(0,109)$ & $(3,255)$ & $(3,286)$ & $(3,291)$ & $(3,329)$ \\
\hline Observações & 1589 & 1575 & 1571 & 1526 & 1526 & 1515 \\
\hline$R^{2}$ ajustado & $-0,000$ & 0,003 & 0,023 & 0,021 & 0,023 & 0,023 \\
\hline
\end{tabular}

Erros-padrão em parênteses. Todas as regressões utilizam erros-padrão robustos a heterocedasticidade.

Padronização da variável socioemocional realizada para o ano de $2012 .{ }^{*} p<0.10,{ }^{* *} p<0.05,{ }^{* * *} p<0.01$ 
Tabela 34 - Estimação de MQO para o ano de 2017 - Abertura para novas experiências - Sertãozinho

\begin{tabular}{|c|c|c|c|c|c|c|}
\hline & (1) & (2) & (3) & (4) & (5) & (6) \\
\hline \multirow[t]{2}{*}{ Creche } & 0,004 & 0,002 & 0,003 & $-0,014$ & $-0,007$ & $-0,001$ \\
\hline & $(0,051)$ & $(0,051)$ & $(0,051)$ & $(0,055)$ & $(0,055)$ & $(0,056)$ \\
\hline \multirow[t]{2}{*}{ Pré-escola } & & 0,056 & 0,063 & 0,181 & 0,141 & 0,144 \\
\hline & & $(0,114)$ & $(0,114)$ & $(0,122)$ & $(0,123)$ & $(0,121)$ \\
\hline \multirow[t]{2}{*}{ Homem } & & & $-0,070$ & $-0,075$ & $-0,075$ & $-0,061$ \\
\hline & & & $(0,050)$ & $(0,054)$ & $(0,054)$ & $(0,054)$ \\
\hline \multirow[t]{2}{*}{ Branco } & & & $-0,124$ & $-0,177^{* *}$ & $-0,221^{* *}$ & $-0,221^{* *}$ \\
\hline & & & $(0,084)$ & $(0,089)$ & $(0,090)$ & $(0,090)$ \\
\hline \multirow[t]{2}{*}{ Pardo } & & & $-0,170^{* *}$ & $-0,222^{* *}$ & $-0,234^{* * *}$ & $-0,234^{* * *}$ \\
\hline & & & $(0,082)$ & $(0,087)$ & $(0,088)$ & $(0,089)$ \\
\hline \multirow[t]{2}{*}{ Amarelo } & & & 0,073 & $-0,029$ & $-0,077$ & $-0,103$ \\
\hline & & & $(0,157)$ & $(0,157)$ & $(0,159)$ & $(0,166)$ \\
\hline \multirow[t]{2}{*}{ Indígena } & & & $-0,143$ & $-0,045$ & $-0,026$ & 0,013 \\
\hline & & & $(0,287)$ & $(0,305)$ & $(0,304)$ & $(0,289)$ \\
\hline \multirow[t]{2}{*}{ Idade } & & & 1,336 & $1,854^{*}$ & $2,070^{* *}$ & 1,724 \\
\hline & & & $(0,955)$ & $(1,022)$ & $(1,030)$ & $(1,067)$ \\
\hline \multirow[t]{2}{*}{ Idade $^{2}$} & & & $-0,039$ & $-0,054^{*}$ & $-0,060^{* *}$ & $-0,049$ \\
\hline & & & $(0,028)$ & $(0,030)$ & $(0,030)$ & $(0,031)$ \\
\hline \multirow[t]{2}{*}{ Mora com o pai } & & & & $-0,059$ & $-0,079$ & $-0,051$ \\
\hline & & & & $(0,192)$ & $(0,194)$ & $(0,196)$ \\
\hline \multirow[t]{2}{*}{ Mora com a mãe } & & & & 0,028 & 0,007 & 0,008 \\
\hline & & & & $(0,131)$ & $(0,132)$ & $(0,133)$ \\
\hline \multirow[t]{2}{*}{ Mora com ambos } & & & & 0,095 & 0,120 & 0,088 \\
\hline & & & & $(0,201)$ & $(0,202)$ & $(0,205)$ \\
\hline \multirow[t]{2}{*}{ Fundamental I } & & & & & $0,247^{* *}$ & $0,249^{* *}$ \\
\hline & & & & & $(0,110)$ & $(0,110)$ \\
\hline \multirow[t]{2}{*}{ Fundamental II } & & & & & $0,334^{* * *}$ & $0,340^{* * *}$ \\
\hline & & & & & $(0,107)$ & $(0,107)$ \\
\hline \multirow[t]{2}{*}{ Ensino Médio } & & & & & $0,322^{* * *}$ & $0,323^{* * *}$ \\
\hline & & & & & $(0,104)$ & $(0,104)$ \\
\hline \multirow[t]{2}{*}{ Ensino Superior } & & & & & $0,431^{* * *}$ & $0,424^{* * *}$ \\
\hline & & & & & $(0,122)$ & $(0,123)$ \\
\hline \multirow[t]{2}{*}{ Não sei } & & & & & 0,090 & 0,113 \\
\hline & & & & & $(0,144)$ & $(0,145)$ \\
\hline \multirow[t]{2}{*}{ Abandono } & & & & & & $-0,316$ \\
\hline & & & & & & $(0,221)$ \\
\hline \multirow[t]{2}{*}{ Reprovou uma vez } & & & & & & $-0,037$ \\
\hline & & & & & & $(0,074)$ \\
\hline \multirow[t]{2}{*}{ Reprovou duas vezes } & & & & & & $-0,220^{*}$ \\
\hline & & & & & & $(0,114)$ \\
\hline \multirow[t]{2}{*}{ Reprovou três vezes ou mais } & & & & & & 0,132 \\
\hline & & & & & & $(0,255)$ \\
\hline \multirow[t]{2}{*}{ Constante } & $-0,002$ & $-0,053$ & $-11,395$ & $-15,876^{*}$ & $-18,013^{* *}$ & $-15,316^{*}$ \\
\hline & $(0,039)$ & $(0,114)$ & $(8,159)$ & $(8,730)$ & $(8,795)$ & $(9,073)$ \\
\hline Observações & 1592 & 1578 & 1574 & 1384 & 1384 & 1382 \\
\hline$R^{2}$ ajustado & $-0,001$ & $-0,001$ & 0,000 & 0,002 & 0,011 & 0,013 \\
\hline
\end{tabular}

Erros-padrão em parênteses. Todas as regressões utilizam erros-padrão robustos a heterocedasticidade.

Padronização da variável socioemocional realizada para o ano de $2017 .{ }^{*} p<0.10,{ }^{* *} p<0.05,{ }^{* * *} p<0.01$ 
Tabela 35 - Estimação de MQO para o ano de 2012 - Conscienciosidade - Sertãozinho

\begin{tabular}{|c|c|c|c|c|c|c|}
\hline & $(1)$ & $(2)$ & (3) & (4) & (5) & (6) \\
\hline \multirow[t]{2}{*}{ Creche } & $-0,082$ & $-0,084$ & $-0,071$ & $-0,055$ & $-0,058$ & $-0,063$ \\
\hline & $(0,051)$ & $(0,051)$ & $(0,051)$ & $(0,053)$ & $(0,053)$ & $(0,053)$ \\
\hline \multirow[t]{2}{*}{ Pré-escola } & & $0,230^{* *}$ & $0,184^{*}$ & 0,172 & $0,179^{*}$ & 0,163 \\
\hline & & $(0,106)$ & $(0,106)$ & $(0,106)$ & $(0,107)$ & $(0,110)$ \\
\hline \multirow[t]{2}{*}{ Homem } & & & $-0,230^{* * *}$ & $-0,223^{* * *}$ & $-0,221^{* * *}$ & $-0,215^{* * *}$ \\
\hline & & & $(0,051)$ & $(0,052)$ & $(0,052)$ & $(0,052)$ \\
\hline \multirow[t]{2}{*}{ Branco } & & & 0,113 & 0,099 & 0,107 & 0,084 \\
\hline & & & $(0,087)$ & $(0,088)$ & $(0,089)$ & $(0,089)$ \\
\hline \multirow[t]{2}{*}{ Pardo } & & & 0,042 & 0,031 & 0,036 & 0,011 \\
\hline & & & $(0,086)$ & $(0,088)$ & $(0,088)$ & $(0,088)$ \\
\hline \multirow[t]{2}{*}{ Amarelo } & & & 0,341 & 0,313 & 0,306 & 0,291 \\
\hline & & & $(0,222)$ & $(0,223)$ & $(0,224)$ & $(0,225)$ \\
\hline \multirow[t]{2}{*}{ Indígena } & & & 0,309 & 0,322 & 0,317 & 0,288 \\
\hline & & & $(0,230)$ & $(0,258)$ & $(0,262)$ & $(0,265)$ \\
\hline \multirow[t]{2}{*}{ Idade } & & & 0,311 & 0,250 & 0,222 & $-0,219$ \\
\hline & & & $(0,595)$ & $(0,611)$ & $(0,611)$ & $(0,676)$ \\
\hline \multirow[t]{2}{*}{ Idade $^{2}$} & & & $-0,017$ & $-0,015$ & $-0,013$ & 0,009 \\
\hline & & & $(0,026)$ & $(0,027)$ & $(0,027)$ & $(0,030)$ \\
\hline \multirow[t]{2}{*}{ Mora com o pai } & & & & 0,401 & 0,418 & 0,323 \\
\hline & & & & $(0,260)$ & $(0,260)$ & $(0,256)$ \\
\hline \multirow[t]{2}{*}{ Mora com a mãe } & & & & 0,280 & $0,300^{*}$ & 0,213 \\
\hline & & & & $(0,183)$ & $(0,182)$ & $(0,175)$ \\
\hline \multirow[t]{2}{*}{ Mora com ambos } & & & & $-0,365$ & $-0,385$ & $-0,298$ \\
\hline & & & & $(0,268)$ & $(0,269)$ & $(0,264)$ \\
\hline \multirow[t]{2}{*}{ Fundamental I } & & & & & $-0,045$ & $-0,039$ \\
\hline & & & & & $(0,093)$ & $(0,093)$ \\
\hline \multirow[t]{2}{*}{ Fundamental II } & & & & & $-0,072$ & $-0,081$ \\
\hline & & & & & $(0,097)$ & $(0,097)$ \\
\hline \multirow[t]{2}{*}{ Ensino Médio } & & & & & $-0,100$ & $-0,120$ \\
\hline & & & & & $(0,096)$ & $(0,096)$ \\
\hline \multirow[t]{2}{*}{ Ensino Superior } & & & & & $-0,035$ & $-0,036$ \\
\hline & & & & & $(0,123)$ & $(0,125)$ \\
\hline \multirow[t]{2}{*}{ Não sei } & & & & & $-0,087$ & $-0,101$ \\
\hline & & & & & $(0,119)$ & $(0,121)$ \\
\hline \multirow[t]{2}{*}{ Abandono } & & & & & & $-0,104$ \\
\hline & & & & & & $(0,182)$ \\
\hline \multirow[t]{2}{*}{ Reprovou uma vez } & & & & & & $-0,128$ \\
\hline & & & & & & $(0,078)$ \\
\hline \multirow[t]{2}{*}{ Reprovou duas vezes } & & & & & & $-0,340^{* * *}$ \\
\hline & & & & & & $(0,119)$ \\
\hline \multirow[t]{2}{*}{ Reprovou três vezes ou mais } & & & & & & $-0,330$ \\
\hline & & & & & & $(0,301)$ \\
\hline \multirow[t]{2}{*}{ Constante } & 0,048 & $-0,167$ & $-1,425$ & $-1,352$ & $-1,150$ & 1,209 \\
\hline & $(0,039)$ & $(0,107)$ & $(3,360)$ & $(3,454)$ & $(3,455)$ & $(3,791)$ \\
\hline Observações & 1589 & 1575 & 1571 & 1526 & 1526 & 1515 \\
\hline$R^{2}$ ajustado & 0,001 & 0,003 & 0,020 & 0,018 & 0,016 & 0,018 \\
\hline
\end{tabular}

Erros-padrão em parênteses. Todas as regressões utilizam erros-padrão robustos a heterocedasticidade.

Padronização da variável socioemocional realizada para o ano de 2012. ${ }^{*} p<0.10,{ }^{* *} p<0.05,{ }^{* * *} p<0.01$ 
Tabela 36 - Estimação de MQO para o ano de 2017 - Conscienciosidade - Sertãozinho

\begin{tabular}{|c|c|c|c|c|c|c|}
\hline & $(1)$ & $(2)$ & $(3)$ & $(4)$ & $(5)$ & $(6)$ \\
\hline \multirow[t]{2}{*}{ Creche } & $-0,067$ & $-0,072$ & $-0,074$ & $-0,050$ & $-0,049$ & $-0,040$ \\
\hline & $(0,052)$ & $(0,052)$ & $(0,052)$ & $(0,056)$ & $(0,056)$ & $(0,056)$ \\
\hline \multirow[t]{2}{*}{ Pré-escola } & & 0,055 & 0,069 & $0,214^{*}$ & $0,225^{*}$ & $0,197^{*}$ \\
\hline & & $(0,107)$ & $(0,107)$ & $(0,119)$ & $(0,120)$ & $(0,119)$ \\
\hline \multirow[t]{2}{*}{ Homem } & & & $-0,015$ & $-0,025$ & $-0,014$ & $-0,004$ \\
\hline & & & $(0,051)$ & $(0,055)$ & $(0,055)$ & $(0,055)$ \\
\hline \multirow[t]{2}{*}{ Branco } & & & $-0,115$ & $-0,097$ & $-0,094$ & $-0,098$ \\
\hline & & & $(0,085)$ & $(0,089)$ & $(0,089)$ & $(0,089)$ \\
\hline \multirow[t]{2}{*}{ Pardo } & & & $-0,079$ & $-0,090$ & $-0,096$ & $-0,092$ \\
\hline & & & $(0,083)$ & $(0,087)$ & $(0,087)$ & $(0,087)$ \\
\hline \multirow[t]{2}{*}{ Amarelo } & & & 0,063 & $-0,048$ & $-0,047$ & $-0,000$ \\
\hline & & & $(0,209)$ & $(0,203)$ & $(0,206)$ & $(0,201)$ \\
\hline \multirow[t]{2}{*}{ Indígena } & & & 0,148 & 0,225 & 0,198 & 0,208 \\
\hline & & & $(0,277)$ & $(0,311)$ & $(0,312)$ & $(0,311)$ \\
\hline \multirow[t]{2}{*}{ Idade } & & & 1,330 & $1,726^{*}$ & 1,630 & 1,009 \\
\hline & & & $(0,972)$ & $(1,021)$ & $(1,011)$ & $(1,019)$ \\
\hline \multirow[t]{2}{*}{ Idade $^{2}$} & & & $-0,038$ & $-0,050^{*}$ & $-0,047$ & $-0,028$ \\
\hline & & & $(0,028)$ & $(0,030)$ & $(0,030)$ & $(0,030)$ \\
\hline \multirow[t]{2}{*}{ Mora com o pai } & & & & $-0,126$ & $-0,111$ & $-0,069$ \\
\hline & & & & $(0,184)$ & $(0,185)$ & $(0,186)$ \\
\hline \multirow[t]{2}{*}{ Mora com a mãe } & & & & 0,041 & 0,042 & 0,046 \\
\hline & & & & $(0,123)$ & $(0,123)$ & $(0,120)$ \\
\hline \multirow[t]{2}{*}{ Mora com ambos } & & & & 0,103 & 0,088 & 0,042 \\
\hline & & & & $(0,193)$ & $(0,194)$ & $(0,195)$ \\
\hline \multirow[t]{2}{*}{ Fundamental I } & & & & & 0,016 & $-0,004$ \\
\hline & & & & & $(0,106)$ & $(0,107)$ \\
\hline \multirow[t]{2}{*}{ Fundamental II } & & & & & 0,032 & 0,025 \\
\hline & & & & & $(0,103)$ & $(0,103)$ \\
\hline \multirow[t]{2}{*}{ Ensino Médio } & & & & & 0,004 & $-0,021$ \\
\hline & & & & & $(0,100)$ & $(0,102)$ \\
\hline \multirow[t]{2}{*}{ Ensino Superior } & & & & & $-0,056$ & $-0,085$ \\
\hline & & & & & $(0,126)$ & $(0,127)$ \\
\hline \multirow[t]{2}{*}{ Não sei } & & & & & $-0,248$ & $-0,254^{*}$ \\
\hline & & & & & $(0,152)$ & $(0,153)$ \\
\hline \multirow[t]{2}{*}{ Abandono } & & & & & & $-0,130$ \\
\hline & & & & & & $(0,185)$ \\
\hline \multirow[t]{2}{*}{ Reprovou uma vez } & & & & & & $-0,043$ \\
\hline & & & & & & $(0,075)$ \\
\hline \multirow[t]{2}{*}{ Reprovou duas vezes } & & & & & & $-0,202^{*}$ \\
\hline & & & & & & $(0,119)$ \\
\hline \multirow[t]{2}{*}{ Reprovou três vezes ou mais } & & & & & & $-0,548^{* * *}$ \\
\hline & & & & & & $(0,212)$ \\
\hline \multirow[t]{2}{*}{ Constante } & 0,039 & $-0,009$ & $-11,498$ & $-15,002^{*}$ & $-14,177$ & $-9,208$ \\
\hline & $(0,041)$ & $(0,109)$ & $(8,274)$ & $(8,706)$ & $(8,632)$ & $(8,684)$ \\
\hline Observações & 1593 & 1579 & 1575 & 1385 & 1385 & 1383 \\
\hline$R^{2}$ ajustado & 0,000 & 0,000 & $-0,001$ & $-0,001$ & $-0,001$ & 0,003 \\
\hline
\end{tabular}

Erros-padrão em parênteses. Todas as regressões utilizam erros-padrão robustos a heterocedasticidade.

Padronização da variável socioemocional realizada para o ano de $2017 .{ }^{*} p<0.10,{ }^{* *} p<0.05,{ }^{* * *} p<0.01$ 
Tabela 37 - Estimação de MQO para o ano de 2012 - Extroversão - Sertãozinho

\begin{tabular}{|c|c|c|c|c|c|c|}
\hline & (1) & (2) & (3) & (4) & $(5)$ & (6) \\
\hline \multirow[t]{2}{*}{ Creche } & 0,080 & 0,077 & $0,091^{*}$ & $0,086^{*}$ & $0,092^{*}$ & $0,094^{*}$ \\
\hline & $(0,051)$ & $(0,051)$ & $(0,051)$ & $(0,052)$ & $(0,051)$ & $(0,052)$ \\
\hline \multirow[t]{2}{*}{ Pré-escola } & & $0,220^{* *}$ & $0,206^{*}$ & $0,209^{*}$ & 0,177 & 0,131 \\
\hline & & $(0,108)$ & $(0,107)$ & $(0,109)$ & $(0,108)$ & $(0,111)$ \\
\hline \multirow[t]{2}{*}{ Homem } & & & $-0,073$ & $-0,063$ & $-0,070$ & $-0,058$ \\
\hline & & & $(0,050)$ & $(0,051)$ & $(0,051)$ & $(0,051)$ \\
\hline \multirow[t]{2}{*}{ Branco } & & & 0,064 & 0,065 & 0,027 & 0,019 \\
\hline & & & $(0,082)$ & $(0,084)$ & $(0,084)$ & $(0,086)$ \\
\hline \multirow[t]{2}{*}{ Pardo } & & & $-0,119$ & $-0,110$ & $-0,101$ & $-0,109$ \\
\hline & & & $(0,081)$ & $(0,083)$ & $(0,082)$ & $(0,083)$ \\
\hline \multirow[t]{2}{*}{ Amarelo } & & & $-0,502^{* *}$ & $-0,498^{* *}$ & $-0,487^{* *}$ & $-0,468^{* *}$ \\
\hline & & & $(0,235)$ & $(0,236)$ & $(0,233)$ & $(0,236)$ \\
\hline \multirow[t]{2}{*}{ Indígena } & & & $-0,141$ & $-0,052$ & 0,005 & $-0,015$ \\
\hline & & & $(0,261)$ & $(0,270)$ & $(0,266)$ & $(0,264)$ \\
\hline \multirow[t]{2}{*}{ Idade } & & & 0,328 & 0,325 & 0,381 & 0,494 \\
\hline & & & $(0,616)$ & $(0,623)$ & $(0,620)$ & $(0,652)$ \\
\hline \multirow[t]{2}{*}{ Idade $^{2}$} & & & $-0,014$ & $-0,014$ & $-0,016$ & $-0,019$ \\
\hline & & & $(0,027)$ & $(0,028)$ & $(0,028)$ & $(0,029)$ \\
\hline \multirow[t]{2}{*}{ Mora com o pai } & & & & $-0,259$ & $-0,305$ & $-0,301$ \\
\hline & & & & $(0,319)$ & $(0,318)$ & $(0,329)$ \\
\hline \multirow[t]{2}{*}{ Mora com a mãe } & & & & $-0,162$ & $-0,236$ & $-0,234$ \\
\hline & & & & $(0,258)$ & $(0,262)$ & $(0,274)$ \\
\hline \multirow[t]{2}{*}{ Mora com ambos } & & & & 0,166 & 0,221 & 0,212 \\
\hline & & & & $(0,326)$ & $(0,325)$ & $(0,335)$ \\
\hline \multirow[t]{2}{*}{ Fundamental I } & & & & & 0,057 & 0,047 \\
\hline & & & & & $(0,091)$ & $(0,091)$ \\
\hline \multirow[t]{2}{*}{ Fundamental II } & & & & & $0,212^{* *}$ & $0,203^{* *}$ \\
\hline & & & & & $(0,096)$ & $(0,096)$ \\
\hline \multirow[t]{2}{*}{ Ensino Médio } & & & & & $0,238^{* *}$ & $0,226^{* *}$ \\
\hline & & & & & $(0,094)$ & $(0,094)$ \\
\hline \multirow[t]{2}{*}{ Ensino Superior } & & & & & $0,467^{* * *}$ & $0,465^{* * *}$ \\
\hline & & & & & $(0,129)$ & $(0,129)$ \\
\hline \multirow[t]{2}{*}{ Não sei } & & & & & 0,154 & 0,132 \\
\hline & & & & & $(0,142)$ & $(0,144)$ \\
\hline \multirow[t]{2}{*}{ Abandono } & & & & & & 0,039 \\
\hline & & & & & & $(0,187)$ \\
\hline \multirow[t]{2}{*}{ Reprovou uma vez } & & & & & & $-0,218^{* * *}$ \\
\hline & & & & & & $(0,074)$ \\
\hline \multirow[t]{2}{*}{ Reprovou duas vezes } & & & & & & $-0,037$ \\
\hline & & & & & & $(0,140)$ \\
\hline \multirow[t]{2}{*}{ Reprovou três vezes ou mais } & & & & & & $-0,437$ \\
\hline & & & & & & $(0,366)$ \\
\hline \multirow[t]{2}{*}{ Constante } & $-0,047$ & $-0,247^{* *}$ & $-2,015$ & $-1,777$ & $-2,217$ & $-2,973$ \\
\hline & $(0,038)$ & $(0,107)$ & $(3,456)$ & $(3,519)$ & $(3,503)$ & $(3,659)$ \\
\hline Observações & 1588 & 1574 & 1570 & 1526 & 1526 & 1515 \\
\hline$R^{2}$ ajustado & 0,001 & 0,003 & 0,011 & 0,010 & 0,021 & 0,025 \\
\hline
\end{tabular}

Erros-padrão em parênteses. Todas as regressões utilizam erros-padrão robustos a heterocedasticidade.

Padronização da variável socioemocional realizada para o ano de 2012. ${ }^{*} p<0.10,{ }^{* *} p<0.05,{ }^{* * *} p<0.01$ 
Tabela 38 - Estimação de MQO para o ano de 2017 - Extroversão - Sertãozinho

\begin{tabular}{|c|c|c|c|c|c|c|}
\hline & (1) & (2) & (3) & (4) & (5) & (6) \\
\hline \multirow[t]{2}{*}{ Creche } & $0,088^{*}$ & $0,089^{*}$ & 0,082 & 0,051 & 0,051 & 0,048 \\
\hline & $(0,051)$ & $(0,051)$ & $(0,051)$ & $(0,055)$ & $(0,055)$ & $(0,055)$ \\
\hline \multirow[t]{2}{*}{ Pré-escola } & & $0,190^{*}$ & $0,193^{*}$ & $0,264^{* *}$ & $0,247^{* *}$ & $0,283^{* *}$ \\
\hline & & $(0,106)$ & $(0,107)$ & $(0,115)$ & $(0,115)$ & $(0,119)$ \\
\hline \multirow[t]{2}{*}{ Homem } & & & $-0,099^{*}$ & $-0,094^{*}$ & $-0,094^{*}$ & $-0,096^{*}$ \\
\hline & & & $(0,051)$ & $(0,054)$ & $(0,054)$ & $(0,054)$ \\
\hline \multirow[t]{2}{*}{ Branco } & & & $-0,205^{* *}$ & $-0,215^{* *}$ & $-0,224^{* *}$ & $-0,217^{* *}$ \\
\hline & & & $(0,088)$ & $(0,093)$ & $(0,093)$ & $(0,092)$ \\
\hline \multirow[t]{2}{*}{ Pardo } & & & $-0,154^{*}$ & $-0,174^{*}$ & $-0,169^{*}$ & $-0,168^{*}$ \\
\hline & & & $(0,085)$ & $(0,090)$ & $(0,090)$ & $(0,089)$ \\
\hline \multirow[t]{2}{*}{ Amarelo } & & & 0,049 & $-0,022$ & $-0,039$ & $-0,081$ \\
\hline & & & $(0,193)$ & $(0,190)$ & $(0,189)$ & $(0,190)$ \\
\hline \multirow[t]{2}{*}{ Indígena } & & & $-0,132$ & $-0,213$ & $-0,204$ & $-0,177$ \\
\hline & & & $(0,234)$ & $(0,257)$ & $(0,259)$ & $(0,265)$ \\
\hline \multirow[t]{2}{*}{ Idade } & & & $2,356^{* *}$ & $2,264^{* *}$ & $2,482^{* *}$ & $2,651^{* * *}$ \\
\hline & & & $(0,959)$ & $(1,014)$ & $(1,020)$ & $(1,015)$ \\
\hline \multirow[t]{2}{*}{ Idade $^{2}$} & & & $-0,069^{* *}$ & $-0,066^{* *}$ & $-0,073^{* *}$ & $-0,078^{* * *}$ \\
\hline & & & $(0,028)$ & $(0,030)$ & $(0,030)$ & $(0,030)$ \\
\hline \multirow[t]{2}{*}{ Mora com o pai } & & & & $-0,117$ & $-0,121$ & $-0,117$ \\
\hline & & & & $(0,201)$ & $(0,201)$ & $(0,205)$ \\
\hline \multirow[t]{2}{*}{ Mora com a mãe } & & & & $-0,207^{*}$ & $-0,213^{*}$ & $-0,206^{*}$ \\
\hline & & & & $(0,121)$ & $(0,122)$ & $(0,122)$ \\
\hline \multirow[t]{2}{*}{ Mora com ambos } & & & & 0,090 & 0,098 & 0,094 \\
\hline & & & & $(0,210)$ & $(0,210)$ & $(0,214)$ \\
\hline \multirow[t]{2}{*}{ Fundamental I } & & & & & $-0,144$ & $-0,141$ \\
\hline & & & & & $(0,107)$ & $(0,107)$ \\
\hline \multirow[t]{2}{*}{ Fundamental II } & & & & & $-0,058$ & $-0,058$ \\
\hline & & & & & $(0,104)$ & $(0,103)$ \\
\hline \multirow[t]{2}{*}{ Ensino Médio } & & & & & $-0,018$ & $-0,008$ \\
\hline & & & & & $(0,104)$ & $(0,104)$ \\
\hline \multirow[t]{2}{*}{ Ensino Superior } & & & & & 0,054 & 0,065 \\
\hline & & & & & $(0,128)$ & $(0,127)$ \\
\hline \multirow[t]{2}{*}{ Não sei } & & & & & $-0,116$ & $-0,107$ \\
\hline & & & & & $(0,145)$ & $(0,145)$ \\
\hline \multirow[t]{2}{*}{ Abandono } & & & & & & $-0,171$ \\
\hline & & & & & & $(0,205)$ \\
\hline \multirow[t]{2}{*}{ Reprovou uma vez } & & & & & & 0,121 \\
\hline & & & & & & $(0,076)$ \\
\hline \multirow[t]{2}{*}{ Reprovou duas vezes } & & & & & & 0,005 \\
\hline & & & & & & $(0,107)$ \\
\hline \multirow[t]{2}{*}{ Reprovou três vezes ou mais } & & & & & & $0,490^{* *}$ \\
\hline & & & & & & $(0,204)$ \\
\hline \multirow[t]{2}{*}{ Constante } & $-0,051$ & $-0,226^{* *}$ & $-20,192^{* *}$ & $-19,131^{* *}$ & $-20,938^{* *}$ & $-22,205^{* * *}$ \\
\hline & $(0,040)$ & $(0,107)$ & $(8,128)$ & $(8,590)$ & $(8,647)$ & $(8,597)$ \\
\hline Observações & 1593 & 1579 & 1575 & 1385 & 1385 & 1383 \\
\hline$R^{2}$ ajustado & 0,001 & 0,003 & 0,009 & 0,009 & 0,009 & 0,011 \\
\hline
\end{tabular}

Erros-padrão em parênteses. Todas as regressões utilizam erros-padrão robustos a heterocedasticidade.

Padronização da variável socioemocional realizada para o ano de 2017. ${ }^{*} p<0.10,{ }^{* *} p<0.05,{ }^{* * *} p<0.01$ 
Tabela 39 - Estimação de MQO para o ano de 2012 - Amabilidade - Sertãozinho

\begin{tabular}{|c|c|c|c|c|c|c|}
\hline & (1) & (2) & (3) & (4) & (5) & $(6)$ \\
\hline \multirow[t]{2}{*}{ Creche } & $-0,118^{* *}$ & $-0,117^{* *}$ & $-0,095^{*}$ & $-0,076$ & $-0,077$ & $-0,079$ \\
\hline & $(0,051)$ & $(0,051)$ & $(0,051)$ & $(0,051)$ & $(0,052)$ & $(0,052)$ \\
\hline \multirow[t]{2}{*}{ Pré-escola } & & 0,075 & 0,013 & 0,014 & 0,018 & 0,036 \\
\hline & & $(0,107)$ & $(0,106)$ & $(0,109)$ & $(0,108)$ & $(0,113)$ \\
\hline \multirow[t]{2}{*}{ Homem } & & & $-0,260^{* * *}$ & $-0,256^{* * *}$ & $-0,254^{* * *}$ & $-0,245^{* * *}$ \\
\hline & & & $(0,050)$ & $(0,050)$ & $(0,051)$ & $(0,051)$ \\
\hline \multirow[t]{2}{*}{ Branco } & & & $0,164^{*}$ & $0,173^{*}$ & $0,177^{* *}$ & $0,183^{* *}$ \\
\hline & & & $(0,087)$ & $(0,089)$ & $(0,089)$ & $(0,090)$ \\
\hline \multirow[t]{2}{*}{ Pardo } & & & 0,062 & 0,067 & 0,064 & 0,072 \\
\hline & & & $(0,087)$ & $(0,089)$ & $(0,089)$ & $(0,090)$ \\
\hline \multirow[t]{2}{*}{ Amarelo } & & & 0,181 & 0,175 & 0,170 & 0,182 \\
\hline & & & $(0,201)$ & $(0,202)$ & $(0,199)$ & $(0,202)$ \\
\hline \multirow{2}{*}{ Indígena } & & & $-0,015$ & $-0,042$ & $-0,064$ & $-0,060$ \\
\hline & & & $(0,249)$ & $(0,281)$ & $(0,286)$ & $(0,287)$ \\
\hline \multirow[t]{2}{*}{ Idade } & & & $-0,259$ & $-0,274$ & $-0,241$ & $-0,575$ \\
\hline & & & $(0,571)$ & $(0,578)$ & $(0,580)$ & $(0,615)$ \\
\hline \multirow[t]{2}{*}{ Idade $^{2}$} & & & 0,007 & 0,008 & 0,006 & 0,023 \\
\hline & & & $(0,025)$ & $(0,026)$ & $(0,026)$ & $(0,027)$ \\
\hline \multirow[t]{2}{*}{ Mora com o pai } & & & & $-0,135$ & $-0,119$ & $-0,082$ \\
\hline & & & & $(0,291)$ & $(0,291)$ & $(0,302)$ \\
\hline \multirow[t]{2}{*}{ Mora com a mãe } & & & & $-0,164$ & $-0,150$ & $-0,107$ \\
\hline & & & & $(0,225)$ & $(0,226)$ & $(0,238)$ \\
\hline \multirow[t]{2}{*}{ Mora com ambos } & & & & 0,185 & 0,169 & 0,119 \\
\hline & & & & $(0,298)$ & $(0,299)$ & $(0,309)$ \\
\hline \multirow[t]{2}{*}{ Fundamental I } & & & & & $-0,063$ & $-0,067$ \\
\hline & & & & & $(0,098)$ & $(0,098)$ \\
\hline \multirow[t]{2}{*}{ Fundamental II } & & & & & $-0,116$ & $-0,128$ \\
\hline & & & & & $(0,101)$ & $(0,101)$ \\
\hline \multirow[t]{2}{*}{ Ensino Médio } & & & & & $-0,042$ & $-0,063$ \\
\hline & & & & & $(0,097)$ & $(0,097)$ \\
\hline \multirow[t]{2}{*}{ Ensino Superior } & & & & & $-0,168$ & $-0,178$ \\
\hline & & & & & $(0,126)$ & $(0,128)$ \\
\hline \multirow{2}{*}{ Não sei } & & & & & $-0,086$ & $-0,092$ \\
\hline & & & & & $(0,135)$ & $(0,137)$ \\
\hline \multirow[t]{2}{*}{ Abandono } & & & & & & $-0,155$ \\
\hline & & & & & & $(0,171)$ \\
\hline \multirow[t]{2}{*}{ Reprovou uma vez } & & & & & & $-0,088$ \\
\hline & & & & & & $(0,075)$ \\
\hline \multirow[t]{2}{*}{ Reprovou duas vezes } & & & & & & $-0,208$ \\
\hline & & & & & & $(0,129)$ \\
\hline \multirow[t]{2}{*}{ Reprovou três vezes ou mais } & & & & & & $-0,499$ \\
\hline & & & & & & $(0,356)$ \\
\hline \multirow[t]{2}{*}{ Constante } & $0,069^{*}$ & 0,001 & 2,117 & 2,267 & 2,155 & 3,810 \\
\hline & $(0,039)$ & $(0,107)$ & $(3,225)$ & $(3,281)$ & $(3,294)$ & $(3,469)$ \\
\hline Observações & 1589 & 1575 & 1571 & 1526 & 1526 & 1515 \\
\hline$R^{2}$ ajustado & 0,003 & 0,002 & 0,028 & 0,024 & 0,023 & 0,024 \\
\hline
\end{tabular}

Erros-padrão em parênteses. Todas as regressões utilizam erros-padrão robustos a heterocedasticidade.

Padronização da variável socioemocional realizada para o ano de 2012. ${ }^{*} p<0.10,{ }^{* *} p<0.05,{ }^{* * *} p<0.01$ 
Tabela 40 - Estimação de MQO para o ano de 2017 - Amabilidade - Sertãozinho

\begin{tabular}{|c|c|c|c|c|c|c|}
\hline & (1) & (2) & (3) & (4) & (5) & (6) \\
\hline \multirow[t]{2}{*}{ Creche } & $-0,044$ & $-0,041$ & $-0,042$ & $-0,028$ & $-0,025$ & $-0,019$ \\
\hline & $(0,051)$ & $(0,051)$ & $(0,051)$ & $(0,055)$ & $(0,055)$ & $(0,055)$ \\
\hline \multirow{2}{*}{ Pré-escola } & & 0,117 & 0,132 & 0,165 & 0,167 & 0,129 \\
\hline & & $(0,111)$ & $(0,111)$ & $(0,122)$ & $(0,123)$ & $(0,123)$ \\
\hline \multirow[t]{2}{*}{ Homem } & & & 0,071 & 0,086 & $0,097^{*}$ & $0,108^{*}$ \\
\hline & & & $(0,051)$ & $(0,054)$ & $(0,055)$ & $(0,055)$ \\
\hline \multirow[t]{2}{*}{ Branco } & & & 0,006 & $-0,015$ & $-0,028$ & $-0,035$ \\
\hline & & & $(0,085)$ & $(0,088)$ & $(0,088)$ & $(0,088)$ \\
\hline \multirow[t]{2}{*}{ Pardo } & & & 0,059 & 0,030 & 0,020 & 0,023 \\
\hline & & & $(0,083)$ & $(0,087)$ & $(0,087)$ & $(0,087)$ \\
\hline \multirow[t]{2}{*}{ Amarelo } & & & 0,060 & 0,008 & $-0,011$ & $-0,012$ \\
\hline & & & $(0,197)$ & $(0,201)$ & $(0,200)$ & $(0,207)$ \\
\hline \multirow[t]{2}{*}{ Indígena } & & & $0,477^{* *}$ & $0,500^{* *}$ & $0,487^{* *}$ & $0,481^{* *}$ \\
\hline & & & $(0,225)$ & $(0,239)$ & $(0,238)$ & $(0,233)$ \\
\hline \multirow[t]{2}{*}{ Idade } & & & 0,838 & 0,890 & 0,877 & 0,287 \\
\hline & & & $(0,966)$ & $(1,065)$ & $(1,089)$ & $(1,091)$ \\
\hline \multirow{2}{*}{ Idade $^{2}$} & & & $-0,024$ & $-0,026$ & $-0,026$ & $-0,007$ \\
\hline & & & $(0,028)$ & $(0,031)$ & $(0,032)$ & $(0,032)$ \\
\hline \multirow[t]{2}{*}{ Mora com o pai } & & & & 0,080 & 0,101 & 0,128 \\
\hline & & & & $(0,209)$ & $(0,212)$ & $(0,214)$ \\
\hline \multirow[t]{2}{*}{ Mora com a mãe } & & & & 0,219 & 0,217 & 0,216 \\
\hline & & & & $(0,155)$ & $(0,156)$ & $(0,154)$ \\
\hline \multirow[t]{2}{*}{ Mora com ambos } & & & & $-0,064$ & $-0,085$ & $-0,117$ \\
\hline & & & & $(0,217)$ & $(0,220)$ & $(0,223)$ \\
\hline \multirow[t]{2}{*}{ Fundamental I } & & & & & 0,170 & 0,155 \\
\hline & & & & & $(0,113)$ & $(0,113)$ \\
\hline \multirow[t]{2}{*}{ Fundamental II } & & & & & 0,129 & 0,121 \\
\hline & & & & & $(0,106)$ & $(0,107)$ \\
\hline \multirow[t]{2}{*}{ Ensino Médio } & & & & & 0,083 & 0,061 \\
\hline & & & & & $(0,107)$ & $(0,108)$ \\
\hline \multirow[t]{2}{*}{ Ensino Superior } & & & & & 0,154 & 0,131 \\
\hline & & & & & $(0,127)$ & $(0,128)$ \\
\hline \multirow[t]{2}{*}{ Não sei } & & & & & $-0,183$ & $-0,191$ \\
\hline & & & & & $(0,138)$ & $(0,137)$ \\
\hline \multirow[t]{2}{*}{ Abandono } & & & & & & 0,026 \\
\hline & & & & & & $(0,237)$ \\
\hline \multirow[t]{2}{*}{ Reprovou uma vez } & & & & & & $-0,067$ \\
\hline & & & & & & $(0,074)$ \\
\hline \multirow[t]{2}{*}{ Reprovou duas vezes } & & & & & & $-0,169$ \\
\hline & & & & & & $(0,112)$ \\
\hline \multirow[t]{2}{*}{ Reprovou três vezes ou mais } & & & & & & $-0,608^{* *}$ \\
\hline & & & & & & $(0,250)$ \\
\hline \multirow[t]{2}{*}{ Constante } & 0,026 & $-0,087$ & $-7,413$ & $-7,981$ & $-7,978$ & $-3,248$ \\
\hline & $(0,039)$ & $(0,111)$ & $(8,189)$ & $(9,016)$ & $(9,214)$ & $(9,217)$ \\
\hline Observações & 1593 & 1579 & 1575 & 1385 & 1385 & 1383 \\
\hline$R^{2}$ ajustado & $-0,000$ & $-0,000$ & $-0,000$ & 0,001 & 0,004 & 0,007 \\
\hline
\end{tabular}

Erros-padrão em parênteses. Todas as regressões utilizam erros-padrão robustos a heterocedasticidade.

Padronização da variável socioemocional realizada para o ano de $2017 .{ }^{*} p<0.10,{ }^{* *} p<0.05,{ }^{* * *} p<0.01$ 
Tabela 41 - Estimação de MQO para o ano de 2012 - Estabilidade Emocional - Sertãozinho

\begin{tabular}{|c|c|c|c|c|c|c|}
\hline & $(1)$ & $(2)$ & (3) & $(4)$ & $(5)$ & $(6)$ \\
\hline \multirow[t]{2}{*}{ Creche } & $-0,035$ & $-0,028$ & $-0,037$ & $-0,014$ & $-0,016$ & $-0,014$ \\
\hline & $(0,051)$ & $(0,051)$ & $(0,051)$ & $(0,052)$ & $(0,052)$ & $(0,053)$ \\
\hline \multirow[t]{2}{*}{ Pré-escola } & & $-0,080$ & $-0,077$ & $-0,119$ & $-0,110$ & $-0,088$ \\
\hline & & $(0,116)$ & $(0,117)$ & $(0,115)$ & $(0,115)$ & $(0,119)$ \\
\hline \multirow[t]{2}{*}{ Homem } & & & $0,167^{* * *}$ & $0,170^{* * *}$ & $0,170^{* * *}$ & $0,169^{* * *}$ \\
\hline & & & $(0,050)$ & $(0,051)$ & $(0,051)$ & $(0,052)$ \\
\hline \multirow[t]{2}{*}{ Branco } & & & 0,014 & 0,002 & 0,010 & 0,004 \\
\hline & & & $(0,093)$ & $(0,095)$ & $(0,095)$ & $(0,097)$ \\
\hline \multirow[t]{2}{*}{ Pardo } & & & 0,002 & 0,000 & $-0,004$ & $-0,006$ \\
\hline & & & $(0,092)$ & $(0,093)$ & $(0,094)$ & $(0,095)$ \\
\hline \multirow[t]{2}{*}{ Amarelo } & & & 0,180 & 0,155 & 0,155 & 0,150 \\
\hline & & & $(0,241)$ & $(0,242)$ & $(0,240)$ & $(0,240)$ \\
\hline \multirow[t]{2}{*}{ Indígena } & & & $-0,145$ & $-0,067$ & $-0,077$ & $-0,081$ \\
\hline & & & $(0,325)$ & $(0,321)$ & $(0,321)$ & $(0,323)$ \\
\hline \multirow[t]{2}{*}{ Idade } & & & $-0,791$ & $-0,776$ & $-0,784$ & $-0,939$ \\
\hline & & & $(0,575)$ & $(0,576)$ & $(0,574)$ & $(0,601)$ \\
\hline \multirow[t]{2}{*}{ Idade $^{2}$} & & & 0,032 & 0,030 & 0,031 & 0,038 \\
\hline & & & $(0,025)$ & $(0,025)$ & $(0,025)$ & $(0,027)$ \\
\hline \multirow[t]{2}{*}{ Mora com o pai } & & & & 0,295 & 0,294 & 0,254 \\
\hline & & & & $(0,274)$ & $(0,277)$ & $(0,287)$ \\
\hline \multirow[t]{2}{*}{ Mora com a mãe } & & & & 0,056 & 0,069 & 0,031 \\
\hline & & & & $(0,234)$ & $(0,236)$ & $(0,246)$ \\
\hline \multirow[t]{2}{*}{ Mora com ambos } & & & & $-0,140$ & $-0,144$ & $-0,109$ \\
\hline & & & & $(0,282)$ & $(0,285)$ & $(0,295)$ \\
\hline \multirow[t]{2}{*}{ Fundamental I } & & & & & 0,065 & 0,070 \\
\hline & & & & & $(0,098)$ & $(0,098)$ \\
\hline \multirow[t]{2}{*}{ Fundamental II } & & & & & 0,010 & 0,005 \\
\hline & & & & & $(0,101)$ & $(0,102)$ \\
\hline \multirow[t]{2}{*}{ Ensino Médio } & & & & & $-0,016$ & $-0,021$ \\
\hline & & & & & $(0,101)$ & $(0,101)$ \\
\hline \multirow[t]{2}{*}{ Ensino Superior } & & & & & $-0,042$ & $-0,051$ \\
\hline & & & & & $(0,132)$ & $(0,133)$ \\
\hline \multirow[t]{2}{*}{ Não sei } & & & & & 0,010 & 0,024 \\
\hline & & & & & $(0,135)$ & $(0,136)$ \\
\hline \multirow[t]{2}{*}{ Abandono } & & & & & & $-0,079$ \\
\hline & & & & & & $(0,140)$ \\
\hline \multirow[t]{2}{*}{ Reprovou uma vez } & & & & & & $-0,005$ \\
\hline & & & & & & $(0,077)$ \\
\hline \multirow[t]{2}{*}{ Reprovou duas vezes } & & & & & & $-0,093$ \\
\hline & & & & & & $(0,120)$ \\
\hline \multirow[t]{2}{*}{ Reprovou três vezes ou mais } & & & & & & $-0,252$ \\
\hline & & & & & & $(0,319)$ \\
\hline \multirow[t]{2}{*}{ Constante } & 0,020 & 0,089 & 4,872 & 4,704 & 4,724 & 5,565 \\
\hline & $(0,039)$ & $(0,116)$ & $(3,245)$ & $(3,263)$ & $(3,256)$ & $(3,394)$ \\
\hline Observações & 1588 & 1574 & 1570 & 1526 & 1526 & 1515 \\
\hline$R^{2}$ ajustado & $-0,000$ & $-0,001$ & 0,008 & 0,012 & 0,010 & 0,008 \\
\hline
\end{tabular}

Erros-padrão em parênteses. Todas as regressões utilizam erros-padrão robustos a heterocedasticidade.

Padronização da variável socioemocional realizada para o ano de 2012. ${ }^{*} p<0.10,{ }^{* *} p<0.05,{ }^{* * *} p<0.01$ 
Tabela 42 - Estimação de MQO para o ano de 2017 - Estabilidade Emocional - Sertãozinho

\begin{tabular}{|c|c|c|c|c|c|c|}
\hline & $(1)$ & $(2)$ & $(3)$ & $(4)$ & $(5)$ & $(6)$ \\
\hline \multirow[t]{2}{*}{ Creche } & 0,034 & 0,045 & 0,014 & 0,036 & 0,035 & 0,038 \\
\hline & $(0,051)$ & $(0,051)$ & $(0,048)$ & $(0,051)$ & $(0,051)$ & $(0,051)$ \\
\hline \multirow[t]{2}{*}{ Pré-escola } & & $-0,224^{* *}$ & $-0,089$ & $-0,047$ & $-0,034$ & $-0,032$ \\
\hline & & $(0,113)$ & $(0,105)$ & $(0,119)$ & $(0,121)$ & $(0,122)$ \\
\hline \multirow[t]{2}{*}{ Homem } & & & $0,802^{* * *}$ & $0,793^{* * *}$ & $0,796^{* * *}$ & $0,800^{* * *}$ \\
\hline & & & $(0,046)$ & $(0,050)$ & $(0,050)$ & $(0,051)$ \\
\hline \multirow[t]{2}{*}{ Branco } & & & $-0,148^{*}$ & $-0,163^{* *}$ & $-0,160^{*}$ & $-0,160^{*}$ \\
\hline & & & $(0,077)$ & $(0,082)$ & $(0,083)$ & $(0,083)$ \\
\hline \multirow[t]{2}{*}{ Pardo } & & & $-0,070$ & $-0,065$ & $-0,066$ & $-0,065$ \\
\hline & & & $(0,075)$ & $(0,081)$ & $(0,081)$ & $(0,081)$ \\
\hline \multirow{2}{*}{ Amarelo } & & & 0,024 & $-0,027$ & $-0,017$ & 0,015 \\
\hline & & & $(0,193)$ & $(0,190)$ & $(0,192)$ & $(0,195)$ \\
\hline \multirow[t]{2}{*}{ Indígena } & & & 0,214 & 0,320 & 0,322 & 0,340 \\
\hline & & & $(0,240)$ & $(0,253)$ & $(0,254)$ & $(0,249)$ \\
\hline \multirow[t]{2}{*}{ Idade } & & & 1,278 & 1,232 & 1,104 & 0,955 \\
\hline & & & $(0,855)$ & $(0,895)$ & $(0,904)$ & $(0,897)$ \\
\hline \multirow[t]{2}{*}{ Idade $^{2}$} & & & $-0,036$ & $-0,035$ & $-0,031$ & $-0,026$ \\
\hline & & & $(0,025)$ & $(0,026)$ & $(0,026)$ & $(0,026)$ \\
\hline \multirow[t]{2}{*}{ Mora com o pai } & & & & 0,229 & 0,248 & 0,272 \\
\hline & & & & $(0,183)$ & $(0,183)$ & $(0,185)$ \\
\hline \multirow[t]{2}{*}{ Mora com a mãe } & & & & $0,248^{*}$ & $0,256^{* *}$ & $0,258^{* *}$ \\
\hline & & & & $(0,127)$ & $(0,126)$ & $(0,127)$ \\
\hline \multirow[t]{2}{*}{ Mora com ambos } & & & & $-0,200$ & $-0,223$ & $-0,247$ \\
\hline & & & & $(0,191)$ & $(0,191)$ & $(0,193)$ \\
\hline \multirow[t]{2}{*}{ Fundamental I } & & & & & 0,150 & 0,150 \\
\hline & & & & & $(0,099)$ & $(0,100)$ \\
\hline \multirow[t]{2}{*}{ Fundamental II } & & & & & 0,019 & 0,025 \\
\hline & & & & & $(0,095)$ & $(0,096)$ \\
\hline \multirow[t]{2}{*}{ Ensino Médio } & & & & & 0,047 & 0,046 \\
\hline & & & & & $(0,095)$ & $(0,096)$ \\
\hline \multirow[t]{2}{*}{ Ensino Superior } & & & & & 0,017 & 0,015 \\
\hline & & & & & $(0,117)$ & $(0,118)$ \\
\hline \multirow[t]{2}{*}{ Não sei } & & & & & 0,024 & 0,032 \\
\hline & & & & & $(0,133)$ & $(0,133)$ \\
\hline \multirow[t]{2}{*}{ Abandono } & & & & & & $-0,203$ \\
\hline & & & & & & $(0,204)$ \\
\hline \multirow[t]{2}{*}{ Reprovou uma vez } & & & & & & 0,016 \\
\hline & & & & & & $(0,069)$ \\
\hline \multirow[t]{2}{*}{ Reprovou duas vezes } & & & & & & $-0,069$ \\
\hline & & & & & & $(0,106)$ \\
\hline \multirow[t]{2}{*}{ Reprovou três vezes ou mais } & & & & & & $-0,060$ \\
\hline & & & & & & $(0,234)$ \\
\hline \multirow[t]{2}{*}{ Constante } & $-0,020$ & 0,185 & $-11,435$ & $-11,375$ & $-10,351$ & $-9,156$ \\
\hline & $(0,039)$ & $(0,113)$ & $(7,270)$ & $(7,621)$ & $(7,698)$ & $(7,628)$ \\
\hline Observações & 1592 & 1578 & 1574 & 1384 & 1384 & 1382 \\
\hline$R^{2}$ ajustado & $-0,000$ & 0,002 & 0,164 & 0,160 & 0,160 & 0,158 \\
\hline
\end{tabular}

Erros-padrão em parênteses. Todas as regressões utilizam erros-padrão robustos a heterocedasticidade.

Padronização da variável socioemocional realizada para o ano de $2017 .{ }^{*} p<0.10,{ }^{* *} p<0.05,{ }^{* * *} p<0.01$ 